DE92 015122

\title{
ARTI REFRIGERANT DATABASE
}

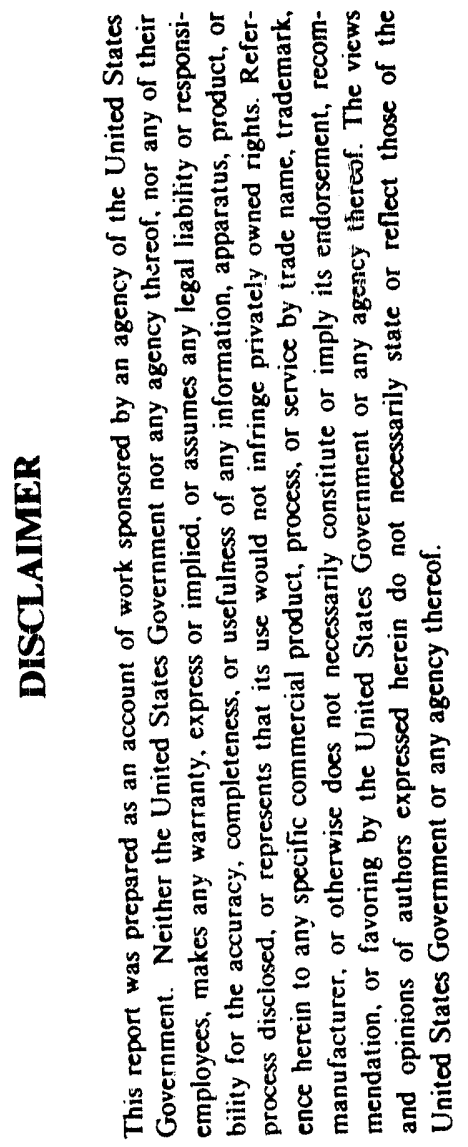

30 April 1992

\author{
prepared by \\ James M. Calm \\ Engineering Consultant \\ Post Office Box 12014 \\ Arlington, VA 22219-2014 USA \\ for the
}

\section{Air-Conditioning and Refrigeration Technology Institute}

1501 Wilson Boulevard, Sixth Floor

Arlington, VA 22209-2403 USA

This report is one in a series prepared for the Materials Compatibility and Lubricant Research (MCLR) Program, under ARTI contract number 0650-5000) for grant number DE.FG02-91CE23810 from the U.S. Department of Energy.

\section{MASTER}

OISTRIBUTION OF THIS DOCUMENT IS UNILIMITEN 
Please refer questions or comments on this document to:

\author{
James M. Calm \\ Engineering Consultant \\ Post Office Box 12104 \\ Arlington, VA 22219-2014 USA \\ telephone: $\quad 703 / 528-5618$ \\ telefax: $\quad 703 / 528-5618$
}

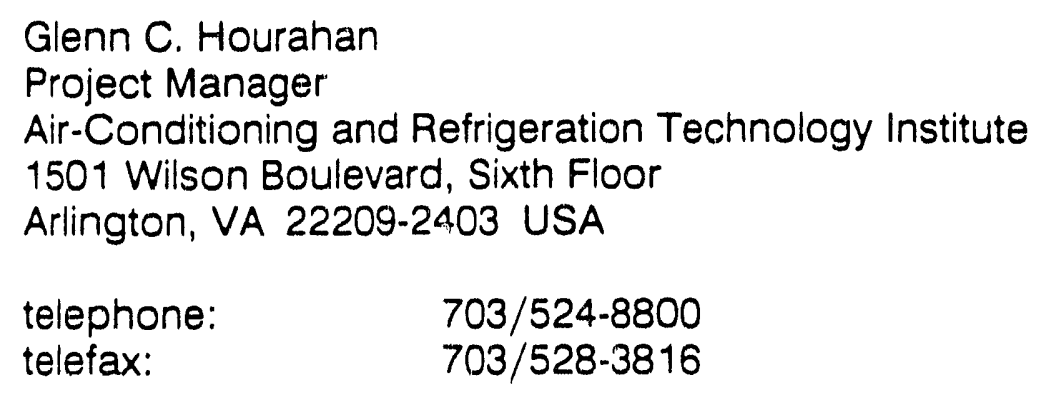

Neither James M. Calm, the Air-Conditioning and Refrigeration Technology Institute (ARTI), nor any person acting on behalf of them: (a) makes any warranty, expressed or implied, with respect to the accuracy, completeness, or usefulness of any information, apparatus, materiai, method, or process disclosed in this document or that such use may not infringe privately owned rights; or (b) assumes any liabilities with respect to use of, or damages resulting from use of, any information, apparatus, material, method, or process disclosed in this document. Reference herein to any specific commercial product, process, or service by trade name, trademark, manufacturer, or otherwise, does not necessarily constitute or imply its endorsement, recommendation, or favoring.

All product and brand names referenced by (TM) or (R) are trademarks or registered trademarks, respectively, of their owners. 


\section{TABLE OF CONTENTS}

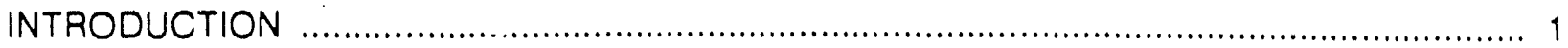

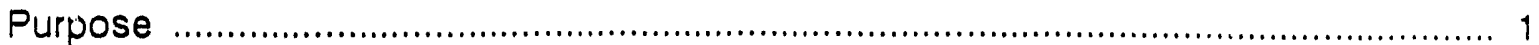

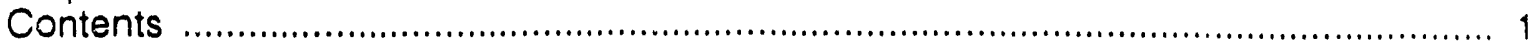

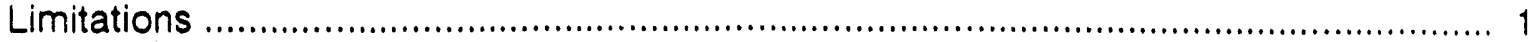

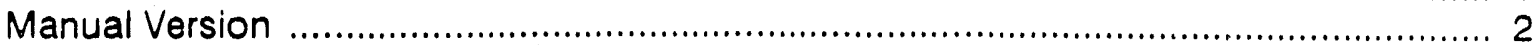

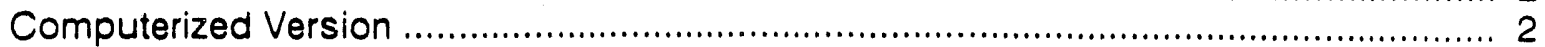

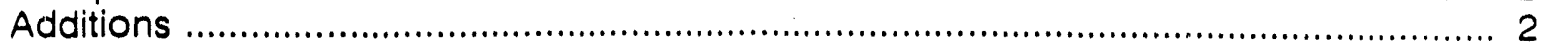

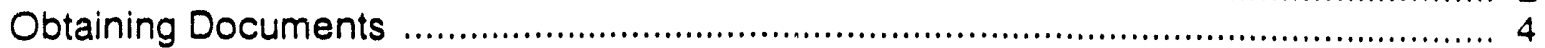

Order Form for Refrigerant Database Documents ................................................ 5

Order Form for the Refrigerant Database ......................................................... 6

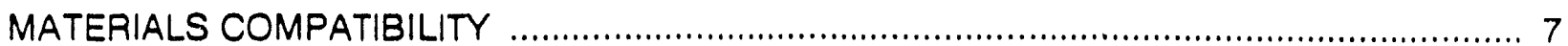

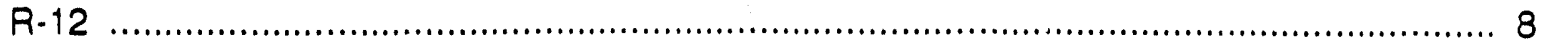

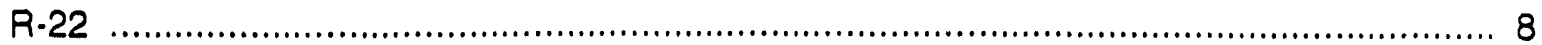

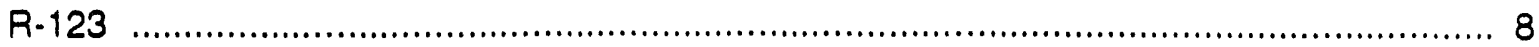

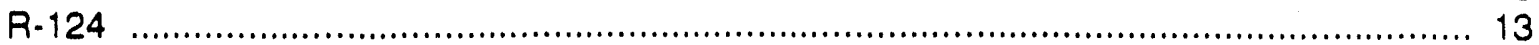

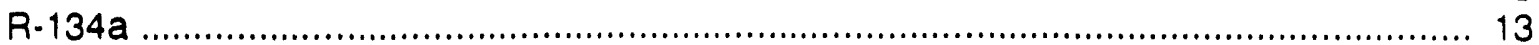

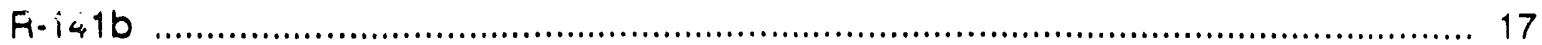

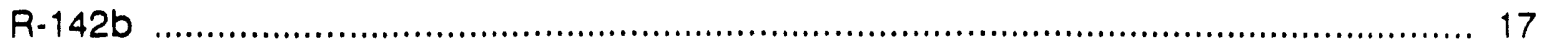

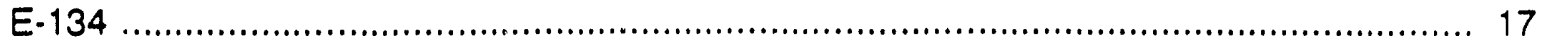

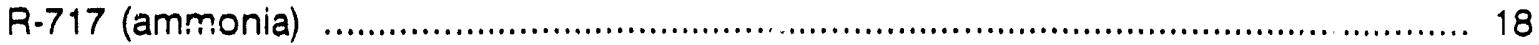

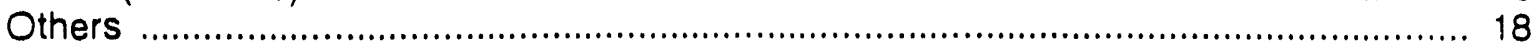

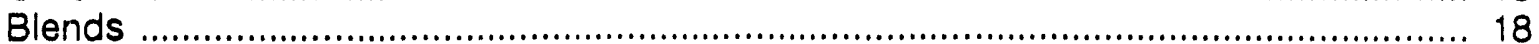

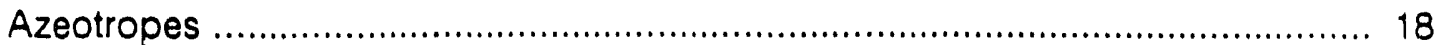

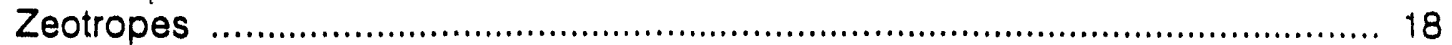

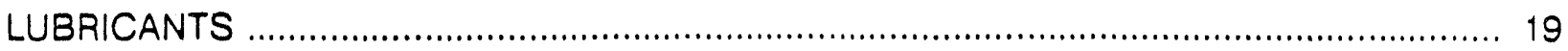

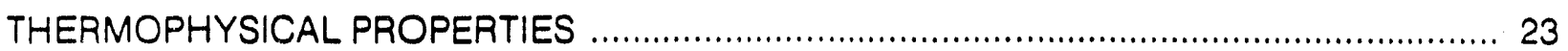

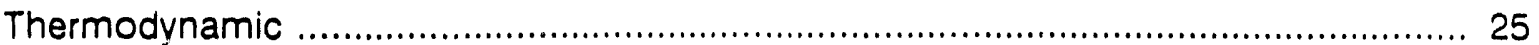

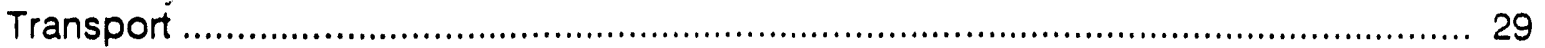

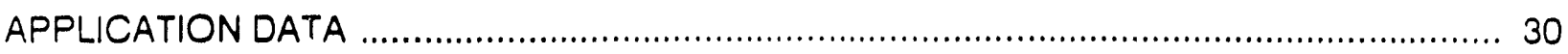

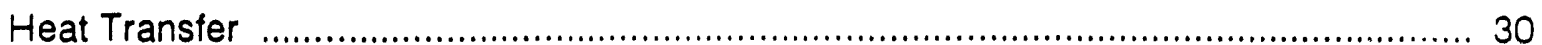

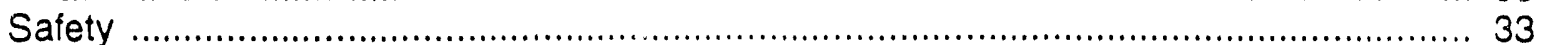

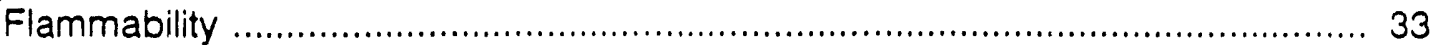

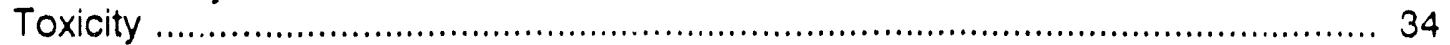

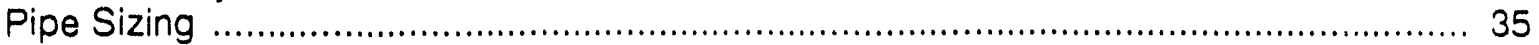

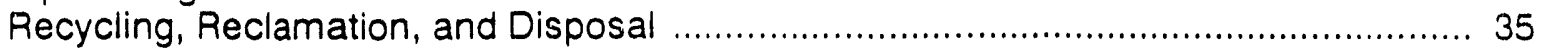

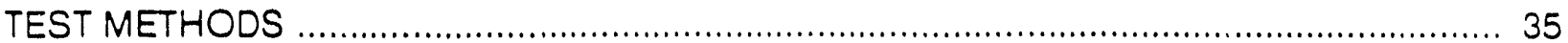




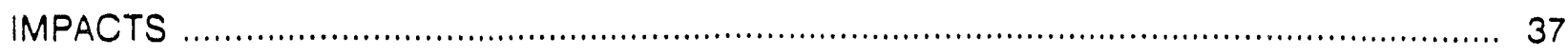

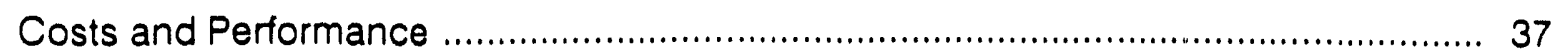

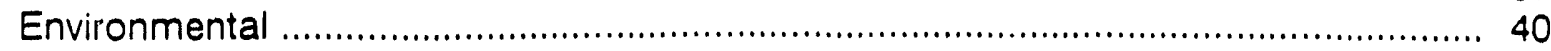

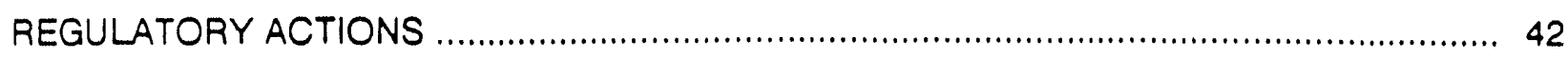

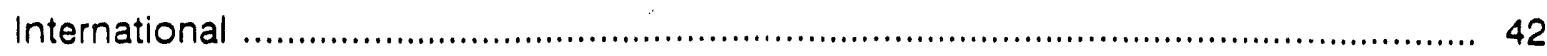

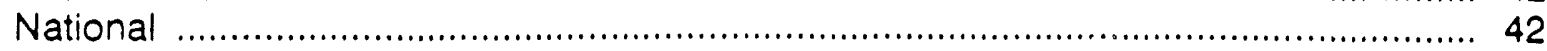

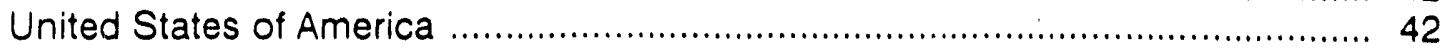

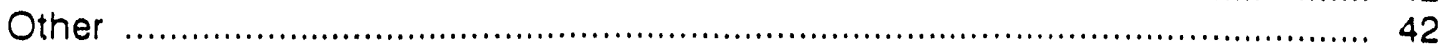

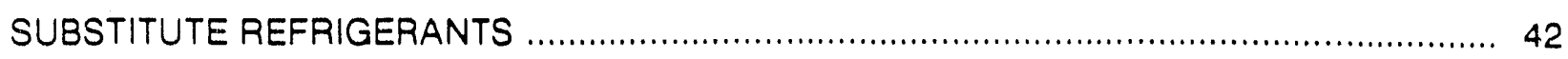

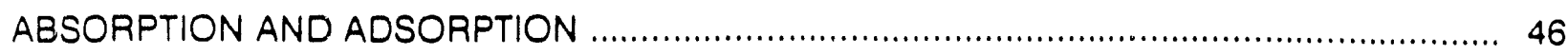

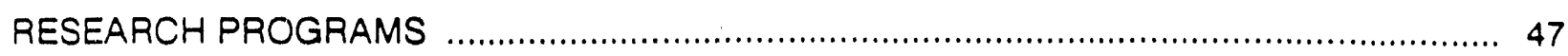

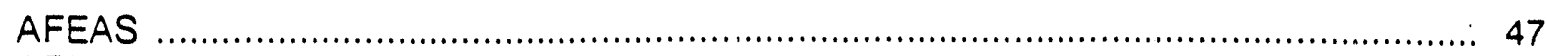

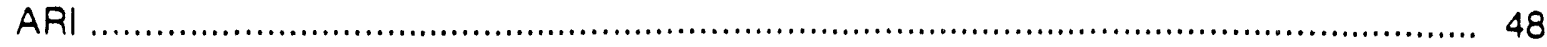

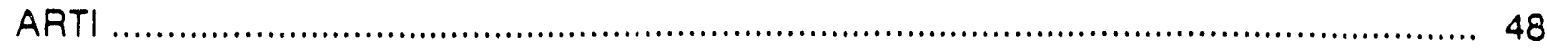

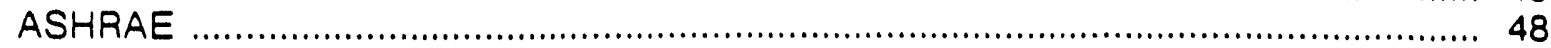

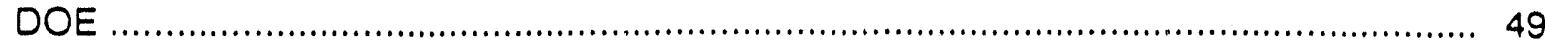

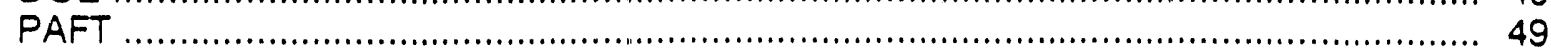

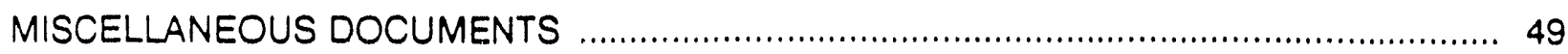




\section{INTRODUCTION}

\section{PURPOSE}

The Refrigerant Database consolidates and facilitates access to information to assist industry in developing equipment using alternative refrigerants. The underlying purpose is to accelerate phase out of chemical compounds of environmental concern.

\section{CONTENTS}

The database provides bibliographic citations and abstracts for publications that may be usefıl in research and design of air-conditioning and refrigeration equipment. The complete dor,uments are not included, though some may be added at a later date.

The database identifies sources of specific information on R-32, R-123, R-124, R-125, R-134a, R-141b, R-142b, R-143a, R-152a, R-290 (propane), R-717 (ammonia), ethers, and others as well as azeotropic and zeotropic blends of these fluids. It addresses polyalkylene glycol (PAG), ester, and other lubricants. It also references documents addressing compatibility of refrigerants and lubricants with metals, plastics, elastomers, motor insulation, and other materials used in refrigerant circuits.

Incomplete citations or abstracts are provided for some documents. They are included to accelerate availability of the information and will be completed or replaced in future updates.

\section{LIMITATIONS}

The Refrigerant Database is intended as a means to assist users in locating sources of information on alternative refrigerants. But, the database is:

- neither a comprehensive nor authoritative reference source,

- not a substitute for independent data collection by users,

- not a substitute for examination of the data, information on how they were arrived at, assumptions, and caveats in the cited documents, and

- not an endorsement of suitability or accuracy of referenced publications. 
Materials compatibility, properties, safety considerations, and other characteristics affecting suitability or desirability rnay be influenced by a number of factors. Among them are specific application conditions, preparation such as drying before use, additives including fillers, impurities, catalytic interactions with other materials used, and changes in compounding between one source or batch and another. Similarly, new findings or corrections may supersede previously published data. The database is only an aid in locating data that may be pertinent; it is not and should not be viewed as the source of data for research, design, analysis, or other purposes.

\section{MANUAL VERSION}

A listing of the database contents is provided in this document. Citations are grouped under the primary or first subject addressed, but are not cross-referenced under other topics. The computerized version, therefore, is better suited to search for information by subject.

Documents added since the February 1992 release of the ARTI Refrigerant Database are flagged by a bar in the margin, as shown to the left. Users looking for new references, therefore, will need to review only citations so indicated.

\section{COMPUTERIZED VERSION}

A companion version of this listing, in computerized form, also is available. The citations and abstracts are the same in both, but the automated version includes retrieval software to help users locate desired subjects. The computerized database provides a very fast and user. friendly means to performs searches for information on specific refrigerants, lubricants, materials, properties, topics, authors, or publications of interest. Individual words or combinations of words - using Boolean logic through a simplified means of specification - may be used to retrieve desired references. The program also provides means to print selected citations and abstracts and to prepare lists of citations for ordering.

The prices for the computerized version of the database are indicated on page 6.

\section{ADDITIONS}

Updates are planned for this databases, with replacement releases scheduled four times a year. Please help in making the database more useful, and facilitating use of alternative refrigerants, by submitting the following:

- corrections to errors identified in the database,

- copies of helpful papers - whether your own or written by others - for inclusion, and 
- suggestions for improving the database.

Please send your inputs to: James M. Calm

Engineering Consultant

Post Office Box 12014

Arlington, VA 22219-2014 USA

Thank you for your help with and use of the database. Its objective is to accelerate phase out of chemical compounds of environmental concern by sharing information needed to do so. 


\section{OBTAINING DOCUMENTS}

With the exception of documents for which availability from an alternative source is indicated, referenced publications should be ordered from the organization that published them. Many of these documents also may be obtained from libraries, including the ESL (see below). An effort will be made to secure permission for JMC to distribute additional documents, to facilitate access to them, but compliance with copyright provisions precludes doing so until appropriate arrangements are made. Reports from national laboratories and the Gas Research Institute may be ordered from the NTIS; most other publications from the U.S. Government may be obtained from the GPO. Addresses for several alternative sources follow:

\begin{tabular}{|c|c|}
\hline ASHRAE & $\begin{array}{l}\text { Publication Sales } \\
\text { American Society of Heating, Refrigerating, } \\
\text { and Air-Conditioning Engineers } \\
1791 \text { Tullie Circle NE } \\
\text { Atlanta, GA } 30329 \text { USA }\end{array}$ \\
\hline EPRI & $\begin{array}{l}\text { Research Reports Center } \\
\text { Post Office Box } 50490 \\
\text { Palo Alto, CA } 94303 \text { USA }\end{array}$ \\
\hline ESL & $\begin{array}{l}\text { Document Delivery } \\
\text { Engineering Societies Library } \\
345 \text { East 4 } 4 \text { th Street } \\
\text { New York, NY } 10017 \text { USA }\end{array}$ \\
\hline GPO & $\begin{array}{l}\text { Superintendent of Documents } \\
\text { U.S. Government Printing Office } \\
\text { Washington, DC } 20402 \text { USA }\end{array}$ \\
\hline$\|R /\| F$ & $\begin{array}{l}\text { Institut International du Froid } \\
177, \text { Boulevard Malesherbes } \\
\text { F.75017 Paris, France }\end{array}$ \\
\hline JAR & $\begin{array}{l}\text { Japanese Association of Refrigeration } \\
\text { Nippon Reito Kyokai } \\
\text { 4th Floor, San-ei Building, } 8 \text { San-ei-cho } \\
\text { Shinjuku-ku, Tokyo } 160 \text { Japan }\end{array}$ \\
\hline JMC & $\begin{array}{l}\text { James M. Calm } \\
\text { Engineering Consultant }\end{array}$ \\
\hline NTIS & $\begin{array}{l}\text { National Technical Information Service } \\
\text { U.S. Department of Commerce } \\
5285 \text { Port Rcyal Road } \\
\text { Springfield, VA } 22161 \text { USA }\end{array}$ \\
\hline SAE & $\begin{array}{l}\text { Society of Automotive Engineers } \\
400 \text { Commonwealth Drive } \\
\text { Warrendale, PA } 15096-0001 \text { USA }\end{array}$ \\
\hline
\end{tabular}

call $1-404 / 636-8400$ or fax $1-404 / 321.5478$ to request publications catalog which provides prices

order catalog MD-7201 or call 1-415/965-4081 for current prices

call $1-212 / 705-7606$ or fax 1-212/486-1086 for current prices

call $1-202 / 783-3238$ for current prices

call 33-1/42.27.32.35 fax 33.1/47.63.17.98 for current prices

call $81-3 / 3359-5231$ or fax $81-3 / 3359-5233$ for current prices

prices and address on next page

call $1-703 / 487.4780$ for current prices

write for current prices

\section{PLEASE REPRODUCE THIS FORM FOR USE WHEN NEEDED $\rightarrow$}




\title{
ORDER FORM FOR REFRIGERANT DATABASE DOCUMENTS
}

use this form only for documents indicated as available from JMC in the Refrigerant Database (prices valid through July 1992)

PLEASE ATTACH A LIST OF THE DOCUMENTS DESIRED: You may photocopy the necessary pages from this report, and circle the desired citations, or use the computerized version of the database to print a list. Charges are based on the page counts indicated in the database.
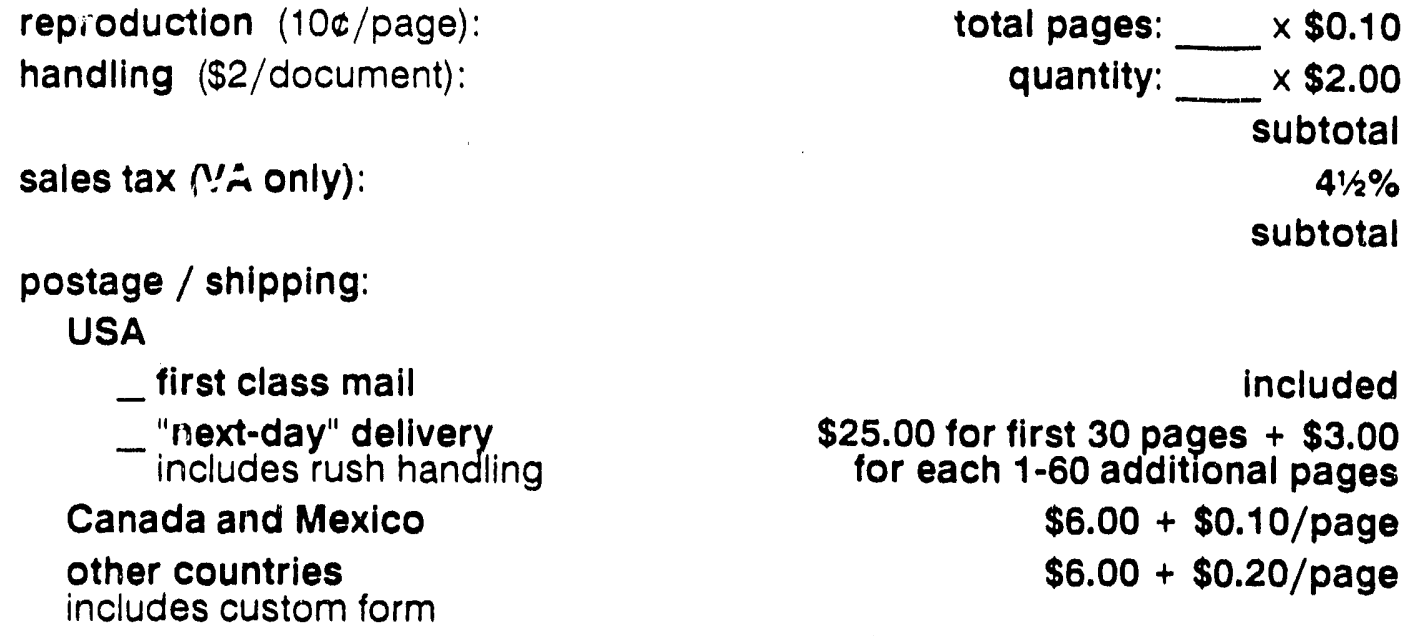

$\$$

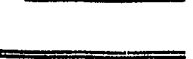

included

$\$ 25.00$ for first 30 pages $+\$ 3.00$

for each 1-60 additional pages

$$
\begin{aligned}
& \$ 6.00+\$ 0.10 / \text { page } \\
& \$ 6.00+\$ 0.20 / \text { page }
\end{aligned}
$$

prepaid total

Prices are stated and remittance should be made in U.S. dollars; payments by check must be drawn

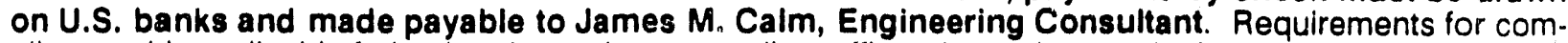
pliance with applicable federal and state laws as well as affirmative action, work place, and other programs are governed by the contract between James M. Calm, Engineering Consultant, and ARTI. No tern's and conditions (including but not limited to those addressing warranties, indemnification, insurance, inspection, and records) stipulated in purchase orders for the database, or documents from it, will apply.

mail/ship to:

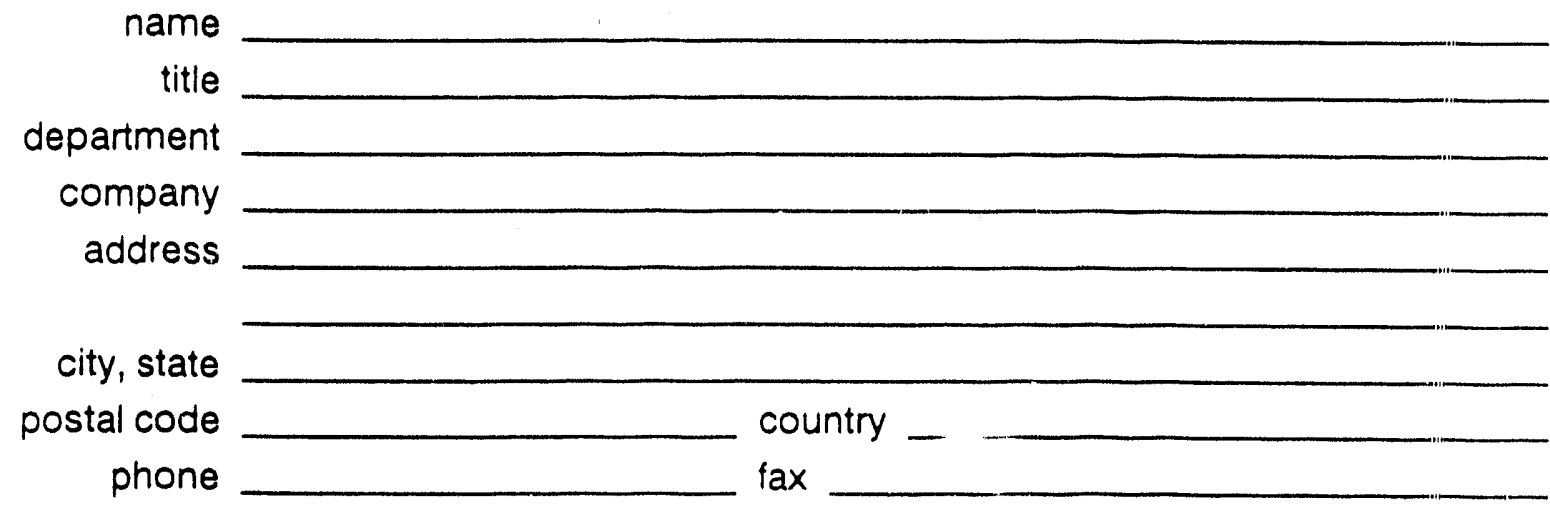

Please send the completed form with payment (checks drawn on U.S. banks only) to:

\author{
James M. Calm \\ Engineering Consultant \\ Post Office Box 12014 \\ Arlington, VA 22219-2014 USA
}

PLEASE REMEMBER TO ATTACH THE LIST OF DESIRED DOCUMENTS 


\section{ORDER FORM FOR THE REFRIGERANT DATABASE}

(for four releases in May, August, and November 1992 as well as February 1993)

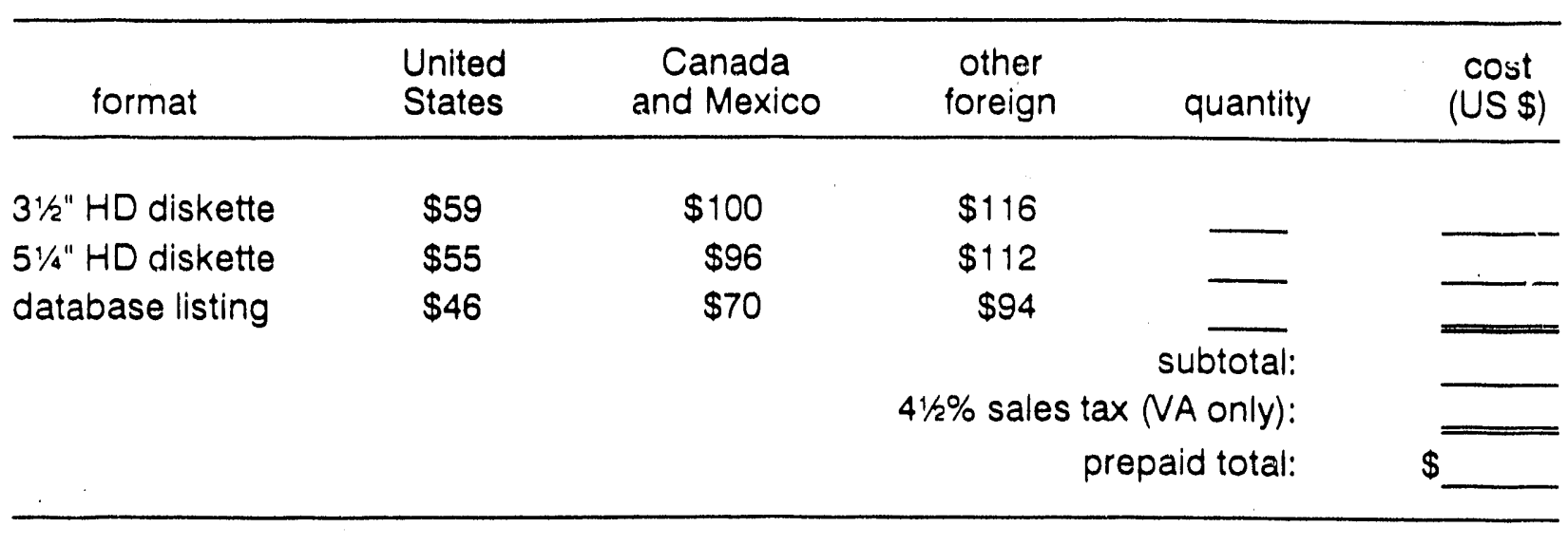

Prices shown are valid through July 1992 and include postage (air mail with customs form outside North America). Foreign prices also include a license fee of $\$ 25$ for the retrieval software accompanying the database. Prices are stated and remittance should be made in U.S. dollars; payments by check must be drawn on U.S. banks and made payable to James M. Calm, Engineering Consultant. Requirements for compliance with applicable federal and state laws as well as affirmative action, work place, and other programs are governed by the contract between James M. Calm, Engineering Consultant, and ARTI. Warranty and liability terms for the retrieval software are as stipulated in the license agreement for it. No terms and conditions (including but not limited to those addressing warranties, indemnification, insurance, inspection, and records) stipulated in purchase orders for the database, or documents from it, will apply.

\section{mail/ship to:}

name
title
department
company
address
city, state
postal code
phone

Please send the completed form with payment to:

James M. Calm

Engineering Consultant

Post Office Box 12014

Arlington, VA 22219-2014 USA

\section{REPRODUCE THIS FORM FOR USE WHEN NEEDED}




\section{MATERIALS COMPATIBILITY}

R. C. Cavestri (Imagination Resources, Incorporated), Compatibllity of Refrigerants and Lubricants with Plastics, report DOE/CE/23810-2F, Air-Conditioning and Refrigeration Technology Institute (ARTI), Artington, VA, April 1992 (12 pages with 5 figures, available from JMC as RDB2420)

This interim report summarizes progress to provide compatibility information on engineering plastics with alternative refrigerants and suitable lubricants. The status of test-specimen procurement and preparation is outlined. The report also addresses experimental methods and modifications to test procedures for the planned work. Solubility plots are included for R-22, R32, R-134a, and R-152a at 20 and $60^{\circ} \mathrm{C}(68$ and $140^{\circ} \mathrm{F}$ ) in polyol ester (EXP-0621 ISO 32); both refrigerant-lubricant viscosity and refrigerant concentration are shown. The solubility data are needed to maintain the refrigerant concentration in the test apparatus that will be used. The plastics that will be tested include Du Pont Vespel DF and DF-ISO, Teflon, BASF UItrapek, Victorex PEEK 45G 300, Radel A-200, Delrin 2 11500, Rynite 530, Zytel 101, Lexan 161, Noryl 731, Ultem 1000, Cycolac GPM4700, Supec G401, Kynar 720, Xydar MG350, Torlon 4301, Torton 4203L. Plenco 04485, Valox 325, and Profax 6331 NW. These plastics will be tested with R-22, R-32, R-123, R-124, R-125, R134a, R-142b, R-143a, R-152a, and E-134.

R. Doerr, S. Kujak, and R. Schafer (The Trane Company), Compatibility of Refrigerants and Lubricants with Motor Materials, report DOE/CE/ 23810-2D, Air-Conditioning and Refrigeration Technology Institute (ARTI), Arlington, VA, 13 April 1992 (11 pages with 7 tables, available from JMC as RDB24 18)

This interim report iniroduces a project, and summarizes procedural steps, to provide compatibility information for 24 motor materials (for hermetic compressors) in 11 refrigerants and 17 refrigerant-lubricant combinations. The report summarizes progress to procure necessary materials and equipment, prepare motor material samples, analyze the refrigerants and lubricants to be used, test the thermal stability of the refrigerant-lubricant systems at $127^{\circ} \mathrm{C}\left(260^{\circ} \mathrm{F}\right)$. and prepare for data collection and analysis. The magnet wires obtained for evaluation include modified polyester overcoated with polyamide imide, modified polyester overcoated with polyamide imide and epoxy saturated glass, and polyester imide overcoated with polyamide imide. Varnishes include Sterling(R) $U$. 475EH solvent epoxy, Y-390PG solvent epoxy phenolic, ER-610 93\% solids epoxy, Y-833 100\% solids VPI epoxy, P. D. George 923 solvent epoxy, and Isopoxy 800 water-borne epoxy. Sheet insulation, slot liner, and phase separator materials include Nomex-Mylar-Nomex(R), Dacron-Mylar-Dacron(R), Mylar(R) MO, Nomex(R) 410, Nomex(R) Mica 418, and Melinex(R) 228. Sleeving insulations to be tested are Nomex(R), Mylar(R), and Nomex-Mylar(R). Lead wire insulations include Dacron-Mylar-Dacron(R) and Dacron-Teflon-Mylar-Dacron(R). Heat cleaned glass, heat shrinkable braided polyester, and Permacel P247 glass-acrylic tapes as well as polyester tie cords also will be examined. the refrigerants to be tested will include R-22, R-32, $R-123, R-124, R-125, R-134 a, R-142 b, R-143 a$, and R-152a; efforts are underway to obtain $E$. 134 and identify an HFC alternative for R-11. Moisture and purity data are provided for the refrigerants received. The lubricants to be tested include a mineral oil (Suniso 3GS), an alkylbenzene (Zerol 150), and two polyakylene glycols (PAGs), namely a modified polyglycol (BRL-150) and a polypropylene glycol diol (Dow P425). Three esters will be tested, namely a polypropylene glycol butyl monoether $(\mathrm{ICl} \mathrm{Em}$. karoX VG32), a pentaerythritol ester branched acid (Emery 2927 ISO 32), and a pentaerythritol ester mixed acid (ICl Emkarate RL244).

G. Hamed and R. H. Seiple (University of Akron), Compatibility of Refrigerants and Lubricants with Elastomers, report $D O E / C E / 23810-2 E$, Air. Conditioning and Refrigeration Technology Institute (ARTI), Arlington, VA, April 1992 (16 pages with 11 figures and 1 table, available from JMC as RDB. 2419)

This interim report introduces a project, and summarizes procedural steps, to provide compatibility information for approximately 94 elastomeric materials in ten refrigerants and suitable lubricants. In situ swell (diameter change) as well as weight and volume changes following immersion will be measured. Property changes will be determined for selected elastomers in a subsequent phase. The report summarizes efforts to obtain and prepare test specimens. Oscillating disk rheometer (ODR) plots are provided for 11 cumpounds including three formulations of polyisoprene, two of neoprene, two of SBR 1502, and four of EPDM. Moisture content measurements are reported for samples of Dow P425, ICl Emkarate RL244, Witco Suniso 3GS, Emery 2927 ISO 32, Shrieve Zerol, and $\mathrm{ICI}$ Emkarox VG32 lubricants. The moisture levels found were higher than expected.

H. M. Parmelee (E. I. du Pont de Nemours and Company), Sealed-Tube Stability Tests on Refrigeration Materials, paper 1924, ASHRAE Transactions, American Society of Heating, Refrigerat- 
Ing, and Air-Conditioning Engineers, Atlanta, GA volume 71, part 1, pages 154-161 and 167-168, January 1965 (10 pages with 29 tables, RDB0013)

This paper summarizes an investigation into the stability of fluorocarbon refrigerants alone and in the presence of olls, metals, nonmrtallic components of refrigeration systems, and residual cleaning and degreasing agents. It is based on sealed-tube stability tests, performed at elevated temperatures, for periods as long as three years. Results are reported for $R-11, R-12$, R-13B1, R-22, R-113, R-114, R-115, R-124, R216, R-C318, R-500, and R-502. The testing included examination of decomposition products, specifically including the fraction converted into other refrigerants. The metals tested included aluminum, brass, cadmium, copper, iron, lead, magnesium, mercury, steel, and zinc. The effects of selected additives and inhibitors, including phenyl alpha naphthylamine, molybdenum disulfide, and tricresyl phosphate (TCP), also were examined. The paper concludes that the life of a system should be longer if made chemically simpler, because every added material provides a possibility of increased chemical reactions.

H. O. Spauschus (Spauschus Associates, Incorporated), Compatibility Requirements for CFC Alternatives, International Journal of Refrigeration, Paris, France, volume 13, number 3, Marchi 1990, pages 73.78 (6 pages, RDB1101)

This paper reviews the materials compatibility and fluid property information required for design and successful commercial application of air-conditioning and refrigeration equipment. Information on alternative refrigerants, including the leading candidates, future prospects, and long-term possibilities, are summarized. Methods of predicting compatibility based on structural information and modeling are proposed.

W. O. Walker, S. Rosen, and S. L. Levy, Stability of Mixtures of Refrigerants and Refrigerating Oils, ASHRAE Journal, American Society of Heating, Refrigerating, and Air-Conditioning Engineers, Atlanta, $G A$, volume 4, number 8, pages 59-72, August 1961 (RDB2323)

\section{$\underline{R-12}$}

A. Factor and P. M. Miranda (General Electric Company). An Investigation of the Mechanism of the R12-Oil-Steel Reaction, Wear, Elsevier Sequoia, Lausanne, Switzerland, volume 150, pages $41-58,1991$ (18 pages with 3 figures and 12 tables, RDB2309)
A study of chemical interactions between R-12, hydrocarbon lubricating olls, and steel is summarized. While R-12 is quite stable thermally, it decomposes rapidly when heated above $150^{\circ} \mathrm{C}$ $\left(300^{\circ} \mathrm{C}\right)$ in the presence of oils and metals, such as iron or aluminum. Sealed-tube tesis were performed for 3 days at $200^{\circ} \mathrm{C}\left(392^{\circ} \mathrm{F}\right)$, using a naphthenic mineral oll (Suniso 3GS), to simulate conditions in an operating hermetic refrigeration compressor. The mechanism of the degradation reaction was explored by testing the effect of the presence of various probe and model compounds. The paper reviews prior studies, presents the experimental approach, and summarizes the subsequent analyses. It identifies the additives, free radical initiators, and inhibitors used to explore reactions and to passivate steel surfaces. The results of gas chromatography and GPC analyses are tabulated. The results indicate that except for formation of somie $\mathrm{FeCL}_{3}$ and $\mathrm{R}-22$, free radical reactions do not appear to play a major role. The preponderance of the data indicates that Friedel-Crafts reactions, especially alkylation, play a key role in the decomposition.

D. E. Kvalnes and H. M. Parmelee, Behavior of Freon-12 and Freon-22 in Sealed Tube Tests, Refrigerating Engineering, volume 65, number 11, pages $4 \mathrm{ff}$, November 1957; republished as bulletin 25, E. I. du Pont de Nemours and Company, Incorporated, Wilmington, DE (RDB2322)

\section{$\underline{R-22}$}

H. O. Spauschus and G. C. Doderer (General Electric Company), Chemical Reactions of Refrigerant 22, ASHRAE Transactions, American Soclety of Heating, Refrigerating and Air-Conditioning Engineers, Atlanta, GA, volume 71, part I, pages $162 \mathrm{ff}$, 1965 (RDB2327)

\section{$\underline{R-123}$}

[R-]123 Refrigerant Analyses, report NIST-1, Chemistry Laboratory, The Trane Company, La Crosse, WI, 14 March 1988 (1 page with 1 table, available from JMC as RDB0022)

A table compares the chemical purity of R-123 samples, from Allied-Signal and Du Pont Chemicals, with distilled R-1\%. Results are tabulated for chloride-ion content, high boiling temperature impurities, neutralization value. moisture content, and organic purity determined by gas chromatography. The moisture content in the R-123 samples was 
higher than expected, but not judged to be significant.

HCFC-123 Refrigerant Analyses, report NIST-9, Chemistry Laboratory. The Trane Company, La Crosse, WI, 24 November 1988 (1 page with 1 table, available from JMC as RDBO030)

A table compares the purity of new, used, and distilled-used specimens of R-123. Quartitative results are compared for moisture content and high-boiling residue. No change from new $R$. 123 was found by gas chromatography after use in hermetic centrifugal chillers.

Decomposition Rates of R-11 and R-123, Carrier Corporation, Syracuse, NY, Septernber 1989 (3 pages with 3 figures, available from JMC as RD80019)

The fraction of R-123 that decomposes in solution with Zerol alkylbenzene lubricaltt after 14 days is plotted as a function of temperature. Less than $1 \%$ decomposition was measured at 82 and $121^{\circ} \mathrm{C}\left(180^{\circ}\right.$ and $\left.250^{\circ} \mathrm{F}\right)$, but this in. creasert to $6.2 \%$ at $177^{\circ} \mathrm{C}\left(350^{\circ} \mathrm{F}\right)$. Decomposition of R-11 and R-123 after 4 and 14 days, respectively, at $121^{\circ} \mathrm{C}\left(250^{\circ} \mathrm{F}\right)$ is compared for mixtures of $5 \%$ lubricant by weight. One alkylbenzene (Zerol 300) and four mineral oils (Mobil DTE Heavy Medium, Mobil DTE 26, Rando HD68 , and Suniso 4GS) were tested.

Motor Insulations in R-123 and R-134a, Carrier Corporation, Syracuse, NY, September 1989 (2. pages with 2 figures, available from JMC as RDB. 0015)

Two vharts show the effects of R-123 and R$134 a$ on cured motor insulations. XV-572, XY. 587. Isopoxy(R) 800 , Dolphon polyester, and Sterling(R) $\cup-475$ were tested for weight change. percent extractables, and Shore $D$ hardness loss. Quantitative data, after aging for ten days at $93^{\circ} \mathrm{C}\left(200^{\circ} \mathrm{F}\right)$ for $\mathrm{R}-123$ and at $38^{\circ} \mathrm{C}\left(100^{\circ} \mathrm{F}\right)$ for $R-134 a$, are given.

Plastic Immersion Tests in Fluorocarbon-123, repon NIST-7, E. I. du Pont de Nemours and Comipany, Incorporated. Wilmington, DE undated (\$5 pages with 2 tables, available from JMC as RDB. 0303)

Results of compatibility tests are presented for 13 plastics, after immersion for four hours at 24 ${ }^{\circ} \mathrm{C}\left(75^{\circ} \mathrm{F}\right)$ and after thermal-aging for 100 hours at $54^{\circ} \mathrm{C}\left(130^{\circ} \mathrm{F}\right)$ in R-123. The plastics included linear polyethylene Alathon 7050, polypropylene Alathon 9140, methylmethacrylate (cast) Lucite, nylon Zytel(R) 101, TFE Teflon(R) type 1, polycarbonate Lexan, ABS polymer Kralastic, polystyrene Styron 475 , epoxy G-10-3675, ethyl cellulose, acetal Delrin(R) 500x, polyvinyl alco- hol, and unplasticized polywinyl chloride. Quantitative data are presented for length change, weight change, and for percent extractables. The appearances of the plastic and liquid R-123 are described. The linear polyethy. lene Alathon 7050, nyton Zytel(R) 101, epoxy G. 10-3675, Delrin(R) 500X, and polyvinyl chloride plastics were judyed to be compatible with $R$. 123.

Elastomer Immersion Tests for Fluorocarbon123. technical report NIST-8, Freon(R) Products Laboratory, E. I. du Pont de Nemours and Com. pany, Incorporated. Wilmington, DE, undated (5 pages with 2 tables, available from JMC as RDB. 0304)

Results are summirized for immersion tests of 13 elastomers in R-123 for up to seven days at 75 and $130^{\circ} \mathrm{F}\left(24\right.$ and $54^{\circ} \mathrm{C}$ ). Quantitative results of the linear-swell tests are provided, in. cluding intermediate and final changes in length and weight as well as the fraction of extrac. tables. Qualitative changes in appearance and physical properties of the elastomers and in the appearance of the liquid are tabulated. The tested elastomers were two urethane rubbers (Adiprene(R) $C$ and Adiprene(R) $L$ ), a hydrocarbon rubber (Nordel(A)), a fuoroelastomer $\mathrm{Ni}$ ton(R) A), a sillicone rubber (General Electric SE361), a nitrile silicone rubber (NSR-X5602), a synthetic rubber (Hypalon(R) 40), natural rubber polysilfide rubber (Thiokol(R) FA), Buna(TM) N, Buna(TM) $S$, chloroprene (neoprene $W$ ), and Butyl(TM). Of those tested, only Triokol(R) FA appears suitable for use and prolonged contact with R-123.

Polymer/Elastomer Pertormance in R-123 and R-134a, Carrier Corporation, Syracuse, NY, September 1989 (4 pages with 3 flgures, available from JMC as ROB0018)

Two graphs compare swell for polymers and elastomers in R-11 and R.123 at room temperature and at $93^{\circ} \mathrm{C}\left(200^{\circ} \mathrm{F}\right)$. The materials in. clude a nitrile copolymer, fluoroelastomer $\mathrm{Ni}$ ton(R) A), isopriane (neoprene), nylon, phosphazene (Eypel-F), polytetrafluoroethane (Gylon), two polyolefins (Alcryn and a polypropylene). and two thermoplastics (Geolast(R) olefinic thermoplastic and Hytrel(R) polyester). R.123 produced much greater swelling than did R-11. Quantitative values are given for swell and extactables of elastomeric materials in R-134a at $93^{\circ} \mathrm{C}\left(200^{\circ} \mathrm{F}\right)$ for ten days. These materials include Gylon, neoprene, nitrile, nylon $6 / 6$, polypropylune, and Viton(R) A.

Summary of Physical Property, Solubility, and Compatibility Data for [HC]FC-123, report NIST. 9. E. I. du Pont de Nemours and Company, Incor- 
porated, Wilmington, DE, undated (11 pages with 3 figures and 4 tables, available from JMC as RDB0305)

Liquid density, vapor pressure, viscosity, surface tension, and Kauri-butanol number are provided for R-123. The solubility of water and various substances in $R-123$ also are given. Additionally, the report qualitatively summarizes compatibility tests with various magnet wire varnishes, including Alkanex terephthalate polyester, enamel oleoresin, Ensolex acrylic, epoxy, Anavar isocyanate-modified polyvinyl, Lecton acrylic, Nylclad nylon-coated polyvinyl, polyimide, polyurethane, and Formvar polyvinyl.

Metal Corrosion Tests with [HC]FC-123 and Distilled Water, report NIST-10, E. I. du Pont de Nemours and Company, Incorporated, Wilmington, $D E$, undated (5 pages with 2 tables, available from JMC as RDB0306)

Compatibility results of $\mathrm{R}-123$ and distilled water with cold-rolled steel 1020, stainless steel 304 nickel, monel, copper, aluminum 2S, zinc, and magnesium alloy FS-1 aro reported for dry and wet conditions. Results are tabulated at the liquid boiling point after exposure for 100 hours and after 100 days at $55^{\circ} \mathrm{C}\left(130^{\circ} \mathrm{F}\right)$. Decomposition of the R-123, metal corrosion rates, and the appearances of the llquid and metal are presented. R-123 was judged suitable with all of the metals under dry-test conditions, but suitable only with the stainless steel after 100-day wet exposure. Additionally, only the stainless steel, nickel, and monel showed no corrosion after the 100-day wet-exposure test.

Material Compatibility of Alternative Refrigerants: Usability/Compatibility of R-123 Roceived from Refrigerant Suppliers, report NIST-2, Chiernistry Laboratory, The Trane Company, La Crosse. WI. 15 April 1988 (2 pages with 1 table, available from JMC as RDBO023)

This report of chemical analyses addresses the compatibility of R-123 samples from Allied-Signal and Du Pont Chemicals with red neoprene 2337 elastomer material. Test rings were exposed to R-123 in both vapor and liquid phases for 160 hours at $77^{\circ} \mathrm{C}\left(170^{\circ} \mathrm{F}\right)$ using Trane Standard Test Method 3.7-04. Control samples were similarly exposed to R-11. Cross-sectional diameter, volume swell, and durometer hardness are tabulated before and after exposures. Some extraction of processing and/or base oils was observed with all three refrigerant samples. No precipitation of waxlike materials, cracks, or blisters were evident in any of the refrigerants. The increases in diameter and volume and decreases in durometer hardness were lower in $R$. 123 than in $r .11$. The differences between results from the two R-123 samples were minor.
Material Compatibility of Alternative Refrigerants: Usability/Compatibility of R-123 Received from Refrigerant Suppliers, report NIST-3, Chemistry Laboratory, The Trane Company, La Crosse, WI, 15 April 1988 (4 pages with 2 tables, available from JMC as RDBO024)

Swell tests of elastomeric compounds in R-11 and R-123 at $77^{\circ} \mathrm{C}\left(170^{\circ} \mathrm{F}\right.$ ) for 72 hours are reported. The elastomers included yellow nitrile 7507, red neoprene 2337, and green neoprene 2167. Quantitative data are presented for volume swell, cross-sectional diameter, and durometer hardness. Nitrile exhibited swelling $400-600 \%$ greater in R-123 than in R-11. The neoprene samples exposed to R-123 exhibited less or comparable swelling to those exposed to R-11.

Material Compatibility of Alternative Refrigerants: Usability/Compatibility of R-123 Received from Refrigerant Suppliers with Elastomer Materials, report NIST-4, Chemistry Laboratory, The Trane Company, La Crosse, WI, 10 May 1988 (3 pages with 2 tables, available from JMC as RDB0025)

Swell and durometer test data are tabulated for yellow nitrile 7507, red neoprene 2337, and green neoprene 2167 test rings exposed to $50 / 50$ mixtures of R-11 and R-123 with 250 SUS white oil. The tests were repeated for separate samples of R-12'3 from Allied-Signal and Du Pont Chemicals. Samples were aged in stainless steel test vessels for 3 days (72 hours) at 77 ${ }^{\circ} \mathrm{C}\left(170^{\circ} \mathrm{F}\right)$. Cross-sectional diameter, volume swell, and durometer hardness were measured both before and after exposures, for both the vapor and liquid phases of the refrigerants, and compared. The hardness measurements were repeated after 2-3 days of drying to allow sii gasing.

Material Compatibility of Alternative Refrigerants: Compatibility of R-123 Received from Refrigerant Suppliers with Proposed Elastomer Materials, repori NIST-5, Chemistry Laboratory, The Trane Company, La Crosse, WI, 6 June 1988 (2 pages with 1 table, available from JMC as RDB0026)

Measurements of weight, volume, density, dimensions, and durometer hardriess are reported for Morton Thiokol(R) polysulfide rubber ST. Data are compared before and after exposures to both the vapor and liquid phases of $R$. 123. Aging was performed in stainless steel test vessels for 3 days $\left(72\right.$ hours) at $77^{\circ} \mathrm{C}\left(170^{\circ} \mathrm{F}\right)$. The tabulated data summarize measurements for tests in the refrigerant alone and in a 50/50 mixture with 250 SUS white oil. The tests were repeated for separate samples of R-123 from Al. lied-Signal and Du Pont Chemicals. Data for 
exposures to the Allied-Signal R.123 refrigerant without lubricant were lost, due to an experimental problem, and were not remeasured. The document concludes that this rubber formulation would not be acceptable as an elastomer for use in a R-123 environment, but it does not rule out use of other polysulfide rubbers. The test data suggest that this rubber compound is affected more severely by $100 \%$ R-123 than by the mixture of R-123 and lubricant.

Material Compatibility of Alternative Refrigerant 123: Shiort Term Suitability of Chloroprene Sheet Gasket Material, report NIST-6, Chemistry Laboratory, The Trane Company, La Crosse, WI, 7 October 1988 (1 page, available from JMC as RDB. 0027)

Results are qualitatively summarized for compression and flexibility tests of Reinz chloroprene sheet gasket material exposed to R-123. The exposures were for 24 hour at $25^{\circ} \mathrm{C}\left(77^{\circ} \mathrm{F}\right)$ and at $100^{\circ} \mathrm{C}\left(212^{\circ} \mathrm{F}\right)$. All samples failed when folded before reaching a $180^{\circ}$ angle.

Material Compatibility of Alternative Refrigerant 123: Physical Properties of O-Rings for Applicability in Alternative Refrigerant 123 and Refrigerant 11, report NIST-7, Chemistry Laboratory, The Trane Company, La Crosse, WI, 27 October 1988 (2 pages with 2 tables, available from JMC as RDB0028)

heat aging in air of neoprene; 2347 elastorier 0 rings and fluid resistance tests with R-1 :, R-123, ASTM \# 3 oil, and 250 SUS white oil

Material Compatibility of Alternative Refrigerant 123: Elastomer Chemistry of and Specifications for Chloroprene, report NIST-8, Chemistry Laboratory. The Trane Company, La Crosse, WI. 10 November 1988 (2 pages with 1 table, available from JMC as RDB0029)

heat aging in air and R-11 vapor and liquid, $R$. 123 vapor and liquid, ASTM \#3 oil, and 250 SUS white oil of red (neoprene 2337), green (neoprene 2167), and a new-compound chloroprene (neoprene 2347) elastomer o-rings and green chloroprene (neoprene 2167) elastomer cord rings

Teflex O-Rings, Size 214. Sealmore Industries, report NIST-10, Chemistry Laboratory. The Trane Company, La Crosse. WI, 27 January 1989 (1 page with 1 table, available from JMC as RDB0031)

A table compares the swell properties of Teflex o-rings in R-11, R-123, and in 250 SUS white oil with each refrigerant in a $50 \%$ refrigerant mixture. Quantitative results are presented after a 70 -hour exposure at $77^{\circ} \mathrm{C}\left(170^{\circ} \mathrm{F}\right)$. The R-123 samples exhibited a volume change three-times higher than those of the R-11 samples. How- ever, the o-ring density changes were compa. rable for the $R-11$ and $R-123$ refrigerantlubricant mixtures.

HCFC.-123 Compatibility with Teflex NPG V-214 O-Rings Covered with High Density Teflon, report NIST-11, Chemistry Laboratory. The Trane Company, La Crosse, WI, 16 March 1989 (1 page, available from JMC as RDB0032)

Results of swell testing 1 eflon(R)-coated Viton(R) o-rings in R-123 at $100^{\circ} \mathrm{C}\left(212^{\circ} \mathrm{F}\right)$ are reported. Testing stopped after 72 hours due to o-ring failure.

Stability of CFC-11 and HCFC-123, report NIST. 12. Chemistry Laboratory, The Trane Company, La Crosse, WI, 17 April 1989 (3 pages with 1 table, available from JMC as RDB0033)

Sealed-tube test results are compared for $R-11$ and R-123 after exposure to 250 SUS white mineral oil and metallic catalysts (aluminum, copper, and steel). Qualitative and quantitative decomposition effects are presented after 168 hours at $100^{\circ} \mathrm{C}\left(212^{\circ} \mathrm{F}\right), 121^{\circ} \mathrm{C}\left(250^{\circ} \mathrm{F}\right)$, and $150^{\circ} \mathrm{C}\left(302^{\circ} \mathrm{F}\right)$. The thermal stabiity of $\mathrm{R}-123$ and oil was judged to be greater than the thermal stability of R-11 and oil.

Evaluation of Epoxy Varnish Materials for Alternative Refrigerant HCFC.123, report NIST.13, Chemistry Laboratory, The Trane Company, La Crosse, WI, 25 August 1989 (9 pages with 8 tables, available from JMC as RDB0034)

thermal-aging tests in air, R-11, and R-123 for Sterting(R) 364, Schenectady Isopoxy 800 , Schenectady 8620, Epoxylite 477, and P. D. George 923 epoxy varnishes

Vitor: O.Aing and Cord Ring Swell Data in Both R-11 and HCFC-123, report NIST-14, Chemistry Laboratory, The Trane Company, La Crosse. WI, 13 September 1989 (1 page with 1 table, available from JMC as RDB0035)

Comparisons are presented for immersion of Viton(R) o-rings and cord rings in $R-11$ and $R$. 123. Data are tabulated for 70-hour exposures at $77^{\circ} \mathrm{C}\left(170^{\circ} \mathrm{F}\right)$. The volume change of the Viton(R) materials in R-123 was found to be approximately three times that for R-11.

H. B. Ginder, Compatibility Test - 15\# Carbon Bursting Disk (2.5"), York International Corporation, York, PA, July 1989 (1 page, available from JMC as RDBO011)

A $64 \mathrm{~mm}\left(2 \frac{1}{2}\right)$ carbon bursting disk was im. mersed in R-123 at room temperature for 16 days. Subsequent testing for leaks and jorosity, using R-22, indicated that the disk did not develop leaks. 
H. B. Ginder, Compatibility Test - O-Rings, Gasket, Oil Filter, Etc., York International Corporation, York, PA, July 1989 (1 page with 1 table, available from JMC as RDB0009)

A table summarizes the swelling of various materials immersed in R.123 and R-11. The materials include elastomeric Niton(R), Buna(TM) $N$ and neoprene) o-rings, a Buna(TM) $N$ bushing, and components of a Kaydon oil-line filter (cork and Buna(TM) $N$ gaskets, pleated paper, and adhesive). Quantitative results are presented after a two week exposure at room temperature in a mixture of $90 \%$ refrigerant and $10 \%$ naphthenic oil. The R-123 test samples swelled considerably more than the R-11 samples. The Buna(TM) $N$ bushing swelled $79 \%$ in R-123, as compared to $7.1 \%$ in R.11. The document concludes that Buna(TM) $N$ formulations are not too compatible with $R-123$, but that Viton $(R)$ and neoprene appear to be acceptable. Compatisility concerns also are cited for the gaskets and adhesive in the oil filter.

T. P. Gross, Compatibility Test - Green-Colored Vison O-Ring, York International Corporation, York, PA, July 1989 (1 page, availabie from JMC as RDB0012)

Swell data are presented for green-colored Viton $(R)$ o-rings immersed in R-123 and R-11 for three week at room temperature. The o-rings showed initial linear swell of $19.8 \%$ in R-123, which changed to $4.4 \%$ after drying overnight. Samples exposed to R-11 showed initial linear swell of $3.0 \%$. The elastomers exhibited no significant loss in physical properties in either fluid.

T.P. Gross, Compatibility Test - Loctite Sealants (Pipe Sealant with Teflon, Grade AV), York Internationa, Corporation, York, PA, July 1989 (1 page, available from JMC as RDB0010)

Two Loctite(R) compounds (pipe sealant with Teflon(A) and Grade AV) were applied to threaded fittings and tested with liquid R-123. The report indicates that the two compounds tested appear to be compatible with R.123. based on a seven-day period of exposure and curing. The test procedure and curing considerations for sealants are discussed.

Compatibility of Alternative Refrigerunts with Elastomers, report NIST-11, E. I. du Pont de Nemours and Company, incorporated, Wilmington, $D E$, undated ( 3 pages available from JMC as RDB. 0307)

swell tests of neoprene $W$ and Buna(TM) NC in R-123 and R-124

Mutual Solubilities of Water with Fluorocarbons and Fluorocarbon-Hydrate Formation, report NIST-12, E. I. du Pont de Nemours and Company,
Incorporated, Wilmington, DE, undated (15 pages with 4 figures and 7 tables, available from $J M C$ as RDB0308 with one missing page)

Test procedures and results are described for an investigation of the mutual solubility of water and of solid hydrate formation with R-123, $R$ 124, and R-125. Measured and calculated solubility data are tabulated in the temperature range of $77.167^{\circ} \mathrm{C}\left(171.333^{\circ} \mathrm{F}\right)$ for $\mathrm{R}-123$ and $\mathrm{R}$. 124 and $77-138^{\circ} \mathrm{C}\left(171-280^{\circ} \mathrm{F}\right)$ for $\mathrm{R}-125$. Regression equations and plots of the data are provided to compare the data to prior measurements for R-22, R-113, and an unidentified fiuid. Solubility coefficients are plotted for these fluorocarbons in water for $0.120^{\circ} \mathrm{C}\left(30-2.50^{\circ} \mathrm{F}\right)$ at saturated vapor pressure conditions. The fraction of fluorocarbon by weight in water are similarly presented and plotted at saturated vapor and atmospheric pressures. The results coupled with those of eartier work indicate that $R-125, R-134 a, R-142 b$, and R-152a form solid water hydrates, but that R-123 and R-124 do not. The document discusses implications of the findings on specifications for water content in the refrigerants examined.

Sealed-Tube Stability Test Results: Alternative Refrigerants, Carrier Corporation, Syracuse. NY, September 1989 ( 1 page with 1 table, available from JMC as RDB0020)

A table summarizes the decomposition fraction of R-11, R-12, R-123, and R-134a with Suniso $3 G S$ and Mobil DTE 26 mineral oils and with Zerol 150 and Zerol 300 alkylbenzene lubricants. No decomposition was detected for R-134a; some R-12 decomposed into R-22. R-123 decomposed less than R-11 for all four lubricants.

UL 984 Tests with R-123 and Oils, Carrier Corporation, Syracuse, NY (1 page with 1 table, available from JMC as RDB0016)

A table summarizes modified UL 984 tests of motor materials aged at $82^{\circ} \mathrm{C}\left(180^{\circ} \mathrm{F}\right)$ for 60 days. Control results are compared to those after separate exposures to R-11 and R-123 mixed with $5 \%$ Mobil DTE 26 mineral oil, Zerol 150 alkylbenzene oil, and Rando HD-68. Insula. tion failures ( 1 ma current leakage to ground after 1 minute at $1.5 \mathrm{kV}$ ) and breakdown voltages are reported. Results are summarized for polyester-imide magnet wire, Dacron(R)-Valox $(\mathrm{A})$ lead wire, Teflon( $(R)$ wire sleeving, Mylar( $R)$ end cap. Mylar( $(A)$-Dacron( $(A)$ thermosleeve, Mylar( $(A)$ and Melinex(R) slot liners, and Mylar(R) and Melinex $(R)$ phase separators. Breakdown voltages of 2.7-17.0 kV, but no current leakage failures, are indicated. 
Refrigerant Breakdown Voltage, Buffalo Research Laboratory, Allied-Signal Incorporated, Buffalo, NY. 1 May 1990 (1 page with 1 table, available from JMC as ROB0512)

Refrigerant breakdown voltages, as determined by ASTM D-2477-84, are tabulated for R-11, R12, R-22, R-123, and R-134a at $21^{\circ} \mathrm{C}\left(70^{\circ} \mathrm{F}\right)$ and $93^{\circ} \mathrm{C}\left(200^{\circ} \mathrm{F}\right)$.

\section{$\underline{R-124}$}

P. R. Reed (Du Pont Chemicals) and H. $O$. Spauschus (Spauschus Associates, Incorporated), HCFC-124 Applications and Properties: Comparisons with CFC-114, presentation charts prepared by Spauschus Associates, Incorporated, for E. I. du Pont de Nemours and Company, Incorporated, Wilmington, DE, undated (22 pages with 9 figures and 1 table, available from JMC as RDB. 1206)

The stability, miscibility, and lubricity of R-124 are compared to those of R-114. Qualitative data are presented for sealed-tube tests with metals (copper and steei) and unspecified 300 SUS mineral oils (paraffinic and naphthenic) and with an alkylbenzene lubricant after 14 days at $175^{\circ} \mathrm{C}\left(350^{\circ} \mathrm{F}\right)$. The effects of high moisture content and of lubricant additives on refrigerant stability also are discussed. Alkylbenzene lubricants were judged to be the most suitable for use with R-124.

\section{R-134A}

D. J. Bateman (Du Pont Chemicals), Current Development Status of HFC-134a for Âutomotive Air Conditioning, paper 900213 (SAE International Congress and Exposition, Detroit, MI, 26 February 2 March 1990), Society of Automotive Engineers (SAE), Warrendale, PA, February 1990 (15 pages with 6 figures and 11 tables, RDB2201)

A. P. Cohen, S. R. Dunne, and J. J. Søman, Desiccants for Drying R-134a in Refrigeration Systems, UOP Research and Molecular Sieve Technology, Tarrytown, NY, April 1988 (16 pages with 8 figures and 4 tables, available from JMC as RDB. 0003)

This document summarizes tests of the effectiveness, compatibility, and physical strength of three Union Carbide Molecular Sieves for use as desiccants for R-134a. The molecular sieves tested were $4 A-X H-5$ and $4 A-X H-6$, both commercial products, as well as $X H-7$, a developmental item; all three were tested as $8 \times 12$ mesh beads. These desiccants were exposed to $R$ $134 a$ and a polyalkylene glycol lubricant, Union Carbide UCON LB-525, at $82{ }^{\circ} \mathrm{C}\left(180{ }^{\circ} \mathrm{F}\right)$ and then tested for fluoride content, water capacity, crush strength, and attrition. Plots of fluoride uptake and water-retention capacity, as functions of equivalent exposure time, are provided along with plots of water capacity, crush strength, and attrition versus fluoride content. Isotherms were generated for the three desiccants in R-134a. The document recommends against use of $4 A-X H-5$, currently used for R-12 drying, with R-134a. It suggests that the choice between the remaining types be based on the cost versus required performance, especially with respect to their relative strength characteristics. Significant build-up of fluoride v'as detected on the 4A-XH-5 molecular sieve, due to chemical reaction between R-134a and the desiccant. Further information on a long-term test of a $4 A-X H-6$ sample addressed is provided in document RDB0309.

P. D. Guy, G. Thompsett $(\mathrm{ICl}$ Chemicals and Polymers, Limited), and T. W. Dekleva (ICl Americas, Incorporated), Compatibilities of Nonmetallic Materials with R- $\{34 a$ and Alternative Lubricants in Refrigeration Systems, paper AN-92-5-4 Winter Meeting, Anaheim, CA, January 1992), ASHRAE Transactions, American Society of Heating, Refrigerating arid Air-Conditioning Engineers, Atlanta, $G A$, volume 98 , part 1 , in publication (13 pages with 17 tables, RDB2104)

This paper reviews the compatibility of nonmetallic materials with R-134a and associated lubricants, based on sealed-tube tests as well as analytical investigations of compressor life tests and field elaluations. The test and analytical methods used also are reviewed. The materials addressed include ethylene propylene dimer monomer (EPDM) rubber, fluorinated polymer. natural rubber, nitrile rubber, nylon, and polyethylene terephthalate (PET). Data on weight, volume, tensile-strength, and elongation change as well as on hardness are compared to those for R-12 with naphthenic mineral oil. The paper notes that while an enormous amount of information has been developed by industry for compatibility of alternative refrigerants with as. sociated lubricants and materials, most of it has not been published.

J. G. Johnson, R-134a, R-123, and Mineral Oil Compatibility with Steel, Aluminum, and Copper, SnyderGeneral Corporation, Staunton, VA, 4 September 1990 (4 pages with 1 figure and 1 table. available from JMC as RDB0902)

The chemical and thermal stability of R-123 and R.134a with Suniso 4GS mineral oil in the pres. ence of ferrous and nonferrous metals were 
compared to that of $\$ .12$ and R.500 under the same conditions. Sti bility was gauged using sealed-tube tests for 14 days at $175^{\circ} \mathrm{C}\left(350^{\circ} \mathrm{F}\right)$; test results are compared by gas chromatography, to identify decomposition products, and by visual analysis. The metals used for the tests were Sandvic valve steel, OFHC copper wire, and aluminum 85 bearing material. R-134a was found to be superior to R-12 and R-500 in stability and reactivity, but immediate decomposition was evident for R-123.

E. D. Lawler, HFC-134a and Mineral Oil Materials Compatibility with Hermetic Motor Insulation System for McQuay PEH048/050 Centrifugal Water Chillers, SnyderGeneral Corporation, Staunton, VA, 29 August 1990 (2 pages with 4 tables, available from JMC as RDB0901)

The compatibility of R-134a and mineral oils (both naphthenic and paraffinic) with the hermetic motor insulation materials used in centrifugal water chillers are examined. Baseline tests were run with R-12 and naphthenic oil for comparison purposes. Results are presented for varnish bonding for amide-imide-polyester film and dielectric retention of copper magnet wire with and without varnish treatment. Results also are summarized for retention of flexibility for Mylar(R), Nomex(R), and Dacron(R)-Mylar(R). Dacron $(R)$ sheet insulation, as well as for dielectric retention of flexible hermetic lead wire. The materials were generally unaffected. One exception was a weakening of epoxy varnish in the presence of R-134a and naphthenic oil' (reduced $13.5 \%$ compared to the mixture of $R$ 12 and naphthenic oil). Flexibility of film insulation was adequately maintained and retained dielectric was acceptable.

E. D. Lawler, Compatibility of Various Elastomers in Refrigerant HFC-134a with Several Lubricants, SnyderGeneral Corporation, Staunton, VA, 5 September 1990 (3 pages with 3 tables, available from JMC as RDB0903)

Results of materials compatibility testing of orings with $\mathrm{A}-134 \mathrm{a}$ and naphthenic mineral oil, alkylbenzene, and polyalkylene glycol (PAG) lubricants are presented. The elastomers evaluated were nitrile HSN, nitrile ASM 3215, and neoprene ASM 3209. Thermal aging tests were conducted separately for the refrigerant and lubricants and for refrigerant-lubricant mixtures. Changes are noted for hardness, tensile strength, elongation, and volume. The property changes experienced by the elastomers were no greater than, and generally less than, tr.ose experienced when aged in the presence of either R-12 or R-22. Nitrile, however, appears to shrink slightly when soaked in alkylbenzene. The neoprene swelled slightly when subjected individually to either $R-134 a$ or the PAG, and there was an unacceptable amount of shrinkage when aged in a mixture of R-134a and 5\% PAG.

K. S Sanvordenker (Tecumseh Products Company), Materials Compatibility of R-134a in Refrigerant Systems, ASHRAE Transactions, volume 95, part 2; republished in ASHFAE Special Publication, CFCs: Time of Transition, American Society of Heating, Refrigerating, and Air-Conditioning Engineers, Atlanta, GA, pages 211-216, January 1989 (6 pages with 5 figures and 1 table, RDB0001)

Miscibility and pressure-temperature solubility diagrams are presented for R.134a with polyg. lycol (butyl monoether, polyoxyethylene-propylene, and polyoxypropylene glycol) and polyol ester (dibasic acid ester and neopentyl ester) lubricants. The effects of R-134a on two magnet-wire insulations (polyester-imide and polyester enamel overcoated with amide-imide), two unidentified anaerubic adhesives, three elastomeric o-rings (chloroprene, ethylene propylene rubber, and nitrile), and a type $4 \mathrm{~A}$ molecular-sieve desiccant are addressed. Compressor and refrigerator-freezer tests with R-134a and selected lubricants are described.

H. O. Spauschus (Spauschus Associates, Incorporated), HFC-134a as a Substitute Refrigerant for CFC-12, Status of CFCs - Refrigeration Systems and Refrigerant Properties (proceedings of the meetings of IIR Commissions B1, B2, E1, and E2, Purdue University, West Lafayette, IN), International Institute of Refrigeration, Paris, France, pages 397 400. July 1988; republished in International Journal of Refrigeration, Paris, France, volume 13, number 11 , November 1988, pages 389-392 (4 pages, RDB1102)

This paper discusses compressor and refrigeration system requirements and information gaps for R-134a applications. It summarizes the reasons $R \cdot 134 a$ is viewed as a leading candidate for replacement of R-12. The paper reviews some of the basic properties of R-134a, including stability, system chemistry, solubility, and lubricity. Additional information that is systemspecific will need to be developed for each major application: automotive, home appliance, or centrifugal chillers.

R. H. P. Thomas and H. T. Pham (Allied-Signal Incorporated), Evaluation of Environmentally ACceptable Refrigerant-Lubricant Mixtures for Refrigeration and Air Conditioning, paper 891967 (Passenger Car Meeting, Dearborn, MI), Society of Automotive Engineers, Warrendale, PA, September 1989 (9 pages with 6 tables and 5 figures as RDB0503)

Laboratory data on the compatibility of $R-134 a$ with lubricants and the compatibility of the re- 
frigerant-Jubricant mixtures with elastomirs and other materials are reviewed. Miscibility of R$134 a$ in three polyglycols, a dihydroxy and two butyl-capped monhydroxy polyalkylene glycols (PAGs), and solubility for R-134a with the first of these are discussed. Stability, dry and with moisture present, also is addressed by comparing copper plating at $149^{\circ} \mathrm{C}\left(300^{\circ} \mathrm{F}\right)$ for the systems with R-134a and PAGs to R-12 with mineral oil. Tests of fluoride-ion production in sealed-tube tests, to determine the effects of air and water, are presented. Hose permeability with the refrigerant alone and with the refrigerant-lubricant mixtures, lubricity test using pin and v-block (Falex machine) tests, and swell tests with elastomers are described. The elastomers tested include three nitriles, epichlorohydrin, two neoprenes, a chlorosulfonited polyethylene, and a chlorinated polyethylene. The basic finding is that the R-134a. "JAG combination is workable.

S. G. Sundaresan and W. R. Finkenstadt (Copeland Corpcration), Polyalkylene Glycol and Polyol ester Lubricant Candidates for Use with HFC. $134 a$ in Refrigeration Compressors, paper AN92-5-3 Winter Meeting, Anaheim, CA, January 1992), ASHRAE Transactions, American Soclety of Heating, Refrigerating and Air-Conditioning Engineers, Atlanta, $G A$, volume 98, part 1 , in publication (8 pages with 4 figures and 6 tables, RDB2103)

This paper addresses polyalkylene glycol (PAG) and ester lubricants for use with R-134a in refrigeration compressors, with emphasis on lubricity and materials compatibility. The PAGs addressed include diols (having two free hydroxyl groups), monoethers (one hydroxyl group), and end-capped PAGs (no free hydroxyl groups). The esters include dibasic (DBE), pentaerythritol (PE), trimethylolpropane (TMP), and neopentyl glycol (NPG). Properties of 17 $P A G$ and 22 ester candidates are presented along with miscibility profiles for five of them. Sealed-tube test results are tabulated for four lubricants with metals (aluminum, stainless steel, and copper), magnet wire enamel, epoxy, PET film and fiber, polyamide (nylon 6/6), polyimide, polyetherketone (PEK), chloroprene o-ring, and nonasbestos (nitrile binder with clay silicate filler) gasket material. Hygroscopicity and wear from life testing, in semihermetic reciprocating-piston compressors, are summarized. While the exact cause-and-effect mechanisms leading to failure of a connecting rod in one test and wrist pin distress in others have not been established, noticeable differences are reported for the several lubricants. The results indicate that end-capped PAGs and PEs are viable candidates. Esters are preferred over PAGs for retrofit due to their miscibility with hy- drocarbon lubricants anid compatibility with residual chlorine.

S. G Sundaresan and W. R. Finkenstadt (Copeland Corpioration), Degradation of Polyethylene Terephthalate Films in the Presence of Lubricants for HFC-134a: A Critical Issue for Hermetic Motor Insulation Systems, International Journal of Refrigeration. Paris, France, volume 14, number 11 , November 1991, pages 317-320 (4 pages with 3 figures and 2 tables, RDB2202)

An investigation of polyethylene terephthalate (PET) embrittlement mechanisms with lubricants is summarized. PET is widely used as an insulating material in motors for hermetic compressors. The paper reviews related studies and summarizes both the experimental approach and findings. Degradation was measured after thermal-aging in sealed tubes at 130 , 150 , and $175^{\circ} \mathrm{C}\left(166,302\right.$, an $\left.\mathrm{c}^{\prime} 347^{\circ} \mathrm{F}\right)$ for 7,14 , and 28 days. The effects of drying the PET film and lubricants were evaluated. Three polyalkylene glycols (PAGs) were studied including monol, diol, and end-capped (modified) polypropylene glycols. A pentaerythritol (PE) ester and a PAG-monol and PE-ester blend also were investigated. All five lubricants were ISO 32 (150 SUS) viscosity for use with R-134a. The effects of moisture content, temperature, and lubricant structure were examined. The results were compared to those of PET in R-12 with mineral oil. The study confirmed earlier findings that PET films must be dried, to less than $0.1 \%$ moisture content by weight, to minimize embrittlement by moisture. Residual water in the PET, even after drying, may exceed ten times that contributed by the lubricant and has a greater effect. The extent of embrittlement increases with the number of free hydroxyl groups in PAGs, and neither the monol nor diol was found to be acceptable. The end-capped PAG and ester lubricants showed no adverse reaction with dried PET film.

S. G. Sundaresan and W. R. Finkenstadt, Evaluation of Polyalkylene Glycol Candidates with HFC-134a in Refrigeration Compressors, presentation charts (ASHRAE Annual Meeting, Vancouver, BC, Canada, June 1989), Copeland Corporation, Sidney, OH, June 1989 (25 pages with 2 figures and 7 tables, available from JMC as RDB0529)

Miscibility is shown for $55-100 \%$ R-134a with four unidentified polyalkylene gly col (PAG) lu. bricants (150-180 SUS). Compatibility of the refrigerant-polyglycol mixtures with metals, motor materials, and structural polymers are qualitatively presented. The metals include copper, aluminum, and stainless steel. The motor materials include two magnet-wire insulations (epoxy coated and polyester enamel overcoated with 
polyamide-imide), a polyethylene terephthalate (PET) slot liner, and an unspecified lead wire insulation. The structural polymers include a chloroprene seal, nonasbestos gasket (nitrile binder and clay silicates as filler), nylon $6 / 6$, polyetherketone (PEK), and polyimide. Effects of the refrigerant-lubricant mixtures on compressor durability were quantitatively reported for test conditions of break-in, normal load, start/stop, high load, high compression ratio, and flooded start.

Polyglycol Sealed-Tube Tests, Carrier Corporation, Syracuse, NY, September 1989 (1 page with 1 table, available from JMC as RDB0021)

A table compares tests of R-12 and R-134a with two polyalkylene glycol (PAG) lubricants, Nippon RS680 and Glygoyle 11. No decomposition was detected for R-134a with either oil. R-12 decomposition was reported at $75-90 \%$ with the two lubricants.

Elastomer Compatibility with HFC-134a: Experimental Details, report NIST-1, Freon(R) Products Laboratory, E. I. du Pont de Nemours and Company, Incorporated, Wilmington, DE, undated circa 1989 (2 pages with 2 tables, avallable from JMC as RDB0531)

Compatibility tests of elastomers with R-134a and a naphthenic mineral oil (Suniso 5GS) are summarized. Duplicate samples of two neoprene $W$ samples, National O-Ring and Parker, were exposed for 18 days. Lengths and weights were measured before exposure, immediately after removal, and after storage in ambient air for an additional 15 days. No color change or particulate residue were noted. Temporary and final linear swelling by $4.43-5.76 \%$ and 3.07 . $4.37 \%$ was measured. Weight changes of -0.77 to $+1.86 \%$ were noted upon removal, but they changed to $-3.71 \%$ to $-1.01 \%$ after drying.

Compatibility of Elastomers with HFC-134a at About $25^{\circ} \mathrm{C}$, report NIST-2, Freon(R) Products Laboratory, E. I. du Pont de Nemours and Company, Incorporated, Wilmington DE, 17 July 1989 (15 pages with 13 tables, available from JMC as RDB0532)

A broad range of elastomers were tested to compare compatibility with R-134a to that with R-12. The tests were performed at approximately $25^{\circ} \mathrm{C}\left(77^{\circ} \mathrm{F}\right)$, for consistency with historic data. The influences of the refrigerant were measured after immersion for 27 days and again after 14 days of drying in air. Length weight, Shore A hardness, appearance and physical properties are tabulated, the last based on qualitative observations for stretching. bending, squeezing, and flexing. The elastomers tested were Adiprene(R) L. Buna(TM)
N, Buna(TM) S, Butyl(TM) rubber, Hypalon(R) 48, natural rubber, neoprene $W$. Nordel(R), sillicone, Thiokol(R) FA, and Viton(R) A. For R-134a, Adiprene(R) $L$, buna $N$, Butyl(TM) rubber, Hypalon(R) 48, natural rubber, neoprene $W$, and Nordel(R) were judged to be preferred and Thiokol(R) FA recommended, but not preferred. For R-12, Adiprene(A) $L$, Buna (TM) $N$, and Hypalon $(R) 48$ were preferred, and neoprene $W$, Nordel(R), Thiokol(R) FA recommended, b'st not at the preferred level. Buna(TM) S, sillicone, and Viton(R) A were not recommended for either $R$ 12 or R-134a.

Compatibility of Elastomers with HFC-134a, document ARTD-5, E. I. du Pont de Nemours and Company, Incorporated, Wilmington, DE, 7 November 1989 (16 pages, available from JMC as RDB0538)

Compatibility of [H]FC-134a with Refrigeration System Materials, report NIST-4, Freon(R) Products Laboratory, E. I. du Pont de Nemours and Company, Incorporated, Wilmington, DE, $14 \mathrm{De}$ cember 1976 (7 pages with 3 tables, available from JMC as RDB0534)

Compatibility of Nonmetallic Materials with Refrigerants and Lubricants, $\mathrm{ICl}$ Chemicals and Polymers Limited, Runcoin, Cheshire, UK, 16 May 1989 (3 pages with 1 table, available from JMC as RDB0004)

A table summarizes the swell (dimensional change) and weight gain of various elastomeric and plastic materials immersed in R-134a. The materials included Buna(TM), Butyl(TM), Hypalon(R), NBR, Gartock neoprene, nitrile, nitrile Dunlop, nylon, Oilite and M229 rubber asbestos, polyetheretherketone (PEEK), Polypenco Nylatron, polytetrafluoroethane (PTFE), Reinz Thermolit $K$, terylene braid, and Viton(R). Quantitative results are presented for refrigerant-lubricant mixtures with $10 \%$ polyalkylene glycol (PAG); the lubricants, ranging in viscosity from ISO 33 to 120 , are not specifically identified. Some results also are given with $100 \%$ refrigerant.

Disassembly and Inspection of Compressor in Laboratory Refrigerator Charged with R-134a, report NIST-13, E. I. du Pont de Nemours and Company, Incorporated, Wilmington, DE, undated (40 pages with 50 figures and 3 tables, available from JM!C as RDB0309)

This report documents a detailed inspection of a hermetic compressor, operated for 8.7 years with R-134a and a polyalkylene glycol lubricant, Union Carbide UCON LB-525. An unmodified Frigidaire refrigerator was charged with $R-134 a$ in November 1977, but the compressor failed a 
month later. The failure analysis was not 10 cated, but the cause is belleved to have been a manufacturing defect. The compressor was replaced and the refrigerator returned to service in July 1978; it. operated without incident until March 1987. The refrigerator was functioning normally when shut down for compressor disassembly, to determine the long-term effects of this refrigerant-oil system. This report provides a photographic record of the disassembly, summarizes detailed chemical and metallurgical analyses, and includes profilometer readings to evaluate the effect of slight copper plating on steel bearing surfaces. A hardened steel vane spring, which broke when dropped, had been severely fatigued during service. The polyethylene slot liner insulation showed embrittlement, but was not analyzed. Very limited refrigerant decomposition was found, and the report concludes that R-134a use had very little effect on the metal parts of the compressor. Particles trapped in the oil produced slight scars on metallic contact surfaces. The molecular sieve drier contained $5 \%$ residual water, compared to a saturation value of $19-20 \%$. Unanswered questions remain concerning the refrigerant-lubricant stability; addition of an oil stabilizer or use of a different oil may be indicated. General Electric Company and Tecumseh Products Company assisted in disassembling the compressor and interpreting the visual evidence. Further examination of the desiccant used, Union Carbide molecular sieve type $4 A-X H-6$, is reported in document RDB0003.

Current Development Status of HFC-134a for Automotive Air Conditioning, document ARTD-2, E. I. du Pont de Nemours and Company, Incorporated, Wilmington, DE, undated (16 pages, available from JMC as RDB0536)

UL 984 Tests with R-134a and Oils, Carrier Corporation, Syracuse, NY (1 page with 1 table, available from JMC as RDB0017)

A table summarizes UL 984 tests of motor materials aged at $110^{\circ} \mathrm{C}\left(230^{\circ} \mathrm{F}\right)$ for 60 days. Con. trol results are compared to those after separate exposures to R-12 mixed with Suniso 3GS mineral oil and R-134a mixed with the same oil and with Zerol 150 alkylbenzene oil. Insulation failures ( 1 ma current leakage to ground after 1 minute at $1.5 \mathrm{kV}$ ) and breakdown voltages are reported. Results are summarized for polyesterimide magnet wire, Dacron-Valox $(R)$ lead wire, Teflon( $R$ ) wire sleeving, Mylar(R) end cap, MylarDacron $(R)$ thermosleeve, Mylar $(R)$ and Melinex $(R)$ slot liners, and Mylar(R) and Melinex(R) phase separators. Breakdown voltages of $0.7-15.5 \mathrm{kV}$ are indicated; current leakage failures resulted only for the polyesterimide magnet wire.

\section{$\underline{R \cdot 141 B}$}

Isotron A-141b Foam Blowing Agent: Material Compatibility, preliminary information bulletin, Elf Atochem North America, Incorporated (provided by the former Pennwalt Corporation), King of Prussia, PA, May 1989 (1 page with 1 table. avallable from JMC as RDB0519)

A table provides quantitative and qualitative data on weight change and swelling for common elastomers, plastics, refrigerator liner materials, and roofing membrane materials after a two-week exposure to R-11 and R-141b. The elastomeric materials include neoprene, Butyl(TM), Buna(TM) $N$, and Viton(R). The plastics and refrigerator liner materials include $A B S$ polymer, FEP, Kynar PVDF, polyethylene, polypropylene, polystyrene, polytetrafluoroethane (PTFE), and polywinyl chloride (PVC). The ABS polymer, Buna(TM) $N$, Viton(R), and PVC materials exhibited much greater swelling and weight gain after exposure to R-141b than to R-11. The other materials exhibited results lower than, or comparable to, R.11 after R.141b exposures.

\section{$\underline{R-142 B}$}

K. S. Sanvordenker, Materials Compatibility of R142b for Hermetic Units, Tecumseh Products Company, Ann Arbor, MI, June 1989 (7 pages with 2 figures and 5 tables, available from JMC as RDB0002)

Two figures compare the miscibility of R-142b and R-22 with Capella B and Calumet R015 mineral oils. The miscibility of R-142b with Zerol 150 alkylbenzene lubricant also is discussed. Quantitative data on two magnet wire insulations (polyester-imide and polyester enamel overcoated with amide-imide) with R-142b and R-22 are given for refrigerant absorption, softening, blistering, and retained dielectric strength. R-142b and R-22 effects on the corebond tensile strength of two unidentified solvent-based epoxy-type varnishes also are presented. Additionally, swell tests of R-142b with four elastomeric (neoprene, EPR, nitrile, and $\mathrm{Vi}$ ton(A)) o-rings are given. In each investigation, $R-142 b$ exhibited characteristics comparable to or better than, R-22.

\section{E-134}

T. P. Gross, Sealed-Tube Tests - Grace Ether (E134). York International Corporation, York, PA, 28 
March 1990 (2 pages with 3 tables, available from JMC as RDB0904)

This memo summarizes sealed-tube tests to compare the stability of R-114 and E-134 when aged for up to 72 hours with several lubricants at temperatures as high as $182^{\circ} \mathrm{C}\left(360^{\circ} \mathrm{F}\right)$. The lubricants tested included York. C, Zerol 300 alkylbenzene, and UCON LB-165 polyglycol. Aluminum, copper, and iron wires were included as catalysts. E-134 was found to be somewhat less stable than R-114.

\section{R-717 (AMMONIA)}

G. D. Short (CPI Engineering Services, Incorporated), Refrigeration Lubricants Update: Synthetic and Semi-Synthetic Oils Are Solving Problems with Ammonia and Alternative Refrigerants, Technical Papers of the 12th Annual Meeting (4-7 March 1990, Memphis, TN), International Institute of Ammonia Refrigeration, Washington, DC, pages 19-53, March 1990 (RDB2203)

G. D. Short (CPI Engineering Services, Incorporated), Hydrotreated Oils for Ammonia Refrigeration, Technical Papers of the 7th Annual Meeting (10-13 March 1985, San Antonio, TX), International Institute of Ammonia Refrigeration, Washington, DC, pages 149-176, March 1985 (RDB2204)

\section{OTHERS}

D. J. Bushouse, Degradation of Polyester Films by Alcohols. ASHRAE Journal, American Society of Heating, Refrigerating, and Air-Conditioning Engineers, Atlanta, GA, volume 3, number 9, pages 61 ff, September 1961 (RDB2301)

J. P. Harrington and R. J. Ward, Polyester Film Insulation for Hermetic Motors, ASHRAE Journal, American Society of Heating, Refrigerating, and AirConditioning Engineers, Atlanta, $G A$, volume 1, number 4, pages $75 \mathrm{ff}$, April 1959 (RDB2302)

J. F. Wilson, Effect of Methanol on the Performance of Polyester Film in Reciprocating Refrigeration Compressors, ASHRAE Journal, American Soclety of Heating, Refrigerating, and Air-Conditioning Engineers, Atlanta, GA, volume 10, number 1 , pages $43 \mathrm{ff}$, January 1968 (RDB2205)

\section{BLENDS}

\section{Azeotropes}

Isotron 22/142b Blends for Refrigeration: Material Compatibility, preliminary information bulletin. Elf Atochem North America, Incorporated (provided by the former Pennwalt Corporation), King of Prussia, PA, May 1989 (1 page with 1 table, avallable from JMC as RDB0520)

This bulletin summarizes the procedure and findings for two-week exposures of selected refrigeration system materials both to R-12 and to $a$ blend of R-22/R-142b (55/25). The materials tested included copper wire, polyimide insulation, and several plastics and elastomers. The plastics included nylon (Zytel(R) 101), PTFE, FEP, PVDF (Kynar), PVC, low-density polyethylene, polypropylene, polystyrene, high-impact polystyrene, and high-gloss ABS. The elastomers included neoprene, Butyl(TM), Buna(TM) $N$, and Viton(R). Swell (length increase percentage), weight gain (percentage), and appearance (including qualitative observations on hardness and embrittlement) are tabulated.

\section{Zeotropes}

D. J. Bateman, D. B. Bivens, R. A. Gorski, W. D. Wells (Du Pont Chemicals), R. A. Lindstrom, R. L. Morse, and R. L. Shimon (Tecumseh Products Company), Refrigerant Blends for the Automotive Air Conditioning Aftermarket, paper 900216 (SAE International Congress and Exposition, Detroit, MI, 26 February - 2 March 1990), Society of Automotive Engineers (SAE), Warrendile, PA, February 1990 (14 pages with 12 figures and 8 tables, RDB2206)

Alternative Refrigerant Blends, E. I. du Pont de Nemours and Company, Incorporated, Wilmington, DE, 1989 (18 pages, available from JMC as RDB0530)

Compatibility of Elastomers with the Ternary Blends of HCFC-22/HFC-152a/CFC-114 and HCFC-22/HFC-152a/HCFC-124, document ARTD 3, E. I. du Pont de Nemours and Company, Incorporated, Wilmington, DE, 7 November 1989 (26 pages, available from JMC as RDB0537)

Ternary Refrigerant Blends, document ARTD-10, E. I. du Pont de Nemours and Company, Incorporated. Wilmington, $D E$, undated (6 pages, available from JMC as RDB0539)

Ternary Refrigerant Blends for the Automotive Aftermarket, document ARTD-1, E. I. du Pont de 
Nemours and Company, Incorporated, Wilmington, $D E$, undated (12 pages, available from JMC as RDB0535)

test results for R-22/152a/114 (36/24/40) (blend KCD-9430) and R-22/152a/124 (36/24) 40) (blend KCD-9433) for automotive use; concludes that the blends are not drop-in replacements for R-12, but that technologies exist or can be developed to accomplish retrofit while maintaining acceptable performance; topics covered include environmental impacts; toxicity; properties; flammability; compatibility data for hoses constructed of nylon, Hypalon(R) 48, nitrile; compatibility data for elastomers including epichlorohydrin, neoprene, nitrile; compatibility data for molecular-sieve desiccants; and solubility and lubricity data for BVM-100N, Idemitsu, and Mopar mineral oils and Zerol 500 alkylbenzene oils, the last with three additives for the lubricity tests

Sealed-Tube Stability Tests: Ternary Blends (KCD-9430 and 9433), document ARTD-13, E. I. du Pont de Nemours and Company, Incorporated. Wilmington, DE, April 1990 (5 pages with 6 tables, avallable from JMC as RDB0542)

\section{LUBRICANTS}

L. F. Albright and J. D. Lawler, Viscosity-Solubility Characteristics of Mixtures of R-13B1 and Lubricating Oils, ASHRAE Journal, American Society of Heating, Refrigerating, and Air-Conditioning Engineers, Atlanta, GA, pages 67-70, April 1959 (RDB2207)

L. F. Albright and A. S. Mendelbaum, Solubility and Viscosity Characteristics of Mixtures of Lubricating Oils and Freon 13 and 115, Refrigerating Engineering, volume 64, number 10, pages 37. 47 and 106, October 1956 (RDB2208)

K. Azami, H. Hosoi, and N. Ishikawa, Lubricant Screening for HFC-134a Car Air Conditioning Compressor Reliability, paper 901735 , Society of Automotive Engineers, Warrendale, PA, 1990 (RDB2209)

G. Daniel, M. J. Anderson, W. Schmid, and M. Tokumitsu. Performance of Selected Synthetic Lubricants in Industrial Heat Pumps, Journal of Heat Recovery Systems, volume 2 [?], number 4 , pages 359-368, 1982; volume 26 [?], number 5 , pages 5-9, 1984 (RDB2210)
D. J. Glova, High-Temperature Solubility of Refrigerants in Lubricating Oil, AStiRAE Transactions, American Society of Heating, Refrigerating and Air-Conditloning Engineers, Atlanta, GA, volume 90, part 2B, pages 806-825, 1984 (RDB2211)

D. F. Huttenlocher (Spauschus Associates, Incorporated), Chemical and Thermal Stability of Refrigerant-Lubricant Mixtures with Meials, report $D O E / C E / 23810-2 B$, Air-Conditioning and Refrigeration Technology Institute (ARTI), Arlington, VA, 31 March 1992 (27 pages with 11 figures and 12 tables, avallable from JMC as RDB2416)

This interim report summarizes stability data, based on sealed tube tests, for mixtures of refrigerants and lubricants in the presence of a valve steel strip. Tabular results are presented for R-123 with mineral oil at 105, 150, and 175 ${ }^{\circ} \mathrm{C}\left(221,302\right.$, and $\left.347^{\circ} \mathrm{F}\right)$. The findings indicate that prolonged exposures to temperatures exceeding approximately $150^{\circ} \mathrm{C}\left(302^{\circ} \mathrm{F}\right)$ lead to rapid chemical deterioration, yielding $R-133 a$ and R-143a as decomposition products. Preliminary data, for tests at 150 and $175^{\circ} \mathrm{C}(302$, and $347^{\circ} \mathrm{F}$ ), are presented for R-22 with a mineral oil (Suniso 3GS), R-124 and R-142b with an alkylbenzene (Zerol 150), and R-32, R-125, R134a, and R-143a with pentaerythritol ester branched acid (Castrol Icematic SW32). Preliminary results also are presented for R-134a with a higher-viscosity pentaerythritol ester (Emery 2928 ISO 100). The information provided incluises visual observations, chemical analyses, and gas chromatographs with summary data indicating the fraction of refrigerant that reacted. The preliminary results suggest that the seven refrigerant-lubricant systems are very stable at the temperatures tested, and that further testing is needed to define the upper temperature limits.

S. Komatsuzaki, Y. Homma, K. Kawashima, and Y. Itoh (Hitachi Limited), Polyalkylene Glycol as Lubricant for HFC-134a Compressors, Lubrication Engineering. Soclety of Tribologists and Lubrica. tion Engineers (STLE), volume 47, number 12 , pages 1018-1025, December 1991 (RDB2212)

S. Komatsuzakl and Y. Homma, Antiseizure and Antiwear Properties of Lubricating Oils Under Refrigerant Gas Environments, paper 90-AM-6C1 (45th Annual Meeting, Denver, CO, 7-10 May 1990), Society of Tribologists and Lubrication Engineers (STLE), May 1990; republished in Lubrica. tion Engineering, STLE, volume 47, pages 193-198, 1991, May 1990 (RDB2213)

S. Komatsuzaki, T. Tomobe, and Y. Homma (Hitachi Limited), Additive Effects on Lubricity and Thermal Stability of Refrigerator Oils, Lubrication Engineering, Society of Tribologists and Lu- 
brication Engineers (STLE), volume 43, pages 31 . 36, 1987 (RDB2423)

J. L. Little, Viscosity of Lubricating Oll - Freon 22 Mixtures, Refrigerating Engineering, pages 1191 . 1195, November 1952 (RDB2214)

M. B. Pate, S. C. Zoz, and L. Berkenbosch (lowa State University of Science and Technology), Miscibility of Lubricants with Refrigerants, report $\mathrm{DOE} / \mathrm{CE} / 23810-2 \mathrm{C}$, Alr-Conditloning and Refrigeration Technology Institute (ARTI), Arlington, VA, April 1992 ' 2 nages with 4 tables, available from JMC as RDB2417)

This interim report summarizes progress for an investigation of miscibility of lubricants with refrigerants. Qualitative miscibility observations are tabulated for R-134a with two polyalkylene glycols (PAGs), namely a polypropylene glycol butyl monoether (ICl Emkarox VG32) and a pclypropylene glycol diol (Dow P425). Results also are given for a pentaeryth,itol ester branched acid (Castrol Icematic SW32) and for a pentaerythritol ester mixed acid (ICl Emkarate RL244): These tests were performed at nominal lubricant concentrations of 10,50 , and $95 \%$ over a temperature range of -50 to $+90^{\circ} \mathrm{C}(-58$ to $+162^{\circ} \mathrm{F}$ ). Of those tested, Emkarox VG32 remained fully miscible for the full range of concentrations and temperatures tested. Procedures to charge the refrigerant and lubricant into test cells and a method to quantify immiscibility, based on visual observations, were developed. The experimental apparatus being used was modified for the project and additional unidentified refrigerants and lubricants were ordered. The report discusses problems encountered with the procedures used and identifies procedures adopted to reduce the probability of test cell ruptures.

H. M. Parmelee, Viscosity of Refrigerant-Oil Mixtures at Evaporator Conditions, ASHRAE Transactions, American Society of Heating, Refrigerating, and Air-Conditioning Engineers, Atlanta, GA, volume 70, pages 173-180, 1964 (RDB2215)

K. S. Sanvordenker (Tecumseh Products Company), Durability of HFC 134a Compressors the Role of the Lubricant, (proceedings of the 42nd Annual International Appliance Technical Conference, University of Wisconsin, Madison, WI, May 1991), reprint by Tecumseh Products Company, Tecumseh, MI, 1991 ( 8 pages with 2 figures and 2 tables, RDB2216)

Properties of polyalkylene glycol (PAG) and polyol ester lubricants are examined, with emphasis on inherent thermal stability and suitability for use with R-134a in refrigeration compres- sors. The PAGs addressed include diols, monoethers, ester-ethers, and diethers, all stabllized with $200 \mathrm{ppm}$ BHT. Plots of hygroscopicity and miscibility of PAGs with mineral oils are provided. The decomposition kinetics, based on sealed-tube tests, are tabulated. The effects summarized include temperature $\left(177-260{ }^{\circ} \mathrm{C}\right.$, $350-500^{\circ} \mathrm{F}$ ), presence of metals (steel, copper, and aluminum) or R-134a, and PAG type. Problems of hygroscopicity, incomplete misolbility with mineral oils, and incompatibility with chlorinated solvents exist, but they can be handled by proper housekeeping procedures. Lack of thermal stability, even in the absence of metals, at $177-204^{\circ} \mathrm{C}\left(350-400{ }^{\circ} \mathrm{F}\right)$ is identified as a key shortcoming for the PAG candidates. The effects of time, metal catalysts, and initial moisture are tabulated for polyol esters, again at elevated temperatures $\left(204-260^{\circ} \mathrm{C}, 400-500^{\circ} \mathrm{F}\right.$ ). Pentaerythritol tetra ester is emphasized due, in part, to its better miscibility with R-134a compared to other neopentyl esters. Decomposition also was observed, but only in the presence of steel. A metal passivator specific to steel was found to provide a simple remer. $\%$

K. S. Sanvordenker (Tecumseh Products Company), Mechanism of Oil-R12 Reactions - the Role of Iron Catalyst in Glass Sealed Tubes, ASHRAE Transactions, American Soclety of Heating, Refrigerating and Alr-Conditioning Engineers, Atlanta, $G A$, volume 91, part $1 A$, pages 356-369, 1985 (RDB2217)

K. S. Sanvordenker (Tecumseh Products Company), Lubrication by Oil-Refrigerant Mixtures: Behavior in the Falex Tester, ASHRAE Transactions, American Soclety of Heating, Refrigerating and Alr-Conditioning Engineers, Atlanta, GA, volume 90, pages 799-805, 1984 (RDB2422)

K. S. Sanvordenker and M. W. Larime (Tecumseh Products Company). A Review of Synthetic Olls for Refrigeration Use, ASHRAE Transactions, American Society of Heating, Refrigerating and AirConditioning Engineers, Atlanta, GA, volume 78 , part 2, 1972; republished in symposium bulletin NA-72-5 (ASHRAE Annual Meeting, Nassau, Bahamas), June 1972 (RDB2218)

B. H. Shoemaker, Synthetic Lubricating Oils, Industrial Engineering Chemistry, volume 42, number 12, page 2414, 1959 (RDB2219)

G. D. Short (CPI Engineering Services, Incorporated) and R. C. Cavestri (Imagination Resources, Incorporated), High-Viscosity Ester Lubricants for Alternative Refrigerants, paper AN-92-5-2 (Winter Meeting, Anaheim, CA, January 1992), ASHRAE Transactions. American Society of Heating, Refrigerating and Alr-Conditioning Engineers. 
Atlanta, GA, volume 98 , part 1 , in publication (7 pages with 3 figures and 5 tables, RDB2102)

This paper describes the development of highviscosity (ISO 68 and above), modified polyol ester lubricants and their interactions with refrigerants. Typical properties are presented for 11 conventional and modified pentaerythritol (PE) esters, including several di- and tri-PEs, as well as for a modifled trimethylolpropane (TMP) ester. Data are reported with R-123, R-134a, R152a, E-134, and E-245. The apparatus used to measure viscosity and density is described. The viscosity of a modifled, high-viscosity ester with R-134a is presented for evaluation of the hydrodynamic lubrication and sealing of compression areas. Chemical and thermal stability and lubricity test results are provided for durability considerations.

G. D. Short (CPI Engineering Services, Incorporated) and R. C. Cavestri (Imagination Resources, incorporated), Selection and Performance of Synthetic and Semi-Synthetic Lubricants for Use with Alternative Refrigerants in Refrigeration Applications, Proceedings of the 1990 USNC/IIRPurdue Refrigeration Conference and ASHRAE. Purdue CFC Conference, edited by D. R. Tree, Purdue University, West Lafayette, IN, pages 163172 . July 1990 (10 pages with 10 figures, RDB2220)

G. D. Short (CP) Engineering Services, Incorporated), Synthetic Lubricants and Their Refrigeration Applications, (paper 89-AM-7A-1, 44th Annual Meeting, Atlanta, GA, May 1989), Lubrication Engineering, Society of Tribologists and Lubrication Engineers (STLE), volume 46, number 4, pages 239-247, April 1990 (RDB2221)

L. I. Sjöholm (Teknikgruppen $A B$ ) and G. D. Short (CPI Engineering Services, Incorporated), TwinScrew Compressor Performance and Complex Ester Lubricants with HCFC-22, Proceedings of the 1990 International Compressor Engineering Conference at Purdue, edited by W. Soedel, Pur. due University, West Lafayette, IN, pages 724-732, July 1990 (9 pages with 8 figures, RDB2222)

L. I. Sjöholm (Teknikgruppen $A B$ ) and G. D. Short (CPI Engineering Services, Incorporated). TwinScrew Compressor Performance and Suitable Lubricants with HFC-134a, Proceedings of the 1990 International Compressor Engineering Conference at Purdue, edited by $W$. Soedel, Purdue University, West Lafayette, IN, pages 733-740, July 1990 (8 pages with 7 figures (RDB2223)

H. O. Spauschus (Georgia Institute of Technology) and L. M. Speaker, A Review of Viscosity Data for Oil-Refrigerant Solutions, ASHRAE Transactions, American Society of Heating, Refrigerating and Air-
Conditioning Engineers, Atlanta, GA, volume 93, part 2, pages $667-681,1987$ (RDB2224)

H. O. Spauschus (Georgia Institute of Technology), Evaluation of Lubricants for Refrigeration and Air-Conditioning Compressors, ASHRAE Trans. actions, American Society of Heating, Refrigerating and Air-Conditioning Engineers, Atlanta, GA, volume 90, part 2, pages 784-798, 1984; republished in ASHRAE Journal, volume 26, number 5, pages $59 \mathrm{ff}, 1984$ (RDB2225)

H. O. Spauschus (General Electric Company), Vapor Pressures, Volumes, and Miscibility Limits of Refrigerant 22-Oil Solutions, ASHRAE Transactions, American Society of Heating, Refrigerating and Air-Conditioning Engineers, Atlanta, GA, 1964 (RDB2226)

H. O. Spauschus (General Electric Company) Thermodynamic Properties of Refrigerant-Oil Solutions: Dichlorodifluoromethane $(\mathcal{B}-12)$ and Petroleum Oil, ASHRAE Journal, American Society of Heating, Refrigerating, and Air-Conditioning Engineers, Atlanta, GA, pages 63 ff, August 1963 (RDB2227)

R. H. P. Thomas and H. T. Pham (Alled-Signal Incorporated), Solubility and Miscibility of Environmentally Safer Refrigerant-Lubricant Mixtures, paper AN-92-5-1 Winter Meeting, Anaheim, $C A$, January 1992), ASHRAE Transactions, American Society of Heating, Refrigerating and Air-Conditioning Engineers. Atlanta, GA, volume 98 , part 1, in publication (6 pages with 9 figures and 1 table as RDB2101)

Solubility and miscibility data are presented for R-134a with two polyalkylene glycol (PAG) lubricants (AP-150 and AP-500) and three modified PAGs (BRL-150, BRL-300, and BRL-500). Solubility was determined by measuring the equilibrium vapor pressure of mixtures of 10 . $90 \%$ refrigerant (by weight) in the lubricants for $10-70^{\circ} \mathrm{C}\left(50-158^{\circ} \mathrm{F}\right)$. Miscibility was determined by visual observation of a sealed sample im mersed in a thermostated bath for a range of -60 to $+70^{\circ} \mathrm{C}\left(-76\right.$ to $\left.+158^{\circ} \mathrm{F}\right)$. Differences in miscibility curve characteristics are contrasted to mineral oils. The paper examines occurrence of lower critical solution temperatures (LCSTS). Similarities of refrigerant-oil systerns to solventpolymer solutions are addressed, leading to correlations of the solubility data using the Flory-Huggins theory. While further analysis is indicated, Flory-Huggins type plots allow deduction of composition in a refrigerant-Iubricant system, given the temperature and pressure and assuming equilibrium. 
R. H. P. Thomas, R. P. Robinson, R. H. Chen, and W-T. Wu (Allied-Signal Incorporated), The Solubility of R-32/125 in Modified Polyalkylene Glycols, Proceedings of the International CFC and Halon Alternatives Conference (Baltimore, MD), Alliance for Responsible CFC Pollcy, Artington, VA, pages 375-383, December 1991 (9 pages with 2 figures and 2 tables, RDB2228)

R. H. P. Thomas, W-T. Wu, and H. T. Pham (AlliedSignal incorporated), The Solubility and Viscosity of Mixtures of R-134a with Modified Polyglycols, paper 48 , proceedings of the XVIIIth International Congress of Refrigeration (Montreal, Québec, Canada, August 1991), International Institute of Refrigeration, Paris, France, August 1991 (9 pages with 7 figures, RDB2229)

The solubilities and viscosities of mixtures of R134a with two modifled polyalkvlene glycol (PAG) lubricants are reported. The pistoncylinder type viscometer and apparatus for measuring solubility are described. The solubility of R-134a in BRL-150 (a 150 SUS experimental lubricant) is plotted for $10.70^{\circ} \mathrm{C}(50-158$ ${ }^{\circ} \mathrm{F}$ ) in concentrations of $0-100 \%$. Its viscosity in BRL-150 and BRL-300 (300 SUS) is plotted both as functions of temperature for -20 to $+80^{\circ} \mathrm{C}(-4$ to $176^{\circ} \mathrm{F}$ ) and pressure. Analysis of the solubility shows that it can be described by the FloryHugins theory.

R. H. P. Thomas, W-T. Wu, and H. T. Pham (AlliedSignal Incorporated), Solubility and Viscosity of R-134a Refrigerant/Lubricant Mixtures, ASHRAE Journal, American Society of Heating, Refrigerating, and Air-Conditioning Engineers, Atlanta, GA, pages 37-38, February 1991 (2 pages with 3 figures, RDB2230)

N. A. Van Gaalen, S. C. Zoz, and M. B. Pate (lowa State University of Science and Technology). The Solubility and Viscosity of Solutions of R-502 in a Naphthenic Oil and in an Alkylbenzene at High Pressures and Temperatures, paper 3519 (RP. 580), ASHRAE Transactions, American Society of Heating, Refrigerating and Alr-Conditionirig Engineers, Atlanta, GA, volume 97, part 2, pages 285 292, 1991 (8 pages with 14 figures and 2 tables, RDB2344)

N. A. Van Gaalen and M. B. Pate (lowa State University of Science and Technology). Methods of Measuring the Solubility and Viscosity of Lubricating Oil/Refrigerant Mixtures, report ISU-ERIAmes-91191 (ASHRAE RP-580), lowa State University of Science and Technology, Ames, IA, 1991 (RDB2345)

N. A. Van Gaalen, M. B. Pate, and S. C. Zoz (lowa State University of Science and Technology). The Measurement of Solubility and Viscosity of
Oil/Refrigerant Mixtures at High Pressures and Temperatures: Test Facility and Initial Results for R-22/Naphthenic Oil Mixiures, ASHRAE Transactions, American Soclety of Heating, Refrigerating and Air-Conditioning Engineers, Atlanta, GA, volume 96, part 2, pages 183-190, 1990 (RDB2231)

N. A. Van Gaalen, M. B. Pate, and S. C. Zoz (lowa State University of Sclence and Technology). The Solubility and Viscosity of Solutions of HCF in Naphthenic Oil and in Alkylbenzene al thing Pressures and Temperatures, ASHRAE Trats: tions. American Society of Heating, Refrigeratis and Air-Conditioning Engineers, Atlanta, GA, volume 96, part 2, pages $100 \mathrm{ff}, 1990$ (RDB2232)

G. van der Waal, The Relationship Between the Chemical Structure of Ester Base Fluids and Their Influence on Elastomer Seals and Wear Characteristics, Journal of Synthetic Lubricants, volume 1, pages 280-301, 1985 (RDB2233)

Boundary Lubrication of Ternary Blends (KCD. 9430 and 9433), document ARTD-12, E. I. du Pont de Nemours and Company, Incorporated. Wilm. ington, DE, undated ( 3 pages, avallable from JMC as RDB0541)

Oils for Alternative Refrigerants, document ARTD-i 1, E. I. du Pont de Nemours and Company, Incorporated, Wilmington, DE, undated (4 pages, available from JMC as RDB0540)

Real Time Determination of Lubricant Concentrations Dissolved in Alternative Refrigerants, ASHRAE research project 761-TRP, American Society of Heating, Refrigerating and Air-Conditioning Engineers, Atlanta, GA (ASH0761)

This project will e'valuate three means of measuring the concentration of lubricants circulating in refrigeration systems. The apparatus to be addressec include a viscometer, a densimeter, and an acoustic velocity sensor. The project is a follow-up to a prior project, Real Time Deter. mination of Concentration of Oil Dissolved in Refrigerant Flow Streani Without Sample Removal (RP-365), completed in January 1988. Three alternative refrigerants will be evaluated, including R-123, R-134a, and a third to be determined. Each will be tested with two lubricants in concentrations of $0.6 \%$ at temperatures representative of condenser outlets, namely 24 . $49^{\circ} \mathrm{C}\left(75-120^{\circ} \mathrm{F}\right)$. Proposals for this research are due at ASHRAE Headquarters by 1 June 1992; it is sponsored by ASHRAE Technical Committee 1.2, Instruments and Measurements.

Solubility of R-123 and R-134a in Oils, Carrier Corporation, Syracuse, NY, September 1989 (3 
pages with 3 figures, available from JMC as RDB. 0014)

Two figures summarize the solubility of R-123 with Mobil DTE 26 and Mobil DTE Heavy Medium mineral olls for -29 to $-23^{\circ} \mathrm{C}(-20$ to -10 $\left.{ }^{\circ} \mathrm{F}\right)$. Critical solution temperatures are shown for solutions of $70-95 \%$ R-134a in unidentified 300 and 750 SUS polyglycol lubricants.

Solubility of Refrigerant in Lubricants: HFC134a, report NIST-3. Freon(R) Products Laboratory, E. I. du Pont de Nemours and Company, Incorporated. Wilmington, DE, undated circa 1989 (3 pages with 2 tables, available from JMC as RDB0533)

Solubility data for R-134a are presented for a range of lubricants based on tests run from -50 to $+93^{\circ} \mathrm{C}\left(-58\right.$ to $\left.199^{\circ} \mathrm{F}\right)$. Mixtures of 30,60 , and $90 \%$ refrigerant by weight were tested with the lubricants in air-free sealed tubes. Solubility was determined, following a minimum of 15 minutes with agitation at each temperature; the blends were considered immiscible when they acquired and retained schlieren lines, formed floc, or formed two liquid layers. The lubricants include a polychlorotrifluoroethylene (Halocarbon blend $700 / 95-6.7 / 93.3500$ SUS), four perfluorinated poly alkyl ether oils (Krytox(R) GPL 150 and 480 SUS and Fomblin(R) $Y 25 / 5$ and $Z$. 15, both 417 SUS), and Daikin Demnum(R) S-65 300 SUS), dipentaerythritol esters of fatty acids (Hercules 240 and 290 SUS), PEG esters of fatty acids (CPI Engineering 144,620, and 830 SUS), naphthenic oils (Suniso(A) 5GS 500 SUS $38 \%$ aromatic, Witco 500 SUS and two experimental oils at 520 SUS $47 \%$ aromatic and 529 SUS $75 \%$ aromatic), paraffinic oil (BVM-100N 500 SUS), three alkyl benzenes (Zerol 300 SUS, Conoco DN600 125 SUS, and Nippon Oil Atmos HAB15F 78 SUS), and three silicone oils (Union Carbide L-45 163, 231, and 462 SUS).

\section{THERMOPHYSICAL PROPERTIES}

R. S. Basu, I. R. Shankland, and R. G. Richard (Allied-Signal incorporated), Thermodynamic and Transport Properties of 1,1,1,2-Tetrafluoroethane (R-134a) - An Alternative CFC Substitute in Refrigeration and Air Conditioning, presented paper (AlChE Winter Annual Meeting, Washington, DC, 1988), Buffalo Research Laboratory, Allied. Signal Incorporated, Buffalo, NY, November 1988 (26 pages, RDB0515)
R. S. Basu and D. P. Wilson (Allied-Signal Incorporated). Thermophysical Properties of 1,1,1,2 Tetrafluoroethane (R-134a), International Journal of Thermophysics, Catherine Press, Limited, Brugge, Belgium, volume 10, number 3 , pages 591 . 603, May 1989 (13 pages, RDB0514)

N. F. Carnahan and K. E. Starling, Intermolecular Repulsions and the Equation of State for Fluids. AIChE Journal, American Institute of Chemical Engineers, New York, NY, volume 18, pages $1184 \mathrm{H}$. 1972 (RDB2333)

H. Kubota, Y. Tanaka, T. Makita, H. Kashiwagi, and M. Noguchi, Thermodynamic Properties of 1 Chloro-1,2,2,2-Tetrafluoroethane (R-124), International Journal of Thermophysics, Plenum Publishing Corporation, Brugge, Belgium, volume 9, pages 85-101, 1988 (RDB2332)

M. O. McLinden (National Institute of Standards and Technology, NIST), Physical Properties of Alternatives to the Fully Halogenated Chlorofluorocarbons, ASHRAE Transactions, National Institute of Standards ard Technology, Boulder, CO, 1989 (RDB0906)

The properties of nine halogenated hydrocarbons are collected from a variety of sources, including unpublished data. These data are evaluated and correlated. Considered are the triple point, normal boiling point, and critical point parameters and the temperature dependence of the vapor pressure, saturated liquid density, sol. ubility in water, and hydrolysis rates. The fluids, which are potential alternatives to the fully halo. genated chlorofluorocarbons, are R-22, R-123, R-124, R-125, R-124, R-134a, R-141b, R-142b, and R-152a; also included is ine solvent R-140a (methyl chloroform).

G. Morrison and D. K. Ward (National Institute of Standiards and Technology, NIST), Thermodynamic Properties of Two Alternative Refrigerants, 1,1-Dichloro-2,2,2-Trifluoroethane (R-123) and $1,1,1,2-$ Tetrafluoroethane (R-134a), publication unknown, undated (38 pages with 11 figures and 7 tables, available from JMC as RDB0907)

This paper describes property measurements for R-123 and R-134a. A simple variable-volume sapphire cell was used to obtain vapor-liquid. equilibrium measurements. Vapor pressures and saturation liquid densitles are presented for $R-134 a$ from $-5^{\circ} \mathrm{C}\left(23^{\circ} \mathrm{F}\right)$ to the critical temperature, and for $\mathrm{Fi}_{\mathrm{i}} 123$ at $30.100^{\circ} \mathrm{C}\left(85.210^{\circ} \mathrm{F}\right)$. Saturation vapor density was also determined for R-134a from $35^{\circ} \mathrm{C}$ (95 ${ }^{\circ} \mathrm{F}$ ) to the critical point, where the critical conditions were measured. A mechanical oscillator densimeter was used to provide density measurements of the compressed liquids. These measurements are 
presented from the saturation pressure to 5.5 MPa (800 psi) for R-134a and to 3.5 MPa (500 psi) for R-123 at $5-95^{\circ} \mathrm{C}\left(40-200^{\circ} \mathrm{F}\right)$. Results are summarized and compared with similar measurements made by other groups.

R. R. Singh, E. E. A. Lund, and I. R. Shankland, (Allied-Signal Incorporated), Thermophysical Properties of HFC-32, HFC-125, and HFC. 32/HFC-125, unidentified publication (8 pages with 3 figures and 4 tables, RDB2234)

L. A. Weber (National Institute of Standards and Technology, NIST), Thermophysical Properties of Some Selected Alternative Refrigerants, unpublished presentation at the 1990 USNC/IIR.Purdue Refrigeration Conference and ASHRAE-Purdue CFC Conference (Purdue University, West Lafayette, IN, July 1990 (10 pages, available from JMC as RDB0908)

Research on thermophysical properties for six candidate alternative refrigerants is summarized. Properties measured include gas- and liquid-phase pVT, vapor pressure, surface tension, index of refraction, dielectric constant, gas-phase speed of sound, critical parameters and materials compatibility. Results have been obtained for R-123, R-125, R-134, R-134a, and $R-141 \mathrm{~b}$; some properties have been obtained for E-134.

L. A. Weber (National institute of Standards and Technology, NIST), Vapor Pressures and GasPhase pVT Data for 1,1,1,2-Tetrafluoroethane, International Journal of Thermophysics, Plenum Publishing Corporation, Brugge, Belgium, volume 10, number 3, pages 617-627, May 1989 (12 pages, RDB0909)

New data for the vapor pressure and $\mathrm{pVT}$ surface of R-134a in the temperature range of 40$150{ }^{\circ} \mathrm{C}\left(104-302{ }^{\circ} \mathrm{F}\right)$ are presented. The $\mathrm{pVT}$ data are for the gas phase at densities up to one-half critical. Densities of the saturated vapor are derived at five temperatures from the intersections of the experimental isochores with the vapor pressure curve. The data are represented analytically in order to demonstrate experimental precision and to facilitate calculation of thermodynamic properties.

L. A. Weber (National Institute of Standards and Technology, NIST), Vapor Pressures and GasPhase pVT Data for 1,1-Dichloro-2,2,2-Trifluoroethane, Journal of Chemical and Engineering Data. American Chemical Society, volume 35. number 3, pages 237-240, July 1990 (4 pages with 2 figures and 4 tables, RDB0910)

New data for the and gas-phase pVT surface of R-123 in the temperature range $338-453 \mathrm{~K}$ (149$356^{\circ} \mathrm{F}$ ) at densities up to $0.67 \mathrm{~mol} / \mathrm{L}$ are pre- sented. The data have been represented ana Iytically to demonstrate the precision and to facilitate calculation of thermodynamic properties.

Thermophysical Properties of Pure Substances and Mixtures for Refrigeration, proceedings of the meeting of IIR Comimissions B1 (Herzlia, Israel, March 1990), Internation al Institute of Refrigeration, Paris, France, 1990 (278 pages with 33 papers, RDB1103)

Thermophysical Properties of Refrigerants (R12, Dichlorodifluoromethane), Japanese Association of Refrigeration, Tokyo, Japan, August 1981 with errata dated 1986 (160 pages with 23 figures and 90 tables in both Japanese and English, RDB. 0401)

This comprehensive volume summarizes thermodynamic, transport, physical, chemical, compatibility, and other data available on $R-12$.

Thermophysical Properties of Refrigerants ( $R$ 13B1, Bromotrifluoromethane), Japanese Association of Refrigeration, Tokyo, Japan, March 1989 (162 pages with 25 figures and 50 tables in both Japanese and English, RDB0402)

This comprehensive volume summarizes thermodynamic, transport, physical, chemical, compatibility, and other data available on R-13B1.

Thermophysical Properties of Refrigerants (R22. Chlorodifluoromethane), Japanese Association of Refrigeration, Tokyo, Japan, November 1975 with errata dated 1986 (164 pages with 22 figures and 78 tables in both Japanese and English, RD80403)

This comprehensive volume summarizes thermodynamic, transport, physical, chemical, compatibility, and other data available on R-22.

Thermophysical Properties of Refrigerants (R114, 1,2-Dichlorotetrafluoroethane), Japanese Association of Refrigeration, Tokyo, Japan, March 1986 (162 pages with 23 figures and 46 tables, RDB0404)

This comprehensive volume summarizes thermodynamic, transport, physical, chemical, compatibility, and other data available on R-114.

Thermophysical Properties of Environmentally Acceptable Fluorocarbons - HFC-134a and HCFC-123, Japanese Association of Refrigeration and Japan Flon Gas Association, Tokyo, Japan, 1991 (304 pages with 83 figures and 99 tables in both Japanese and English, RDB2235)

This comprehensive volume summarizes critical, thermodynamic, transport, physical, chemical, compatibility, and other data available on $R$ -

123 and R.134a. Included are tabular data 
and/or plots for solubility, refractive index, dielectric constant, dielectric strength, pVT prop. erties and equations of state, enthalpy, entropy, isobaric and isochoric specific heat capacity, isentropic expansion exponent, speed of sound, surface tension, viscosity, kinematic viscosity, and thermal conductivity. Data on thermal and chemical stability are summarized, including weight and length changes with polypropylene, polystyrene, polyethylene, polyviriylchloride, polyamide, polyimide, chlorinated and chlorosulfonated polyethylene, nitrile butadiene rubber, Bistyi(TM) rubber, fluorocarbon rubber, ethylene propylene diene terpolymer (EPDM), urethane rubber, and polychloroprene. Safety data, including toxicity and flammability, are summarized. The volume contains an extensive list of references as well as discussion of the ranges and differences among property sources identified. An introductory section outlines conversions among several metric systems, including SI, and inch-pound units. It also reviews the environmental concerns with chlorofluorocarbon (CFC) refrigerants.

Thermophysical Properties of Refrigerants (R502, Azeotrope of R-22 and R-115), Japanese Association of Refrigeration, Tokyo, Japan, November 1986 (164 pages with 21 figures and 44 tables. RD80405)

This comprehensive volume summarizes thermodynamic, transport, physical, chemical, compatibility, and other data available on R-502.

\section{THERMODYNAMIC}

H. D. Baehr (Universität Hannover), New Refrigerants, Research Into Their Thermodynamic Propenty Data, Proceedings of the 3rd International En. ergy Agency Heat Pump Conference (Tokyo, Japan, 12-15 March 1990) edited by T. Saito and $Y$. Igarashi, Pergamon Press, Elmsiord. NY, pages 243-251, 1990 (12 pages with 1 figure and 3 tables, RDB0406)

D. P. Wilson and R. S. Basu (Allied-Signal Incorporated). Thermodynamic Properties of a New Stratospterically Safe Working Fluid - R-134a, ASHRAE Special Publication, CFCs: Time of Transition, American Society of Heating, Refrigerating, and Air-Conditioning Engineers, Atlanta, GA, pages 104 H. 1989 (RDB2236)

P. A. Domanski and D. A. Didion, Impact of Refrigerant Propert! Uncertainties on Prediction of Vapor Compression Cycle Performance, report NBSIR 86-3373. National Institute of Standards and Technology (then the National Bureau of Stan. dards), Gaithersburg, MD, Decernber 1986 (54 pages, RDB0922)

This paper presents a sensitivity study of a vapor-compression cycle in the form of a heat pump operating in the cooling mode. The study was performed with the aid of a detailed simulation model; runs were made for different para. metric values and the capacity and power input were compared with results of a run using an unchanged value of the parameters. The effects on evaporator and condenser pressures, and refrigerant mass flow rate are given. The independent variables include thermodynamic and transport properties, as well as the refrigerant flow, heat transfer, and pressure drop coefficients. The parameters which had the most effect on system performance were liquid transport properties, evaporative heat transfer coefficient, and vapor density.

P. F. Malbrunot, P. A. Meunier, G. M. Scatena (Laboratoire des Hauts Pressions, France), W. H. Mears, K. P. Murphy, and J. V. Sinka (Allied-Signal Incorporated, then Allied Chemical Corporation), Pressure-Volume-Temperature Behavior of Difluoromethane, Journal of Chemical and Engineering Data, volume 13, number 1 , pages 16-21, January 1968 (6 pages with 3 figures and 7 tables, RDB2310)

The pressure;-volume-temperature (PVT) properties of R-.j2 are correlated using the Martin. Holl equation of state to within $\pm 0.94 \%$ standard deviation over the experimental ranges: $25-200{ }^{\circ} \mathrm{C}$ (77-392 $\left.{ }^{\circ} \mathrm{F}\right), \quad 0.8-20 \mathrm{MPa}(120-2900$ psia), and $47-1.8 \mathrm{cc} / \mathrm{g}(0.75-0.03 \mathrm{cf} / \mathrm{lb})$. Vapor pressures have been determined from $-83^{\circ} \mathrm{C}$ (. $\left.117^{\circ} \mathrm{F}\right)$ to $78.4^{\circ} \mathrm{C}\left(173^{\circ} \mathrm{F}\right)$, the measured critical temperature. Using liquid densities measured between -25 and $+78^{\circ} \mathrm{C}\left(-13\right.$ and $\left.+172^{\circ} \mathrm{F}\right)$ and densities of saturated vapor computed from the Martin-Hou equation, a rectilinear diameter tine has been developed. The critical pressure and density are $5.830 \mathrm{MPa}$ (846 psia) and 430 $\mathrm{kg} / \mathrm{m}^{3}(26.8 \mathrm{lb} / \mathrm{cf})$, respectively.

G. Morrison and M. O. McLinden, Application of a Hard Sphere Equation of State to Refrigerants and Refrigerant to Mixtures, NBS Technical Note 1226. National Institute of Standards and Technology (then the Nationai Bureau of Standards). Gaithersburg, MD, August 1986 (156 pages, RDB. 0911)

The Carnahan-Starting-DeSantis equation of state is applied to halogenated hydrocarbon refrigerants and their mixtures. A set of thermodynamic functions is derived from the pVT equa. tion of state and the ideal gas heat capacities Reference states are discussed for both pure materials and mixtures. Although the model ex. 
hibits a critical point, it does not quantitatively represent properties in the critical region. Despite this limitation, this model can represent both liquid and gaseous mixtures away from their own critical points, even at conditions near to and above the critical points of their compo. nents. Algorithms and FORTRAN routines for the use of this model are presented along with the numerical coefficients for 11 pure refrigerants and 7 mixtures. Routines for evaluating the coefficients from saturation data are included. Several examples of the application of this equation of state are presented to demonstrate its versatility. The average deviation from the tabulated saturation properties of the 11 pure refrigerants is $0.54 \%$ for pressures, $0.09 \%$ for liquid volumes, and $0.50 \%$ for vapor volumes.

M. O. McLinden (National Institute of Standards and Technology, NIST), Thermodynamic Properties of CFC Alternatives - A Survey of Available Data, CFCs: Today's Options - Tomorrow's Solutions (proceedings of ASHRAE CFC Technology Conference, Gaithersburg, MD, 27-28 September 1989). American Soclety of Heating, Refrigerating, and Air-Conditioning Engineers, Atlanta, GA, pages 17-31, 1990; republished in International Journal of Refrigeration, Paris, France, volurne 13, number 5 , May 1990, pages 149-162 (15 pages with 29 figures and 5 tables, RDB0912)

Thermodynamic properties, from a variety of sources including unpublished data, are summarized for ten potential substitutes for CFC refrigerants. The fluids include R-22, R-23, R-32, R-123, R-124, R-125, R-134a, R-142b, R-143a, and $R-152 a$. The data include triple-point, normal boiling point, and critical point parameters, and the temperature dependence of the vapor pressure, saturated liquid density, and ideal-gas data heat capacity. Also considered are singlephase pVT data. The saturation and ideal-gas data are fit to simple correlations.

M. O. McLinden, J. S. Gallagher, L. A. Weber, G. Morrison, D. Ward, A. R. H. Goodwir, M. R. Moldover, J. W. Schmidt, H. 8. Chae, T. J. Bruno, J. F. Ely, and M. L Huber (National Institute of Standards and Technology, NIST), Measurement and Formulation of the Thermodynamic Proper. ties of Refrigerants 134a $(1,1,1,2$-Tetrafluoroethane) and 123 (1,1-Dichloro-2,2,2-Trifluoroethane), paper 3282, ASHRAE Transactions, American Society of Heating, Refrigerating and AirConditioning Engineers, Atlanta, GA, volume 95, part 2, pages 263-283, 1989 (21 pages, RDB0913)

Thermodynamic properties of R-134a and R-123 are formulated using a modified Benedict. Webb-Rubin (MBWR) equation of state fit to experimental measurements of the critical point, vapor pressure, saturated liquid and vapor vol- umes, superheated pressure-volume-temperature (pVT) behavior, and second virial coefficients derived from $\mathrm{pVT}$ and sound speed measurements. The heat capacity of the ideal gas reference state is determined from sound speed measurements on the low density vapor. Surface tensions are also presented. The experimental methods and results are summarized. compared to the property formulation, and compared to other sources in the literature. Tables and diagrams of the thermodynamic properties of R-123 and R-134a, prepared using the MWW equation of state, are presented. While the various measurements cover different ranges of temperature and pressure, the MBWR formulation is applicable in both the liquid and vapor phases at pressures up to $10,000 \mathrm{kPa}$ (1500 psia); the applicable temperature range is 233 to $450 \mathrm{~K}\left(-40\right.$ to $\left.350^{\circ} \mathrm{F}\right)$ for $\mathrm{R}-134 \mathrm{a}$ and 255 to $450 \mathrm{~K}\left(0\right.$ to $350^{\circ} \mathrm{F}$ ) for R-123. This paper summarizes the results of ASHRAE research project RP -588 .

Y. Monluc, T. Sagawa, H. Sato, and K. Watanabe (Keio University, Japan), Thermodynamic Properties of HFC-125, paper B101, Proceedings of the Twelfth Japan Symposium on Thermophysical Properties, pages 65-68, 1991 (4 pages with 5 figures and 1 table, RDB2427)

This paper reports experimental data for R-125, including vapor pressure and PVT properties in the vapor phase. Vapor pressures were measured for $303-339 \mathrm{~K}\left(86-151^{\circ} \mathrm{F}\right)$ and correlated; the critical pressure (3.633 MPa, 527.3 psia) also was determined based on a critical temperature previously determined by $M$. O. MCLinden of $339.4 \mathrm{~K}\left(151.3^{\circ} \mathrm{F}\right)$. PVT properties were measured along five isochores for temperatures of $240-423 \mathrm{~K}\left(-27\right.$ to $\left.302^{\circ} \mathrm{F}\right)$, pressur'es of 1.5-8.6 $\mathrm{MPa}$ (220-1250 psia), and densities of $97-446$ $\mathrm{kg} / \mathrm{m}^{3}(6-28 \mathrm{lb} / \mathrm{cf})$. The experimental approach and regression equation are presented and vapor pressure measurements are tabulated and plotted. The PVT properties for the vapor phase also are plotted and compared to other published data.

G. Morrison and J. S. Gallagher (National Institute of Standards and Technology, NIST), REFPROP: A Thermodynamic Properties Software Program for Refrigerants and Their Mixtures, publication unknown, 1990 (12 pages with 2 figures, available from JMC, RDB0914)

This paper introduces REFPROP, a computer sofiware package that produces tables of thermodynamic properties for 15 refrigerants and 20 of their binary mixtures. It addresses the Carnahan-Starling-DeSantis (CSD) equation of state chosen for property calculations, the software subroutines included, and sources used to ob- 
tain the incorporated property data. The paper compares output to source data for R-123. (Please see RDB2430 for further information on PEFPROP.)

C-C. Plao, H. Sato, and K. Watanabe (Keio University, Japan), An Experimental Study for PVT Properties of CFC Alternative Refrigerant 1,1,1,2-tetrafluoroethane (R-134a), CFC Alternatives, technical data bulletin 6(1). American Society of Heating, Refrigerating, and Air-Conditioning Engineers, Atlanta, GA, pages 1-9, June 1990; republished in ASHRAE Transactions, Arrerican Society of Heating, Refrigerating, and Air-Conditioning Engineers, Atlanta, GA, volume 96, 1990 (9 pages with 8 figures and 4 tables, RDB2334)

O. Z.Y. Qian, H. Matsunobe, H. Sato, and K. Watanabe (Keio University, Japan), Thermodynamic Property Measurements for Difluoromethane (HFC-32) by a Burnett Method, paper 8103. Proceedings of the Twelth Japan Sympo. sium on Thermophysical Properties, pages 73-76, 1991 (4 pages with 8 figures, RDB2428)

This paper summarizes measurements of vapor pressures of R.32 at temperatul is nf $300.330 \mathrm{~K}$ $\left(80.134^{\circ} \mathrm{F}\right)$ and compressibility factors for 300 $350 \mathrm{~K}\left(80-170^{\circ} \mathrm{F}\right)$ and $0.15-4.3 \mathrm{MPa}(22-624$ psia). The experimental apparatus used, based on a Burnett method, is briefly described. Second and third virial coefficients for property calculations are presented. A systematic error, related to an adsorption effect in the Burnett experimental procedure, and a and correction are discussed.

T. W. Phillips and K. P. Murphy (Allied-Signal Incorporated, then Allied Chemical Corporation), Liquid Viscosity of Halogenated Refrigerants, paper 2152, ASHRAE Transactions. American Society of Heating, Refrigerating, and Air-Conditioning Engineers, Atlanta, GA, volume 76, part II, pages 146 156. June 1970 (12 pages with 5 figures and 3 tables, RDB2315)

Liquid viscosity data are tabulated for $R-11, R-$ 12, R-13, R-22, R-114, R-115, R-133a, R-152a, R$500, R-502, R-31 / R-114, R-115 / R-152 a, R-503$, R-504, and R-32/R-12.

T. W. Phillips and K. P. Murphy (Allied-Signal Incorporated, then Allied Chemical Corporation), Liquid Viscosity of Halocarbons, Journal of Chemical and Engineering Data, volume 15, number 2 , pages 304-307. February 1970 (4 pages with 5 figures and 5 tables, RDB2314)

U. Plöcker, H. Knapp, and J. Prausnitz, Calculation of High-Pressure Vapor-Liquid Equilibria from a Corresponding-States Correlation with Emphasis on Asymmetric Mixtures.
Ind. Eng. Chem. Process Des. Dev., volume 17, number 3, pages 324-332, 1978 (RDB2337)

J. R. Sand, S. K. Fischer (Oak Ridge National Laboratory, ORNL), and J. A. Jones (Jet Propulsion Laboratory, California Institute of Technology), Experimentally Determined and Estimated CSD and LKP Interaction Coefficients for Ozone-Safe Retrigerant Mixtures, International Journal of Refrigeration, Paris, France, in publication (RDB2336)

Estimates of interaction coefficients (ICs) are provided for binary refrigerant blends for both the Carnahan-Starling-Desantis (CSD) and LeeKessler-Plöcker (LKP) equations of state (EOS). These IC values characterize the non-ideal behavior of mixtures, and are useful in calculating thermodynamic properties. The estimates were determined by least-squares fits of the CSD and LKP equations to previously measured, satu. ratrsd vapor pressure (bubble point) data. 71 mixtures of 8 different refrigerants in 18 binary combinations were analyzed. The combinations included R-12/R-152a, R-22/R-124, R-22/R-134, R-22/R-134a, R-22/R-142b, R-22/R-152a, R23/R-22, R-23/R-134a, R-124/R-142b, R-134/R124, R-134/R-142b, R-134a/R-124, R-134a/R134, R-134a/R-142b, R-134a/R-152a, R-152a/R124, R-152a/R-134, and 152a/R-142b. The paper describes the use of IC values, experimental apparatus used to measure the data, presents the resulting ICs, and discusses variances found with previously determined values. Good agreement was found for several known blends, but poor agreement resulted for the well characterized R-22/R-142b blend; further experimental verification is reccmmended. Comparisons between experimental ICs and those ca!culated from physical properties or critical con-' stants of the components suggest that refinement of the property calculation algorithms may be desirable.

L. A. Weber and J. M. H. Levelt Sengers (National Institute of Standards and Technology, NIST). Critical Parameters and Saturation Densities of 1,1-Dichloro-2,2,2-Trifluoroethane, Fluid Phase Equilibria, Elsevier Science Publishers B.V., Amsterdam. The Netherlands, volume 55 , pages 241 . 249, 1990 (9 pages, RDB0915)

An optical cell has been used to determine the critical parameters, $T_{c}$ and $p_{c}$, and densities along the liquid-vapor phase boundary of R-123. The critical temperature was found to be 456.87 $\mathrm{K}\left(363^{\circ} \mathrm{F}\right)$ and the critical density is $550 \mathrm{~kg} / \mathrm{m}^{3}$ The critical pressure was calculated from vapor pressure data to be 36.74 bar, which yields a value of 0.269 for the critical compressibility factor, $Z_{c}$. Measurement temperatures varied 
from $298 \mathrm{~K}\left(77^{\circ} \mathrm{F}\right)$ to the critlcal point for the saturated liquid and from $433 \mathrm{~K}\left(320^{\circ} \mathrm{F}\right)$ to the critical point for saturated vapor.

E. G. Wright (E. I. du Pont de Nemours and Company, Incorporated), Prediction of Refrigerant Ternary Mixture Properties Using the RedlichKwong-Soave Equation of State, Advances in Nonazeotropic Mixture Refrigerants for Heat Pumps, technical data bulletin, American Society of Heating, Refrigerating, and Air-Conditioning Engineers, Atlanta, $\mathrm{GA}$, pages $37-52$, June 1985 (RDB. 2331)

Selected Physical Properties of HCFC-123, HCFC-123a, HCFC-124, HFC-125, HFC-134, HFC-134a, and HFC-143a, preliminary information bulletin, Buffalo Research Laboratory, Allied-Signal Incorporated, Buffalo, NY, May 1990 (1 page with 1 table, avallable from JMC as RDB0504)

The critical temperature in ${ }^{\circ} \mathrm{F}$, critical pressure in psia, critical density in $\mathrm{lb} / \mathrm{cf}$, boiling point temperature in ${ }^{\circ} \mathrm{F}$, and molecular weight (relative molecular mass) are tabulated for R-123, R123a, R-124, R-125, R-134, R-134a, and R-143a. The information presented is preliminary and estimated.

Martin-Hou Equations of State, preliminary information bulletin, Buffalo Research Laboratory, Allied-Signal Incorporated, Buffalo, NY, May 1990 ( 3 pages with 2 tables, available from JMC as RDB0505)

The Martin-Hou equation of State and related equations to calculate the enthalpy and entropy of refrigerants are presented. Reference points and coefficients are provided, in consistent inch-pound units, for R-123, R-123a, R-124, R125, R-134, R-134a, and R-143a. The information presented is preliminary and estimated.

Gas Heat Capacity, preliminary information bulletin, Buffalo Research Laboratory, Allied-Signal Incorporated, Buffalo, NY, 23 May 1990 (1 page with 1 table, available from JMC as RDB0506)

An equation is provided to calculate the gas heat capacity of refrigerants in $B t u / \mathrm{bb} \cdot{ }^{\circ} \mathrm{R}$ as a function of temperature in ${ }^{\circ} R$. Coefficients are provided for R-123, R-123a, R-124, R-125, R134, R-134a, and R-143a. The information presented is preliminary and estimated.

Liquid Density, preliminary information bulletin, Buffalo Research Laboratory, Allied-Signal Incorporated, Buffalo, NY, 1 May 1990 (1 page with 1 table, available from JMC as RDB0507)

An equation is provided to calculate the liquid density of refrigerants in $\mathrm{lb} / \mathrm{cf}$ as a function of critical properties. Coefficients are provided for R-123, R-123a, R-124, R-125, R-134, R-134a, and R-143a. The information presented is preliminary and estimated.

Liquid Viscosity Correlation, preliminary information bulletin, Buffalo Research Laboratory, Allied. Signal Incorporated, Buffalo, NY, 23 May 1990 (1 page with 1 table, available from $J M C$ as RDB0508)

A correlation is provided to calculate the viscosity of refrigerants, in lb/hr.ft, in their liquid state as a function of temperature, in ${ }^{\circ} R$. Coefficients, based on measurements in the range of -20 to $+80^{\circ} \mathrm{C}\left(-4\right.$ to $\left.+176^{\circ} \mathrm{F}\right)$, are provided for R-123, R-123a, R-124, R-125, and R-134a. An equation is included to estimate the viscosity of R-134a in its vapor state. The information presented is preliminary and estimated.

Liquid Thermal Conductivity Correlation, preliminary information bulletin, Buffalo Research Lab. oratory, Allied-Signal Incorporated, Buffalo, NY, 23 May 1990 (1 page with 1 table, available from JMC as RDB0509)

A correlation is provided to calculate the thermal conductivity of refrigerants, in Btu/hr.ft: $\mathrm{F}$, in their liquid state as a function of temperature, in ${ }^{\circ} \mathrm{F}$. Coefficients, based on measurements in the range of $25-70^{\circ} \mathrm{C}\left(77-158^{\circ} \mathrm{F}\right)$, are provided for R-123, R-123a, R-124, R-125, and R-134a. The information presented is preliminary and estimated.

Vapor Thermal Conductivity Correlation, preliminary information bulletin, Buffalo Researnh Lab. oratory, Allied-Signal Incorporated, Buffalo, IY, 23 May 1990 (1 page with 1 table, available from JMC as RDB0510)

A correlation is provided to calculate the thermal conductivity of refrigerants, in Btu/hr.tt. $\mathrm{F}$, in their vapor state as a function of temperature, in ${ }^{\circ} \mathrm{F}$. Coefficients, based on measurements in the range of $25-70^{\circ} \mathrm{C}\left(77-158{ }^{\circ} \mathrm{F}\right)$, are provided for R-123, R-123a, R-124, and R-134a. The information presented is preliminary and estimated.

Vapor Pressure, preliminary information bulletin, Buffalo Research Laboratory, Allied-Signal Incorporated, Buffalo, NY, 1 May 1990 (1 page with 1 table, available from JMC as RDB0511)

An equation is provided to calculate the vapor pressure of refrigerants in psia as a function of temperature in ${ }^{\circ} \mathrm{F}$. Coefficients are provided for R-123, R-123a, R-124, R-125, R-134, R-?34a, and $R-143 a$. The information presented is preliminary and estimated.

REFPROP, A Program for the Calculation of the Thermodynamic Properties of Refrigerants and Refrigerant Mixtures, description, National Insti- 
tute of Standards and Technology, Galthersburg, $M D$, January 1990 (4 pages, RDB1104)

REFPROP calculates thermodynamic properties of refrigerants, both single component and mixtures. Tables produced by REFPROP can be used in estimating the efficiency and capability for a wide range of equipment with conventional and alternative refrigerants. This userfriendly package generates saturation property tables at desired temperatures or pressures, as well as tables of properties with the independent variables chosen from pressure, volume, temperature, entropy, and enthalpy. Dependent variables include those mentioned plus constant-pressure and constant-volume heat capacities, and velocities of sound. Version 1.0 of REFPROP calculates properties for 15 pure refrigerants and 20 binary mixtures. The calculations are based on wide-ranging measurements, including new data for refrigerants $R-123, R-124$, $R-134$, and $R-134 a$, as well as revised correlatlons for R-11, R-13, R-1381, R-14, R-22, R-23, $R-113, R-114, R-142 b$ and R-152a. The Carnahan-Starling-DeSantis equation of state and ideal gas heat capacities are used. REFPROP runs on IBM-compatible personal computers. Future upgrades will include additional refrigerants and ternary blends. (Please see RDB2430 for further information on REFPROP.)

REFPROP, A Program for the Calculation of the Thermodynamic Properties of Refrigerants and Refrigerant Mixtures, NIST Standard Reference Database 23 version 3.0. National Institute of Standards and Technology, Gaithersburg, MD, March 1992 (software and documentation available from NIST, RDB2430)

Version 3.00 of REFPROP calculates properties for 26 pure refrigerants, as well mixtures of up to five of them. These refrigerants include R-11, R12, R-13, R-13B1, R-14, R-21, R-22, R-23, R-113, $R-114, R-115, R-123, R-124, R-125, R-134, R-$ 134a, R-141b, R-142b, R-143, R-143a, R-152a, R-218, R-290 (propane), R-C270 (cyclopropane), RC-318, and E-134. Fourteen thermodynamic properties can be calculated, in user-selected units of measurement. This update replaces version 2.0 (see RDB1105).

J. Gallagher, M. O. McLinden, and G. Morrison, REFPROP, A Program for the Calculation of the Thermodynamic Properties of Refrigerants and Refrigerant Mixtures, NIST Standard Reference Database 23 version 2.0, National Institute of Standards and Technology, Gaithersburg, MD, March 1991 (software and documentation available from NIST, RDB1105)

Version 2.00 of REFPROF calculates properties for 18 pure refrigerants and 24 binary mixtures of them in user-selected units of measurement. These refrigerants include R-11, R-12, R-13, R13B1, R-14, R-22, R-23, R-113, R-114, R-115, R123, R-124, R-125, R-134, and R-134a, R-142b, R-152a, and R-C270. This version has been superseded; see RDB2430.

J. Gallagher, M. O. McLinden, and G. Morrison, REFPROP, A Program for the Calculation of the Thermodynamic Properties of Refrigerants and Refrigerant Mixtures, NIST Standard Reference Database 23 version 1.02, National Institute of Standards and Technology, Gaithersburg, MD, 28 September 1990 (software and documentation, RDB0916)

Version 1.02 of REFPROP calculates propertles for 16 pure refrigerants and 24 binary mixtures of them in user-selected units of measurement. These refrigerants include R-11, R-12, R-13, R13B1, R-14, R-22, R-23, R-113, R-114, R-123, R124, R-125, R-134, and R-131a, R-142b and $R$. 152a. This version has been superseded; see RDB2430.

Thermodynamic Properties of [HC]FC-123, report NIST-5, E. I. du Pont de Nemours and Company, Incorporated, Wilmington, DE, undated (44 pages, avallable from JMC as RDB0301)

tabular and graphical estimates of thermodynamic properties, for saturated and superheated conditions, based on estimated critical properties and Redlich-Kwong equation-of-state; the equation is presented for subsequent use

Thermodynamic Properties of [H]FC-134a, report NIST-6, E. I. du Pont de Nemours and Company, Incorporated, Wilmington, DE, undated (27 pages, available from JMC as RDB0302)

tabular estimates of thermodynamic properties, for saturated and superheated conditions, based on Redlich-Kwong equation-of-state calculations

\section{TRANSPORT}

H. B. Chae, J. W. Schmidt, and M. R. Moldover (National Institute of Standards and Technology, NIST), Surface Tension of Refrigerants R-123 and R-134a, Journal of Chemical and Engineering Data, American Chemical Soclety, pages 6-8, January 1990 (3 pages with 2 figures and 3 tables, RDB0917)

The surface tensions of two environmentally acceptable refrigerants (R-123 and R-134a) were measured with a differential capillary rise technique. Measurements span the temperature 
range -25 to $+140^{\circ} \mathrm{C}\left(-13\right.$ to $\left.284^{\circ} \mathrm{F}\right)$ for $\mathrm{R}-123$ and -10 to $+95^{\circ} \mathrm{C}\left(14\right.$ to $\left.203^{\circ} \mathrm{F}\right)$ for R-134a.

H. B. Chae?, J. W. Schmidt, and M. R. Moldover (National Imistitute of Standards and Technology, NIST), Altermative Refrigerants R-123, R-141b, R142b, and Ri-152a: Critical Temperature, Refractive Index, Surface Tension, and Estimates of Liquid, Vapor, and Critical Densities, Journal of Physical Chemistry, June 1990 (24 pages, RDB. 0918)

Differential capillary rise and refractive index data are reported for five alternative refrigerants: R-123a, R-134, R-141b, R-142b, and R-152a. The data extend from about $25^{\circ} \mathrm{C}\left(77^{\circ} \mathrm{F}\right)$ to the critical point of each fluid and directly yield the critical temperature $T_{c}$ and the temperature-dependent cap illary length. The present data were combined with liquid density data (near ambient temperature) to determine the Lorentz-Lorenz constant. The Lorentz-Lorenz relation is used to estimate the liquid, vapor, and critical densities, and the surface tension. R-141b slowly decomposed when maintained near its critical point (in contact with goild, sapphire, stainless steel, and crown glass).

B. R. Fellows, R. G. Richard, and I. R. Shankland (Allied-Signal Incorpiorated), Electrical Characterization of Alternate: Refrigerants, oaper 45 , proceedings of the XVIIIth International Congress of Refrlgeration (Montreıal, Québec, Canada, August 1991), International Inistitute of Refrigeration, Paris, France, August 1991 (10 pages with 2 figures and 7 tables, RDB2319)

A. R. H. Goodwin, and M. R. Moldover (National Institute of Standards and Technology, NIST), Thermophysical Properties of Gaseous Refrigerants from Speed of Sound Measurements (Apparatus, Model, and Results for 1,1,1,2-Tetrafluoroethane, R-134a), Journal of Chem. Phys., volume 93, number 4, pages 2741-2753, 15 August 1990 (13 pages with 10 figures and 4 tables, RDB0919)

The speed of sound in gaseous R-134a has been obtained between 233.16 and $340 \mathrm{~K}$ from measurements of the frequency of the radial acoustic resonances of a gas-filled spherical cavity. Perfect gas heat capacities and second and third acoustic virial coefficients are used to estimate the density virial coefficlents $B(T)$ and $C(T)$ and an effective square-well potential. The estimates of $B(T)$ are consistent with $B(T)$ deduced from high-quality equation-of-state measurements; those for $C(T)$ are slightly inconsistent. The apparatus and its calibration with argon are described.

I. R. Shankland, R. S. Basu, and D. P. Wilson (Allied-Signal Incorporated), Thermal Conductivity and Viscosity of a New Stratospherically Safe Retrigerant - 1,1,1,2-Tetrafluoroethane (R-134a), Status of CFCs - Refrigeration Systems and Refrigerant Properties (proceedings of the meetings of IIR Commissions B1, B2, E1, and E2, Purdue University, West Lafayette, IN), International Institute of Refrigeration, Paris, France, pages 305-314, July 1988 (9 pages, RDB0516)

I. R. Shankland, Transport Properties of CFC Alternatives, unpublished presentation (Symposium on Global Climate Change and Refrigerant Properties, AlChE Spring National Meeting, Orlando, FL. 1990), Buffalo Research Laboratory, Allied-Signal Incorporated, Buffalo, NY, March 1990 (31 pages, available from JMC as RDB0517)

\section{APPLICATION DATA}

Freon(R) Fluorocarbons Properties and Applications, bulletin B-2E, E. I. du Pont de Nemours International S.A., Geneva, Switzerland, undated circa 1984 (12 pages with 1 figure and 10 tables, RDB2433)

This brochure summarizes physical, thermodynamic, safety, and application data for $R-11, R$ 12, R-13, R-13B1, R-14, R-22, R-23, R-113, R114, R-115, R-116, R-152a, R-500, R-502, and R503. Stability and decomposition data are provided for $R-11, R-12, R-13, R-22, R-113, R-114$, R-115, and R-502. Hydrolysis data with water, alone and in the presence of steel, are presented for R-11, R-12, R-22, R-30 (methylene chloride), R-40 (methyl chloride), R-113, R-114, and R-502. Swell data with elastomers are tabulated for R-11, R-12, R-13, R-13B1, R-22, R-30, R-40, R-113, R-114, R-115, R-140a (methyl chloroform), and R-502 with neoprene GN, Buna(TM) $N$ (butadiene acrylonitrile), Buna(TM) S (butadiene styrene), Butyl(TM) (isoprene isobutylene), and polysulfide and natural rubbers. Compatibility data are discussed with lubricants, plastics, and metals.

\section{HEAT TRANSFER}

K. I. Bell, G. F. Hewitt, and S. D. Morris, Nucleate Pool Boiling of Refrigerant/Oil Mixtures, Experi. mental Heat Transfer, volume 1, number 1, 1987 (RDB2402) 
S. Chongrungreong and $\mathrm{H}$. J. Sauer, Jr. (University of Missouri at Rolla), Nucleate Boiling Performance of Refrigerants and Refrigerant Oil Mixtures, Journal of Heat Transfer, American Society of Mechanical Engineers, New York, NY, volume 102, number 4, pages 701-704, 1980 (RDB2401)

J. C. Conklin (Oak Ridge National Laboratory, ORNL) and E. Granryd (Royal Institute of Technology, Sweden). Thermal Performance Analysis for Heat Exchangers Having a Variable Overall Heat Transfer Coetficient, paper 91-WA-NE-7 ASME Winter Annual Meeting, Atlanta, GA), American Society of Mechanical Engineers, New York, NY, December 1991 (6 pages with 5 figures and 4 tables, RDB2341)

J. C. Conklin and E. A. Vineyard (Oak Ridge National Laboratory, ORNL), Tubeside Condensation of Nonazeotropic Refrigerant Mixtures for Two Enhanced Surfaces, Proceedings of the ASME/JSME Thermal Engineering Joint Conference, American Soclety of Mechanical Engineers, New York, NY, USA, Japan Society of Mechanical Engineers. Tokyo, Japan, volume 3 , pages 251 . 256, 1991 (6 pages with 9 figures, RDB2410)

J. C. Conklin and E. A. Vineyard (Oak Ridge National Laboratory, ORNL), Tubeside Evaporation of Nonazeotropic Refrigerant Mixtures from Two Enhanced Surfaces, paper 90-WA-HT-8 ASME Winter Annual Meeting, Dallas, TX), American Society of Mechanical Engineers, New York, NY, November 1990 (7 pages with 9 figures, RDB2342)

S. J. Eckels and M. B. Pate, An Experimental Comparison of Condensation Heat Transfer Coefficients for HFC-134a and CFC-12, International Journal of Refrigeration, Paris, France, volume 13, number 11, November 1990; republished in Proceedings of the 1990 USNC/IIR-Purdue Refrigeration Conference and ASHRAE-Purdue CFC Conference, edited by $D$. R. Tree, Purdue University, West Lafayette, IN, July 1990 (RDB2238)

S. J. Eckels and M. B. Pate, A Comparison of R134a and R-12 In-Tube Heat Transfer Coetticients Based on Existing Correlations, CFC Alternatives, technical data bulletin 6(1). American Society of Heating, Refrigerating, and Air-Conditioning Engineers, Atlanta, GA, pages 25-34, June 1990; republished in ASHRAE Transactions, American Society of Heating, Refrigerating and Air-Conditioning Engineers, Atlanta, GA, volume 96, part 1 , 1990 (10 pages with 16 figures and 2 tables, RDB2239)

E. Granryd (Royal Institute of Technology, Sweden), Heat Transfer in Flow Evaporation of Nonazeotropic Refrigerant Mixtures - a Theoretical Approach, paper 251, proceedings of the XVIIlth
International Congress of Refrigeration (Montreal Québec, Canada, August 1991), International Institute of Refrigeration, Paris, France, August 1991 (12 pages with 6 ilgures, RDB2409)

E. Granryd (Royal Institute of Technology, Sweden) and J. C. Conklin (Oak Ridge National Laboratory, ORNL). Thermal Performance Analysis for Heat Exchangers Using Nonazeotropic Refrigerant Mixtures, Heat Transfer in Advanced Energy' Systems, American Society of Mechanical Engineers, New York, NY, Heat Transfer Division volume 151 and Advanced Energy Systems Division volume 18 , pages 25-32, November 1990 (8 pages with $10 \mathrm{fig}$ ures, RDB2330)

D. W. Hughes, J. T. McMullan, K. A. Mawhinney, and R. Morgan, Influence of Oil on Evaporator Heat Transfer (Results for R-12 and Shell Clavus 68), International Journal of Refrigeration. Paris France, volume 7, number 3, pages 150-158, May 1984 (10 pages, RDB0923)

Experiments to investigate the influence of lubricating oll on heat transfer and refrigerant flow in evaporators are described. R-12 and Shell Clavus 68 oil were used. Efforts were made to model actual operation as closely as possible. The oil was found to have a significant effect on refrigerant flow and pressure drop. Measurements made on the heat transfer coefficient indicated that the oil had different effects depending on the fluld flow regime. No effect was apparent for annular-wavy regimes, but the presence of oil significantly reduced the heat transfer coefficient for annular-film flows.

D. L. Jackman and M. K. Jensen, Nucleate Pool Boiling of Refrigerant/Oil Mixtures, paper 82WA/HT-45, American Society of Mechanical Engineers, New York, NY, 1982 (RDB2403)

D. S. Jung and R. Radermacher (University of Maryland), Prediction of Heat Transfer Coetticients of Various Refrigerants During Evaporation, paper 3492, ASHRAE Transactions, American Society of Heating, Refrigerating and Air-Conditioning Engineers, Atlanta, GA, volume 97, part 2, pages 48-53, 1991 ( 6 pages with 7 figures and 3 ta. bles, RDB2347)

D. S. Jung (University of Maryland), M. O. McLinden (National Institute of Standards and Technology, NIST), R. Radermacher (University of Maryland), and D. A. Didion (NIST), A Study of FlowBoiling Heat Transfer with Refrigerant Mixtures. International Journal of Heat and Mass Transfer. volume 32, number 9, pages 1751-1764, Septem. ber 1989 (RDB2348) 
C. Pais and R. L. Webb (Pennsylvania State University). Literature Survey of Pool Boiling on Enhanced Surfaces, ASHRAE Transactions, American Society of Heating, Refrigerating and Air-Conditioning Engineers, Atlanta, GA, volume 97, part 1, 1991 (RDB2405)

M. B. Pate, Evaporation and Condensation Heat Transfer Coefficients for HCFC-124/HCFC. 22/HFC-152a, Proceedings of the 1990 USNC/IIRPurdue Refrigeration Conference and ASHRAE. Purdue CFC Conference, edited by D. R. Tree, Purdive University, West Lafayette, IN, July 1990 (RDB2240)

L. M. Schlager, M. B. Pate, and A. E. Bergles, Oil Quantity Measurements in Smooth and MicroFin Tubes During Evaporation and Condensation of Refrigerant-Oil Mixtures (RP-469), ASHRAE Transactions, American Society of Heating, Refrigerating and Air-Conditioning Engineers, Atlanta, GA, volume 97, part 1, 1990 (RDB2241)

L. M. Schlager, M. B. Pate, and A. E. Bergles, Performance Predictions of Refrigerant-Oil Mixtures in Smooth and Internally Finned Tubes, 2 papers, ASHRAE Transactions, American Society of Heating, Refrigerating and Air-Conditioning Engineers, Atlanta, GA, volume 96, part 1, 1990 (RDB2242)

L. M. Schlager, M. B. Pate, and A. E. Bergles, Performance of Micro-Fin Tubes with Refrigerant 22 and Oil Mixtures, ASHRAE Journal, American Soclety of Heating, Refrigerating and Air-Conditioning Engineers, Atlanta, GA, pages 17.28, November 1989 (RDB2243)

L. M. Schlager, M. B. Pate, and A. E. Bergles, Heat Transfer and Pressure Drop During Evaporation and Condensation of R-22 in Horizontal MicroFin Tubes, International Journal of Refrigeration, Paris France, volume 12, number 1, pages 6-14, January 1989 (9 pages, RDB2244)

L. M. Schlager, M. B. Pate, and A. E. Bergles, Heat Transfer and Pressure Drop Performance of Smooth and Internally Finned Tubes with Oil and Refrigerant 22 Mixtures, ASHRAE Transac. tions, American Society of Heating, Refrigerating and Air-Conditioning Engineers, Atlanta, GA, volume 95, part 2, 1989 (RDB2245)

L. M. Schlager, M. B. Pate, and A. E. Bergles, Evaporation and Condensation of RefrigerantOil Mixtures in a Low-Fin Tube, ASHRAE Transactions. American Society of Heating. Refrigerating and Air-Conditioning Engineers, Atlanta, GA, volume 94, part 2, pages 1176-1194, 1989 (RDB2343)
M. W. Spatz and J. Zheng (Allled-Signal Incorporated), An Experimental Evaluation of the Heat Transfer Coefficients of R-134a Relative to R-12, Proceedings of the 1990 USNC/IIR-Purdue Refrig. eration Conference and ASHRAE.Purdue CFC Conference, edited by D. R. Tree, Purdue University, West Lafayette, IN, pages 225-233, July 1990 (9 pages with 8 figures, RDB0501)

K. Stephan and M. Körner (Technical University of Berlin), Calculation of Heat Transfer for Vaporizing Binary Mixtures, summary translation by Allied-Signal Incorporated from German text published in Chem. Ing. Tech., volume 41, number 7, pages 409-417, 1968; includes notes on the document prepared by $R$. R. Singh, Alled-Signal Incorporated, 22 October 1990 (8 pages with 5 figures, available from JMC as RDB0905)

R. L. Webb and C. Pais (Pennsylvania State University). Nucleate Pool Boiling Data for Five Refrigerants on Three Tube Geometries, ASHRAE Transactions, American Society of Heating, Refrigerating and Air-Conditloning Engineers, Atlanta, GA, volume 97, part 1, 1991 (RDB2404)

Experimental Determination of the Effect of Oil on Heat Transfer in Flooded Evaporators with Refrigerants HCFC-123, HFC-134a, and HCFC. 22. ASHRAE research project 751-TRP, American Society of Heating, Refrigerating and Alr-Condltioning Engineers, Atlanta, GA (ASH0751)

This project will determine average shell-side boiling coefficients for R-22, R-123, and R-134a with compatible lubricants for finned and enhanced tube surfaces, as used in flooded evaporators. The work will expand on that ad. dressed in ASHRAE RP-392, by covering the influences of the lubricants. Heat flux, mass flux, and vapor quality will cover typical conditions for air conditioning and refrigeration for lubricant concentrations of $0-10 \%$ at evaporator temperatures of approximately $4{ }^{\circ} \mathrm{C}\left(40^{\circ} \mathrm{F}\right)$. Proposals for this research are due at ASHRAE Headquarters by 1 June 1992; it is sponsored by ASHRAE Technical Committee 8.5, Liquid to Refrigerant Heat Exchangers.

Performance of Turbo-B Enhanced Boiling Tubes in CFC-11 and HCFC-123, E. I. du Pont de Nemours and Company, Incorporated, Wilmington, $D E$, and Wolverine Tube, Incorporated, Decatur, AL, 17 December 1990 (9 pages with 2 flgures and 2 tables, available from JMC as RDBOC02)

This document compares the performance of a commercially-available, enhanced heat transfer lube with R-11 and R-123. By varying the temperature of water flowing through a tube positioned in a refrigerant bath, the overall heat transfer coefficient and heat flux capábility of 
the copper tube were determined. Tabular data and overall heat transfer coefficient and heat flux plots are presented. The heat transfer coefficient for R-123 was $3-6 \%$ lower than that for R-11.

Performance of Turbo-B Enhanced Boiling Tubes in CFC-12 and HFC-134a, E. I. du Pont de Nemours and Company, Incorporated, Wilmington, $D E$, and Wolverine Tube, Incorporated, Decatur, AL, 17 December 1990 (6 pages with 2 figures and 2 tables, avallable from JMC as RDBOCO3)

This document compares the performance of a commerclally-avallable, enhanced heat transfer tube with R-12 and R-134a. By varying the temperature of water flowing through a tube positioned in a refrigerant bath, the overall heat transfer coefficient and heat flux capabillty of the copper tube were determined. Tabular data and overall heat transfer coefficient and heat flux plots are presented. The heat transfer coefficient for R-134a was $4-30 \%$ higher than that for R-12.

\section{SAFETY}

\section{Flammability}

Combustion of Ammonia With and Without Oil Vapor, ASHRAE research project RP-682, American Soclety of Heating, Refrigerating and Air-Conditioning Engineers, Atlanta, GA (ASH0682)

This project will redetermine the flammability limits of ammonla (R-717) in air as well as the combustibility of air-ammonia-oil and air-ammonia-methane mixtures, in concentrations of $100-250,000 \mathrm{ppm}$. It also will examine the geometric configurations for release that facilitate combustion, in order to improve discharge designs for flaring. The contractor for this research is Kansas State University, led by $D$. L. Fenton and K. S. Chapman; it is sponsored by ASHRAE Technical Committee 10.1, Custom Engineered Refrigeration Systems.

Flammability Characteristics of Isotron 141b. preliminary information bulletin, Elf Atochem North America, incorporated (provided by the former Pennwalt Corporation), King of Prussia, PA, May 1989 (1 page, available from JMC as RDB0521)

Lower and upper flammability limits (LFL and UFL), as a volume percentage of refrigerant in humid air, are given for R.141b based on ASTM E681 tests. The limits cited are $7.4-15.5 \%$ at 21 ${ }^{\circ} \mathrm{C}\left(70^{\circ} \mathrm{F}\right)$ and $5.8-16.5 \%$ at $120^{\circ} \mathrm{C}\left(250^{\circ} \mathrm{F}\right)$. The maximum explosion pressure and maximum rate of pressure rise are tabulated for the same temperatures. Flammability characteristics of ethyl alcohol and R-290 (propane) are presented for comparison. A higher concentration of $\mathrm{R}-141 \mathrm{~b}$ is required for flammability. Additionally, R-141b exhlbits significaritly lower rates of pressure rise and lower heats of combustion.

Results of Testing: Limits of Flammability for Isotron 141b, preliminary Information bulletin, Elf Atochem North America, Incorporated (provided by the former Pennwalt Corporation), King of Prussla, PA, May 1989 (4 pages with 5 figures and 1 table, avallable from JMC as RDB0522, picture missing)

Lower and upper flammability limits (LFL and UFL), as a volume percentage of refrigerant in humid air, are given for R-141b based on ASTM E681-85 tests. The limits cited are $7.4-15.5 \%$ at $21^{\circ} \mathrm{C}\left(70^{\circ} \mathrm{F}\right)$ and $5.8-16.5 \%$ at $120^{\circ} \mathrm{C}\left(250^{\circ} \mathrm{F}\right)$. Comparative data are presented for R-600a (isobutane) and ethanol, $1.86-8.5 \%$ and 3.46 $18.4 \%$ respectively. A modified test procedure and the method of determining flammability lim. its are presented. Additionally, the effects of humidity, temperature, and ignition source on flammability testing are discussed.

Results of Testing: Flashpoint of Isotron 141b preliminary information bulletin, Elf Atochem North America, Incorporated (provided by the former Pennwalt Corporation), King of Prussia, PA, May 1989 (1 page, available from JMC as RDB0523, plcture missing)

The procedure and results of measuring the flash point of R-141b are summarized based on ASTM D1310 tests using a Fisher/Tag open cup apparatus. No flash point was observed for this fluid even though it has lower and upper flammability limits. The nature of the liquid is such that it does not produce a vapor layer that will flash according to the standard test method. The document notes that similar behavior has been observed for chlorinated solvents such as R-140a (methyl chloroform) and R-30 (methylene chloride).

Results of Testing: Maximum Rate of Pressure Rise - Maximum Explosion Pressure of Isotron $141 \mathrm{~b}$, preliminary information bulletin, Elf Atochem North America, Incorporated (provided by the former Pennwalt Corporation), King of Prussia, PA. May 1989 (2 pages with 1 table, available from JMC as RDB0524, picture missing)

The procedure and results of measuring the maximum rate of pressure rise and maximum explosion pressure of R-141b are summarized. The rate of pressure rise is reported as 262 and $220 \mathrm{kPa} / \mathrm{s}(38$ and $32 \mathrm{psi} / \mathrm{s})$ at $21^{\circ} \mathrm{C}\left(70^{\circ} \mathrm{F}\right)$ and $120^{\circ} \mathrm{C}\left(250^{\circ} \mathrm{F}\right)$, respectively, in a $0.37 \mathrm{~m}^{3}(13.1$ 
cf) vessel. The maximum pressure is reported as 78 and 57 psig at corresponding conditions. A comparison of normalized rates of pressure rise (the $\mathrm{Kg}$ ) shows R-141b to be approximately 230 times less severe than R-290 (propane) and 50 times less severe than ethanol.

Flammability Characteristics of Isotron 142b, preliminary information bulletin, Elf Atochem North America, Incorporated (provided by the former Pennwalt Corporation), King of Prussla, PA, May 1989 (1 page, available from JMC as RDB0525)

Lower and upper flammability limits (LFL and UFL), as a volume percentage of refrigerant in humid air, are given for $R-142 \mathrm{~b}$ based on ASTM E681 tests. The LFL cited is $7.8 \%$ at $21^{\circ} \mathrm{C}(70$ $\left.{ }^{\circ} \mathrm{F}\right)$ using a fuse wire as the ignition source. The cited LFL and UFL, using a match as the Ignition source, are $6.9-17.0 \%$ at $21^{\circ} \mathrm{C}\left(70{ }^{\circ} \mathrm{F}\right)$ and 6.1 . $17.8 \%$ at $120^{\circ} \mathrm{C}\left(250^{\circ} \mathrm{F}\right)$. The maximum explosion pressure and maximum rate of pressure rise are tabulated for the same temperatures. Flammability characteristics of ethyl alcohol and R-290 (propane) are presented for comparison. A higher concentration of R-142b is required for flammability. Addlionally, R-142b exhibits sig: nificantly. lower rates of pressure rise and lower heats of combustion.

Results of Testing: Limits of Flammability for isotron 142b, preliminary information bulletin, Elf Atochem North America, Incorporated (provided by the former Pennwalt Corporation), King of Prussia, PA, May 1989 (4 pages, avallable from JMC as RDB0526, picture missing)

Lower and upper flammability limits (LFL and UFL), as a volume percentage of refrigerant in humid air, are given for R-142b based on ASTM E681 tests. The LFL cited is $7.8 \%$ at $21^{\circ} \mathrm{C}(70$ $\left.{ }^{\circ} \mathrm{F}\right)$ using a fuse wire as the ignition source. The cited LFL and UFL, using a match as the ignition source, are $6.9-17.0 \%$ at $21^{\circ} \mathrm{C}\left(70^{\circ} \mathrm{F}\right)$ and 6.1 . $17.8 \%$ at $120^{\circ} \mathrm{C}\left(250^{\circ} \mathrm{F}\right)$. Comparative data are presented for R-600a (isobutane) and ethanol, $1.86-8.5 \%$ and $3.46-18.4 \%$ respectively. A modified test procedure and the method of determining flammability limits are presented. Additionally, the effects of humidity, temperature, and ignition source on flammability testing are discussed.

Results of Testing: Flashpoint of Isotron 142b, preliminary information bulletin, Elf Atochem North America, Incorporated (provided by the former Pennwalt Corporation), King of Prussia, PA, May 1989 (1 page with 1 figure, available from JMC as RDB0527, picture missing)

The procedure and results of measuring the flash point of R-142b are summarized based on ASTM D1310 tests using a Fisher/Tag open cup apparatus. No flash point was observed for this fluld. An upward extension of a test flame was observed when passed over a sample of the refrigerant. The extension grew with increasing temperature of the refrigerant, but the vapor space above the liquid nelther flashed nor burned away from the test flame.

Results of Testing: Maximum Rate of Pressure Rise - Maximum Explosion Pressure of Isotron 142b, preliminary information bulletin, Elf Atochem North America, Incorporated (provided by the former Pennwalt Corporation), King of Prussia, PA, May 1989 (2 pages with 1 table, avallable from JMC as RDB0528, picture missing)

The procedure and results of measuring the maximum rate of pressure rise and maximum explosion pressure of $\mathrm{R}-142 \mathrm{~b}$ are summarized. The rate of pressure rise is reported as 606 and $634 \mathrm{kPa} / \mathrm{s}$ (88 and $92 \mathrm{psi} / \mathrm{s})$ at $21^{\circ} \mathrm{C}\left(70^{\circ} \mathrm{F}\right)$ and $120^{\circ} \mathrm{C}\left(250^{\circ} \mathrm{F}\right)$, respectively, in a $0.37 \mathrm{~m}^{3}(13.1$ cf) vessel. The maximum pressure is reported as 88 and 68 psig at corresponding conditlons. A comparison of normalized rates of pressure rise $(\mathrm{Kg})$ shows R-142b to be approximately 100 times less severe than R-290 (propane) and 23 times less severe than ethanol.

\section{Toxicity}

Clement Associates, Incorporated, Health Effects Assessment for Ammonia, The Fertilizer Institute, Washington, DC, February 1990 (148 pages, RDB. 1106)

This document reviews data relevant to assessing the health effects of inhalation exposure to ammonia. The focus is on chronic exposures; information on subchronic and acute exposures also is reviewed to acquire a complate picture of the toxicity of ammonia. Physical and chemical properties, sources, environmental fate, environmental effects, and other related topics are discussed to provide context and perspective.

Report on Testing and Analysis of the Concentration of HCFC-123 in Field Installations with General Machinery Rooms Containing Hermetic Centrifugal Chillers, report CFC-1, The Trane Company, La Crosse, WI, October 1991 (34 pages with 14 figures and 15 tables, RDB2246)

This report provides measured data on R-123 concentrations in equipment rooms housing hermetic centrifugal chillers. Twelve sites, representing a broad range of applications, were tested during normal operation. Additional data were taken at two sites during refrigerant transfers. Measurements were made by gas chro- 
matography, both on site and using actlvated charcoal tubes (suissequently analyzed in laboratories). All of the sites except one were determined to have concentrations substantlally less than 1 ppm, if any. Concentrations above minimum quantiflable levels, 0.33-0.56 ppm, were detected in only two cases. Leakage from empty, but Improperly sealed, refrigerant drums was identified as the probable cause for one site. The sources in the other were Improperty sealed drums and a leak from the purge vent line. The latter was ascribed to improper field installation and use of incompatible piping materials. A retest of this site, after corrections, found concentrations In line with the others. Reports on the individual sites and summary discussion describe the tests and safety considerations for refrigerants. The findings emphasize the importance of following proper refrigerant handling and storage procedures as well as installation recommendations.

\section{PIPE SIZING}

T. Atwood (Alled-Signal Incorporated), Pipe Sizing and Pressure Drop Calculations for HFC-134a, ASHRAE Journal, American Society of Heating, Refrigerating, and Air-Conditioning Engineers, Atlanta, GA, pages 62-66, April 1990 (5 pages, RDB0513)

\section{RECYCLING, RECLAMATION, AND DISPOSAL}

R. E. Kauffman (University of Dayton Research Institute), Chemical Analysis and Recycling of Used Refrigerant from Filed Systems, paper 3555(RP-601) Winter Meeting, Anaheim, CA, January 1992), ASHRAE Transactions, American Society of Heating, Refrigerating and Air-Conditioning Engineers, Atlanta, GA, volume 98, part 1, in publication ( 9 pages with 4 figures and 1 table, RDB2429)

This paper summarizes research to identify and quantify the typical contaminant levels in used refrigerants. A total of 39 samples were taken from both normally operating and failed airconditioning and refrigerating systems. These samples included R-11 from centrifugal chillers, $R-12$ from commercial refrigeration systems, $R$. 22 from unitary heat pumps and air condition. ers, and R-502 from low-temperature frozen food cases. Results are summarized for measurement of water content (Karl Fisher tech. nique), acid content (ASTM 664 tests), ion content (ion-specific electrode), high-boiling content (gravimetric technique, gas chromatogra- phy, and mass spectrography), particulate content (direct-current plasma emission spectrometer and scanning electron microscope), and volatile impurity content (gas chromatography and mass spectrometry). The contaminant levels found exceeded those of new refrigerants, but the types and concentrations varied by refrigerant, application, and whether a system burnout had occurred. Laboratory tests evalu. ated a recycling scheme based on oll separation followed by water and acid removal, by an alumina/molecular sleve filter/dryer. The preliminary study showed that this recycling procedure is effective in removing acids, but has in. significant effects on volatile impurities and high-bolling residue. The effects of noncondensable gases were not addressed.

Sealed-Tube Tests of Refrigerants from Field Systems Before and After Recycling, ASHRAE research project RP-683, American Society of Heating, Refrigerating and Air-Conditioning Engineers, Atlanta, GA (ASH0683)

This project will quantify typical contaminant levels in refrigerants after oll separation, filtering, and drying. It also will determine the effects of contaminants at the concentrations found. The focus is on R-11 from centrifugal chillers, R-12 from commercial refrigeration systems, $R-22$ from unitary heat pumps, and R-502 from lowtemperature commercial refrigeration systems. The work is an extension of ASHRAE research project RP-601 and is being performed by the same contractor, the University of Dayton Research Institute led by 'R. E. Kaufman. It is sponsored by ASHRAE Technical Committee 3.3. Contaminant Control in Refrigerating Systems.

State of Knowledge Summary of Chlorofluorocarbon Handling Technologies: Destruction, Recycling, and Encapsulation, draft report for U.S. Department of Energy, E. A. Mueller Consulting Engineers, Baltimore, MD, May 1989 (65 pages, RDB1107)

\section{TEST METHODS}

T. D. Armstrong, Chloride Analyses as a Measure for the Evaluation of Sealed Tube Tests, ASHRAE Transactions, American Society of Heating, Refrig. erating, and Air-Conditloning Engineers, Atlanta, $\mathrm{GA}$, volume 71, part I, pages $150 \mathrm{ff}, 1965$ (RDB. 2325) 
J. J. Baustian, M. B. Pate, and A. E. Bergles, Measuring the Concentration of a Flowing Oil-Refrigerant Mixture with a Bypass Viscometer, ASHRAE Transactions, American Soclety of Heating, Refrigerating and Air-Conditloning Engineers, Atlanta, GA, volume 94, part 2, 1988 (RDB2406)

J. J. Baustian, M. B. Pate, and A. E. Bergles, Measuring the Concentration of a Flowing Oil-Refrigerant Mixture with a Vibrating U-Tube Densimeter, ASHRAE Transactions, American Soclety of Heating, Refrigerating and Air-Conditioning Engineers, Atlanta, GA, volume 94, part 2, 1988 (RDB2407)

J. J. Baustlan, M. B. Pate, and A. E. Bergles, Measuring the Concentration of a Flowing Oil-Refrigerant Mixture with an Acoustic Velocity Sensor, ASHRAE Transactions, American Soclety of Heating, Refrigerating and Air-Conditioning Engineers, Atlanta, GA, volume 94, part 2, 1988 (RDB2408)

J. J. Baustian, M. B. Pate, and A. E. Bergles, Measuring the Concentration of a Flowing Oil-Refrigerant Mixture: Instrumentation Test Facility and Initial Results, ASHRAE Transactions, American Soclety of Heating, Refrigerating and Air-Conditioning Engineers, Atlanta, GA, volume 94, part 1, pages 167-177, 1988 (RDB2247)

T. J. Bruno, Spectroscopic Library for Alternative Refrigerant Analysis, report NIST Special Publica. tion 794, National Institute of Standards and Technology, Boulder, CO, August 1990 (192 pages. avallable from Superintendent of Documents, U.S. Government Printing Office, Washington, DC 20402 USA; order by stock number 003-003$03036-8$ for $\$ 12.00$ prepaid, RDB2250)

This report assembles infrared and mass spectra on a range of ethane and ethylene compounds relevant to research of alternative refrigerants. Limited physical property and safety data also are included. Some compounds addressed are not suited for refrigerant use, but could be found as impurities or as reaction/decomposition products in refrigerant tests. This publication provides an information source to aid in identfication of such compounds. The ethane compounds addressed include R-112, R-112a, R-113, R-113B2, R-113a, R-114, R-114a, R-114B2, R-115, R-116, R-121, R122, R-123, R-123B1, R-123B2, R-123aB1, R124, R-125, R-131, R-131a, R-132b, R-132bB2, $R-133 a, R-133 a B 1, R-134, R-134 a, R-141, R-$ 141b, R-142B1, R-142b, R-143, R-143a, R151B1, R-152a, and R-161. Ethylene compounds covered include R-1110, R-1111, R. 1112a, R-1112aB2, R-1113, R-1114, R-1120, R1121, R-1122B1, R-1123, R-1130, R-1130, R1130a, R-1131a, R-1132a, and R-1141.
G. C. Doderer and H. O. Spauschus (General Electric Company), A Sealed Tube - Gas Chromatograph Method for Measuring Reaction of Refrigerant 12 with Oil, ASHRAE Transactions, American Sociuty of Heating, Refrigerating and Air-Condltioning Engineers, Atlanta, GA, volume 72, part II. 1966 (RDB2326)

S. R. Dunne and T. J. Clancey, Methods of Testing Desiccants for Refrigerant Drying, ASHRAE Transactions, American Society of Heating, Refrigerating and Air-Conditloning Engineers, Atlanta, GA, volume 90, part 1, 1984 (RDB2431)

H. M. Elsey, Small Sealed Tube Procedure for Quality Control of Refrigeration Oils, ASHRAE Transactions, American Society of Heating, Refrigerating and Air-Conditioning Engineers, Atlanta, $\mathrm{GA}$, volume 71, part !, pages $143 \mathrm{ff}, 1965$ (RDB2328)

H. M. Elsey, L. C. Flowers, and J. B. Kelley, A Method of Evaluating Refrigerator Oils, Refrigerating Engineering, volume 60, number 7, pages 737 ff, July 1952 (RDB2321)

D. F. Huttenlocher (General Electric Company). Bench Scale Test Procedure for Hermetic Compressor Lubricants, ASHRAE Journal, American Society of Heating, Refrigerating, and Air-Condltioning Engineers, Atlanta, GA, volume 12, number 6. pages 85-89, June 1969 (RDB2421)

D. E. Kvalnes, The Sealed Tube Test for Refrigeration Oils, ASHRAE Transactions, American Society of Heating, Refrigerating, and Air-Conditioning Engineers, Atlanta, GA, volume 71, part I, pages 138 ff, 1965 (RDB2324)

D. A. Nissen, A Single Apparatus for the Precise Measurement of the Physical Properties of Liquids at Elevated Temperature and Pressure, report SAN080-8034, Sandia National Laboratory, Albuquerque, NM, 1980 (avallable from NTIS, RDB2248)

K. S. Sanvordenker and M. W. Larime (Tecumseh Products Company), Screening Tests for Hermetic Magnet Wire Insulation, Proceedings of the Tenth Electrical Insulation Conference, Institute of Electrical and Electronic Engineers, New York, NY, pages $12.2 \mathrm{ff}, 1971$ (RDB2424)

H. O. Spauschus and D. R. Henderson (Spauschus Associates, Incorporated), New Methods of Determining Viscosity and Pressure of RefrigerantLubricant Mixtures, Proceedings of the 1990 USNC/IIR-Purdue Refrigeration Conference and ASHRAE-Purdue CFC Conference, edited by D. R. Tree, Purdue University, West Lafayette, IN, pages 
173.176, July 1990 (4 pages with 7 figures, reprint available from JMC as RDB2249)

This paper describes new methods for measuring viscosity and vapor pressure of refrigerantlubricant mixtures for compositions of $0-100 \%$ and temperatures from -40 to $150^{\circ} \mathrm{C}$ (.40 to 300 ${ }^{\circ} \mathrm{F}$ ). The equipment and methods also can be applied to fluids for absorption systems. Automatic data acquisition, data reduction, and computer generated graphics are utilized. Typical viscosity-pressure-temperature-composition data are presented to illustrate engineering applicability. The method uses a new viscometer, based on electromagnetic forces arid the time required for a metallic piston to traverse a known distance through the fluid.

H. O. Spauschus and D. R. Hurst, New Stability Test Methods for Aiternative Refrigerants and Mixtures, presentation slides and abstract (seminar on Ozone/CFC - Alternative Studies Update), ASHRAE 1989 Annual Meeting (Vancouver, BC, Canada) Spauschus Associates, Atlanta, GA, June 1989 (15 pages as RDB0544)

$H$. Wijaya and H. M. Hughes (Allied-Signal Incorporated). A Proposed Procedure for Qualifying Halogen Leak Detectors. Proceedings of the International CFC and Halon Alternatives Conference (Baltimore, MD). Alliance for Responsible CFC Polisy, Artington, VA, November 1990 (9 pages with 10 figures and 3 tables, RDB2316)

Refrigerant Extraction Test, Copeland Corporation, Sidney, $\mathrm{OH}$, undated circa 1989 (4 pages with 1 table, available from JMC as RDB0005)

This procedure outlines a test to determine the amount of extractable residue in materials that are used in hermetic refrigerant system when exposed to refrigerant environments. Extractables are determined as the fraction of weight loss after exposure to evaporating refrigerart at elevated temperature and pressure. Charging data are provided for R-12, R-22, and R-502.

Refrigerant-Lubricant Soak Test, Copeland Corporation, Sidney, OH, undated circa 1989 (3 pages. available from JMC as RDB0007)

This procedure outlines a test to determine the effect of materials exposed to a refrigerant-lubricant mixture at operating conditions. The palrameters determined are dimensional, including swell, and weight change; visual observations of decomposition also are addressed. The procedure described is based on thermal-aging in a pressure vessel, preceded and followed by measurements.
Sealed Glass Tube Method for Determining the Stability of Materials Used within Refrigeration Systems, product engineering specification ES23. 138. Copeland Corporation, Sidney, $\mathrm{OH}, 11$ May 1987 (10 pages with 1 figure and 2 tables, available from JMC as RDB0006)

This procedure outlines a sealed-tube test to rate the quality of lubricants with R-12. It is based on visual inspection of the oil and metal (steel and copper) test strips and the amount of reactivity, determined by gas chromatography, after thermal aging at $175^{\circ} \mathrm{C}\left(347^{\circ} \mathrm{F}\right)$ for 3 - and 14-day periods.

Sealed Tube Method to Test the Chemical Stability of Material for Use within Refrigeration Systems, standard ANSI/ASHRAE 97-1989, American Society of Heating, Refrigerating, and AirCurditioning Engineers, Atlanta, GA, 1989 (RDB. 2251)

\section{IMPACTS}

L. J. M. Kuijpers (Phillips Research Laboratories) and S. M. Miner (Consultant), The CFC issue and the CFC Forum at the 1988 Purdue IIR Conference, International Journal of Refrigeration, Paris, France, volume 12, number 3, pages 118-124, May 1989 ( 8 pages with 4 figures and 2 tables, RDB. 1108)

L. J. M. Kuijpers et al, Refrigeration, Air Conditioning, and Heat Pumps (Technical Options Report), Technical Progress on Protecting the Ozone Layer, report RWR-570-LK-91423-al, United Nations Environment Programme, Paris, France, December 1991 (RDB2318)

L. J. M. Kuijpers et al, Refrigeration, Air Conditioning, and Heat Pumps (Technical Options Report), Technical Progress on Protecting the Ozone Layer, United Nations Environment Programme, Paris, France, 30 June 1989 (172 pages with 13 figures and 24 tables, available from JMC as RDB2317)

This report is one of five prepared to assess the status of technologies impacted by the Montreal Protocol and to identify options for achieving compliance. The report was prepared by an international panel of 48 individuals, pursuant to Article 6 of the Protocol. It addresses the Pro. tocol and reassessment procedure, refrigerants. domestic refrigeration (including refrigerators and other appliances), retail refrigeration (including commercial uses), transport refriger. 
ation, cold storage, industrial refrigeration, comfort air conditioning, mobile air condition. ing, heat pumps, and refrigerant recycling.

\section{CUSTS AND PERFORMANCE}

R. El-Bourini, K. Hayashi, and T. Adachi (Calsonic Corporation), Automotive Air Conditioning System Pertormance with HFC-134a Refrigerant, paper 900214 (SAE International Congress and Ex. position, Detroit, MI, 26 February - 2 March 1990), Society of Automotive Engineers (SAE), Warrendale, PA, February 1990 (12 pages with 14 figures and 3 tables, RDB2252)

S. K. Fischer and F. A. Creswick, Energy-Use Impact of Chlorofluorocarbon Alternatives, report ORNL/CON-273, Oak Ridge National Laboratory, Oak Ridge. TN, February 1989 (138 pages, available from NTIS, RCB0924)

This study estimates energy-use impacts of phase out of chlorofluorocarbon (CFC) refrigerants under the Montreal Protocol. Major energy-related applications of the fully halogenated CFCs (R-11, R-12, R-113, R-114, and R115) were identified. Four groups of alternative refrigerants then were considered: 1) chemicals with very similar properties (near drop-in substitutes); 2) a fallback scenario relying on available compounds with more product develop. ment; 3) a worst case in which no new chemicals become available, chlorine-containing compounds (e.g., R-22) cannot be used, and fiberglass insulation is used in place of CFC. blown foams; and 4) an advanced technology using highly efficient insulation and refrigeration systems. Energy use will not incre a significantly if near drop-in compounds (principally $R$ 134a, R-123, and R-141b) are used. If they do not become available, national energy use will increase by $1-2$ quad (1015 Btu) per year. Development of advanced technologies could reduce annual energy use by about 0.83 quad. The major impacts are in applications using foam insulations blown with CFCs (e.g., refrigerators, freezers, water heaters, roofs of commercial buildings, and insulated building foundations). The penalty associated with refrigeration equipment is smaller, but is contingent upon attaining the high compressor efficiencies for alternative refrigerants that are available for CFCs.

H. B. Ginder, R-123 versus R-11 Performance Test, York International Corporation, York, PA, 19 July 1989 (2 pages with 1 table, available from JMC as RDB0008)
The performance of a 200-ton chiller, designed for R-11 operation, is compared at nominal rating conditions for R-123 and R-11 with a naphthenic oil. The chiller employs a single-stage centrifugal compressor with an open drive and air-cooled motor. The results at full load indicate a $16.3 \%$ reduction in capacity and an increase of $9.2 \%$ in $\mathrm{kW} /$ ton $(8 \%$ lower efficiency. Although testing at loads of $20-100 \%$ capacity and varied evaporator and condenser conditions are indicated, part-load performance is not reported.

E. Heinzelmann and M. S. Ussyk (Empresa Brasileira de Compressores $S / A$, Embraco), Hermetic Refrigerating Compressors and CFC Substitution, International Journal of Refrigeration, Paris, France, volume 14, number 9 , pages 10-15, January 1991 (6 pages with 11 figures, RDB1201)

This paper presents a basic methodology for screening substitutes for R-12 in refrigerating compressors. Simple analysis of refrigerant thermodynamic properties are presented within the ranges of evaporating and condensing temperatures in which small refrigerating systems operate. Comparisons of vapor pressure, coefficients of performance (COPs), compression ratio, final isentropic compression temperature. and volumetric refrigerant effect are presented for R-12, R-22, R-134a, and R-152a. Additionally, a procedure for developing compressors for use with alternative refrigerants is presented. Material compatibility, performance, reliability, and means of production are considered. The differences between developed and developing countries are notej, using Brazil as an example.

E. D. Lawler, HFC-134a vs R-12 Centrifugal Chiller Performance Comparison, SnyderGeneral Corporation, Staunton, VA, 22 August 1990 (1 page with 1 table, available from JMC as RDB0801)

The performance of a 100-ton, single-stage, hermetic centrifugal water chiller is compared for R-12 and R-134a. Both tests were run at standard rating conditions (ARI Standard 55088) with the chiller operating at its maximum capacity. The compressor gears were changed to increase the impeller speed to accommodate the greater isentropic head rise required with $R$. 134a. The low-pressure cut-out switch and thermostatic expansion valve were adjusted after changing refrigerants, but other hardware and control settings were the same for both tests. The capacity and efficiency increased with R-134a, by 0.8 and $4 \%$, respectively.

E. D. Lawler, HFC-134a vs R-500 Centrifugal Chiller Performance Comparison, SnyderGeneral Corporation, Staunton, VA, 29 August 1990 (1 page with 1 table, available from JMC as RDB0802) 
The performance of a 112-ton, single-stage, hermetic centrifugal water chiller is compared for R-500 and R-134a. Both tests were run at standard rating conditions (ARI Standard 55088) with the chiller operating at its maximum capacity. The chiller initially was tested with $R$ 500 as a baseline and then recharged with $R$ 134a. The lubricant was changed from a naphthenic mineral oil (Suniso 4GS) to an ester (Mobil XRL 1681-1). The low-pressure cut-out switch and thermostatic expansion valve were adjusted after changing refrigerants, but other hardware and control settings were the same for both tests. A third test was run with the impeller replaced to provide higher flow. The compressor gears were changed for a fourth test to increase the impeller speed. The capacity with $R-134$ a decreased by $9.9,1.3$, and $4.1 \%$ for the three tests and the efficiency decreased by 2.8 and $0.5 \%$ for the second and fourth tests, but increased by $0.1 \%$ for the third.

E. E. A. Lund, R. G. Richard, and I. R. Shankland (Allied-Signal incorporated), A Performance Evaluation of Environmentally Acceptable Foam Blowing Agents, Polyurethanes 88 (proceedings of the 31st SPI Annual Technical and Marketing Conference), pages 290-296, 1988 (7 pages, RDB0502)

M. O. McLinden (National Institute of Standards and Technology, NIST), Optimum Refrigerants for Nonideal Cycles: An Analysis Employing Corresponding States, Proceedings of the 1990 USNC/IIR.Purdue Refrigeration Conference and ASHRAE-Purdue CFC Conference, edited by D. R. Tree, Purdue University, West Lafayette, IN, pages 69-79, July 1990 (11 pages with 7 figures, RDB. 0920)

The principle of corresponding states is used to evaluate the effects of the thermodynamic characteristics of working fluid performance in refrigeration cycles. Desired characteristics, expressed in terms of the critical temperature and ideal gas heat capacity using propane as the reference fluid, are examined for various departures from the theoretical (ideal) vapor-com . pression cycle. The baseline cycle for the comparisons include compressor efficiency and heat transfer limitations in the condenser and evaporator. The paper addresses the modified Benedict-Webb-Rubin (MBWR) equation of state chosen for property calculations, the cycle analysis simulation model, and the application of the model to the selection of alternative refrigerants. The results indicate that modifications to the basic vapor-compression cycle should be considered for refrigerants with two or more carbon atoms to achieve maximum en. ergy efficiency.
S. M. Sami (University of Moncton, Canada) and T N. Duong (University of Sherbrooke, Canada), Dynamic Pertormance of Heat Pumps Using R134a, paper 3491, ASHRAE Transactions, American Society of Heating, Refrigerating and AirConditioning Engineers, Atlanta, GA, volume 97, part 2, pages 41-47, 1991 (7 pages with 15 figures, RDB2346)

J. R. Sand, E. A. Vineyard, and V. D. Baxter (Oak Ridge National Laboratory, ORNL), Laboratory Evaluation of an Ozone-Safe Nonazeotropic Refrigerant Mixture in a Lorenz-Meutzner Refrigerator Freezer Design, submitted for publication by the American Society of Heating, Refrigerating and Air-Conditioning Engineers, Atlanta, GA (RDB2412)

J. R. Sand, E. A. Vineyard, and R. J. Nowak (Oak Ridge National Laboratory, ORNL), Comparable Refrigerant Performance Data, Oak Ridge $\mathrm{Na}$ tional Laboratory, Oak Ridge, TN, July 1989 (8 pages with 1 figure and 5 tables as RDB0543)

performance comparisons for R-12, R-22, R-32, R-114, R-124, R-125, R-134, R-134a, R-142b, R143, R-143a, R-152a, R-218, and R-C318 at four standard heat pump rating conditions

M. W. Spatz (Allied-Signal Incorporated), Performance of Alternative Refrigerants from a System's Perspective. Proceedings of the Interna. tional CFC and Halon Alternatives Conference (Baltimore, MD), Alliance for Responsible CFC Policy, Arlington, VA, pages 352-361, December 1991 (10 pages with 5 figures and 3 tables, RDB. 2253)

The modeled coefficients of performance (COPs), capacities, and discharge temperatures for a representative $11 \mathrm{~kW}$ (3 ton) air-to-air heat pump are presented for R-22, R-32/R-125 $(60 / 40), R-134 a$, and R-152a - all HFCs. The analyses were made with a modified version of the Oak Ridge National Laboratory (ORNL) Mark III Heat Pump System Design Model. Calculated COPS are tabulated both with simple replacement of R-22 and with reoptimization of the expansion device, heat exchangers, and tubing sizes. Calculations based on a simple (saturated) thermodynamic cycle indicate $8 \%$ lower, $1 \%$ lower, and $4 \%$ higher efficiency for $R$ 32/R-125, R-134a, and R-152a, respectively, compared to R-22. The magnitude of these differences shrink when subcooling and superheating are introduced. With reoptimization, the differences range from -0.3 to $+3.2 \%$ for a system optimized for both the heating and cooling modes and -0.9 to $+0.6 \%$ for cooling only, depending on the refrigerant. The paper, therefore, concludes that while these three alternative refrigerants could be used without significant energy penalty, other factors need to be ad. 
dressed. The approximately $50 \%$ higher condensing pressure of R-32/R-125 could increase costs. Changes in compressor displacement, increased for R-134a and decreased for R-32/R125 , also effect system costs. The flammability of R-152a would either eliminate it from consid. eration or impact costs by requiring additional safety controls.

T. G. Statt (U.S. Department of Energy, DOE), Energy Implications of Global Climate Change, presentation charts, 1989 ASHRAE Annual Meeting Vancouver, BC, June 1989), U.S. Department of Energy, Washington, DC, June 1989 (16 pages, RDB1109)

E. A. Vineyard (Oak Ridge National Laboratory, ORNL), Laboratory Testing of a Heat Pump System Using an R-13B1/R-152a Refrigerant Mixture, paper 3130, ASHRAE Transactions, American Society of Heating, Refrigerating and Air-Conditioning Engineers, Atlanta, GA, volume 94, part 1. 1988 (11 pages with 8 figures and 4 tables, RDB. 2329)

J. Zheng and J. W. Pelava (Allied-Signal Incorporated), Performance Test of R-12 Alternates in a Hermetic Compressor, paper 149, proceedings of the XVIIIth International Congress of Refrigeration (Montreal, Québec, Canada, August 1991), Interna. tional Institute of Refrigeration, Paris, France, August 1991 (11 pages with 3 figures and 4 tables, RDB2254)

This paper presents measured results of calorimeter tests of replacements for R-12 at -23 to $+1{ }^{\circ} \mathrm{C}\left(-10\right.$ to $\left.+30^{\circ} \mathrm{F}\right)$ evaporating and 38 and $49^{\circ} \mathrm{C}\left(100\right.$ and $\left.120^{\circ} \mathrm{F}\right)$ condensing. The fluids tested included R-134a with a polyalkylene glycol lubricant and four zeotropes with alkylbenzene lubricants. The blends included R-22/R. 124 (55/45 and $43 / 57 \%$ by weight) and R-22/ R-152a/R-124 (50/20/30 and 36/24/40). The compressor discharge temperature, compression ratio, cooling capacity, and efficiency are compared to those of R-12.

Impact of a CFC Ban on the Cost and Pertormance of Household Refrigerators, Centrifugal Chillers, and Commercial/Industrial Systems, technical memorandum to U.S. Department of Energy, Arthur D. Little, Incorporated, Cambridge, $M A$, August 1989 (82 pages, RDB1110)

This report assesses the potential response of and impacts on the refrigeration industry to a regulatory ban on the production of CFC working fluids by the year 2000 . The primary focus is on the most likely alternatives, in each applica. tion category, and their impact on the design and pertormance of new equipment.
Potential Costs of Restricting Chlorofluorocarbon Use, report SR/ESD/89-01, Energy Informa. tion Administration, U.S. Department of Energy, Washington, DC. August 1989 (88 pages, RDB1111)

Report to the Secretary of Energy on Ozone-Depleting Substances, U.S. Department of Energy, Washington, DC, October 1989 (63 pages, RDB. 1112)

analysis of the energy and economic effects of phasing out certain organic chlorine and bromine products

\section{ENVIRONMENTAL}

J. G. Anderson, D. W. Toohey, and W. H. Brune, Free Radicals Within the Antarctic Vortex: The Role of CFCs in Antarctic Ozone Loss, Science, volume 251, pages 39-46, 4 January 1991 (8 pages with 6 figures, RDB 1202)

This article describes experiments and observations linking chlorine and bromine concentrations with ozone depletion in the antarctic vortex. It briefly reports the findings of the National Science Foundation Ozone Experiment (NOZE 1) expedition in the austral spring of 1986. It describes in greater detail the high-altitude mission and in situ measurements of the subsequent Airborne Antarctic Ozone Experiment. Mathematical equations defining the mechanisms of ozone depletion are presented for chlorine and bromine. What sets Antarctic ozone depletion apart in the context of global change is both the severity of the phenomenon and the unusual decoupling of physical and chemical time constraints that control transformation rates in a specific region of the atmosphere. The article concludes that the dramatic reduction in ozone over the antarctic continent would not have oc. curred had CFCs not been released to the atmosphere.

J. M. Calm (Air-Conditioning and Refrigeration Institute), Global Warming (the Next Challenge), presentation charts, Seminar on Refrigerant Practices. National Institute of Standards and Technology, Gaithersburg, MD, 12 February 1991 (9 pages with 14 charts, RDB 1207)

S. K. Fischer (Oak Ridge National Laboratory, ORNL) and M. McFarland (Du Pont Chemicals). Alternatives to CFCs and Global Warming: a Systems Approach to Evaluating Net Contributions, MRS Bulletin, Materials Research Society, volume XVII, number 3 , pages $39-42$ (4 pages with 2 figures and 1 table, RDB2413) 
S. K. Fischer, P. J. Hughes, P. D. Fairchild (Oak Ridge National Laboratory, ORNL), C. L. Kusik, J. T. Dieckmann, E. M. McMahon, and N. Hobday (Arthur D. Little, Incorporated, ADL), Energy and Global Warming Impacts of CFC Alternative Technologies, Alternative Fluorocarbons Environmental Acceptability Study (AFEAS) and U.S. Department of Energy (DOE), Washington, DC, December 1991 (602 pages with 98 figures and 40 tables plus supporting figures and tables in appendices, RDB2432)

This report documents detailed analyses of global warming for options to replace chlorofluorocarbons (CFCs) in energy-related applications. The study addressed both direct and indirect effects, namely greenhouse gas impacts of chemical emissions and carbon dioxide emissions from associated energy use. The report compares impacts, for alternative technologies, on the basis of total equivalent warming impact (TEWI). Domestic refrigerator-freezers, commercial refrigeration, commercial chillers, residential and commercial unitary heating and cooling equipment, automobile air conditioning, building insulation, and solvents for metal and electronic cleaning were examined on an international basis. The refrigerants addressed for household refrigeration included R-12, R-134a, R-22/152a/124, R-22/142b; absorption and Stitting cycles also were assessed. $R-12, R-22, R-134 a, R-502$, and R-717 (ammonia) were examined for commerclal refrigeration. R-11, R-12, R-22, R-123, R-134a, and R717 were addressed for commercial air conditloning along with water-lithium bromide $a b$ sorption cycles. R-22, R-134a, and ammoniawater absorption were analyzed for unitary air conditioners. R-12, R-134a, R-152a, R-290 (propane), and $R-22 / 152 a / 124$ were evaluated for automotive air conditioning along with Brayton and Stirling cyccles.

K. Hearle, F. Riza, A. Whitfield, J. Hemby, J. S. Hoffman, and S. Seidel, Analysis of the Environmental Implications of the Future Growth in Demand for Partially-Halogenated Chlorinated Compounds, report EPA 400/1-90-001, U.S. Environmental Protection Agency, Washington, DC, January 1990 (304 pages, RDB1113)

M. C. MacCracken et al, (Lawrence Livermore National Laboratory), Energy and Climate Change (Report of the DOE Multi-Laboratory Climate Change Committee), Lewis Publishers, Chelsea, MI, USA, February 1990 (182 pages, RDB2313)

S. L. Roan, Ozone Crisis: The 15-Year Evolution of a Sudden Global Emergency, John Wiley and Sons, Incorporated, NY, New York, 1989 (292 pages, RDB1208)
This book reviews the 15-year history of action and reaction to the ozone-depletion problem. The text specifically addresses the intervention of politics, and the control both it and economic pressures had over the scientific community.

M. R. Schoebert and D. L. Hartmann, The Dynamics of the Stratospheric Polar Vortex and Its Relations to Springtime Ozone Depletions, Science, volume 251, pages 46-52, 4 January 1991 (7 pages with 5 figures, RDB1203)

IEA Heat Pump Center Newsletter, issue on Heat Pumps and the Environment, International Energy Agency Heat Pump Center, Sittard. The Netherlands, volume 7, number 2, June 1989 (64 pages, RDB0925)

This issue focuses primarily on refrigerant environmental impacts of refrigerants.

Newly Found Viruses Might be the Key to Controlling Seas, R\&D Magazine, Des Plaines, $I L$, volume 32, number 12, December 1990, page 86 (1 page, RDB1114)

This news brief announces the discovery of a group of unspecified aquatic viruses that may aid in reducing global warming. These viruses encourage reproduction of a class of phytoplankton that absorb carbon dioxide. Other aquatic viruses could control reproduction of oxygen-absorbing phytoplankton that kill marine life by robbing water of oxygen. Additional research is required to better understand these viruses and their affect on marine life.

Possible Environmental Effects of Chlorofluorocarbons, position statement and paper. American Society of Heating, Refrigerating and Air-Conditioning Engineers, Atlanta, GA, 2 February 1989 (12 pages, RDB1115)

Scientific Assessment of Stratospheric Ozone: 1989, report 20, World Meteorological Organization, Geneva, Switzerland, 1989, program description, volume I (534 pages, available from GPO as report 1990-259-707:83731; RDB1116)

Scientific Assessment of Stratospheric Ozone: 1989 (Appendix: AFEAS Report), report 20, World Meteorological Organization, Geneva, Switzerland, 1990, program description, volume II (536 pages, RDB1117)

Assessment of the Impacts Associated with a Total CFC Phase Out, final report, Putnam, Hayes and Bartlett, Incorporated, Washington, DC, July 1989 (60 pages, RDB1118) 


\section{REGULATORY ACTIONS}

\section{INTERNATIONAL}

Montreal Protocol on Substances That Deplete the Ozone Layer, working version, United Nations Environment Programme, June 1990 (28 pages, RDB1119)

This text is an unofficial composite version of the Montreal Protocol as amended in London in June 1990.

\section{NATIONAL}

\section{United States of America}

Comments on the Manufacture, Use, and Disposal of Ozone-Depleting Chemicals (CFCs) to the Subcommittee on Environmental Protection of the Committee on Environment and Public Works of the United States Senate, Motor Vehicle Manufacturers Association (MVMA), Detroit, MI, 19 May 1989 (RDB1155)

\section{Other}

Refrigeration Equipment and Heat Pumps Using CFCs/HCFCs: The Refrigerants Order and Comments, Swedish National Environmental Protection Agency, Stockholm, Sweden, 1988 (71 pages, RDB1130)

Measures of Rationalization of Use and Control of Emission for Specified CFCs, interim report. Ozone Layer Committee, Chemical Product Council. Ministry of International Trade and Industry, Tokyo, Japan, 26 October 1988 (34 pages, RDB1131)

Refrigeration Safety Regulation, translated by the Japan Refrigeration and Air Conditioning Industry Association, Tokyo, Japan (36 pages, RDB 1132)

\section{SUBSTITUTE REFRIGERANTS}

J. L. Adcock, S. B. Mathur, W. A. Van Hook, H. Q. Huang, M. Narkhede, and B-H. Wang (University of Tennessee), Fluorinated Ethers - A New Series of CFC Substitutes. Proceedings of the International CFC and Halon Alternatives Conference (Baltimore, MD), Allance for Responsible CFC Policy, Arlington, VA, pages 386-395, December 1991 (10 pages with 6 tables, RDB2255)

A. L. Beyertein, D. D. DesMarteau, S. H. Hwang (Clemson University), N. D. Smith (Environmental Protection Agency, EPA), and P. Joyner (Electric Power Research institute, EPRI), Physical Property Data on Fluorinated Propanes and Butanes as CFC and HCFC Alternatives, Proceedings of the International CFC and Halon Alternatives Con. ference (Baltimore, MD), Alliance for Responsible CFC Policy, Arlington, VA, pages 396-405, December 1991 (10 pages with 5 tables, RDB2256)

D. A. Didion (National Institute of Standards and Technology, NIST), R. Cohen, and D. R. Tree (Purdue University), The Role of R-22 in Refrigerating and Air-Conditioning Equipment, International Colloquium on Refrigeration and CFCs (Brussels, Belgium, March 1990), International Institute of Refrigeration, Paris, France, to be published (18 pages with 6 figures and 3 tables, RDB0921)

D. A. Didion, Energy Performance Potential of the Alaskan Air Conditioning Company's Refrigerant Mixture, National Institute of Standards and Technology (then the Natlonal Bureau of Standards), Gaithersburg, MD, July 1984 (RDB2320)

R. E. Ertinger (Carrier Corporation), HCFC-22: Requirements for Unitary Products, Proceedings of the International CFC and Halon Alternatives Conference (Baltimore, MD), Alliance for Responsible CFC Policy, Artington, VA, pages 340-347, December 1991 ( 8 pages with 3 figures, RDB2257)

This paper estimates the annual quantity of R-22 required internationally for unitary equipment through the year 2000 . Based on its properties, including efficiency, low cost, and safety, R-22 is the most widely used refrigerant. The paper estimates its 1990 use to be 160 million $\mathrm{kg}$ (352 million (bs), of which $14 \%$ was used for equipment other than unitary (e.g., existing and new chillers). For the unitary portion, $24 \%$ was used in new products and $76 \%$ to service existing equipment. Two parametric scenarios are presented: (1) 3, 5, and $7 \%$ growth in demand for unitary products with no change in service practices, and (2) recovery increasing to 40,60 , or $80 \% / y r$ by 2000 . Based on assumptions for 
usage In room alr-conditioners, duct-free split systems, ducted systems, and commercial unitary systems, the paper projects a range of 77 . 149 million $\mathrm{kg}$ (169-327 million lbs), depending on recovery levels, to be required in 2000 at the $5 \%$ annual new-product growth rate.

J. N. Friedman, Experimental Evaluation of Alaskan Air Conditioning Company's Mixed Refrigerant R-176, Carrier Corporation, Syracuse, NY, 17 August 1984 (13 pages with 2 figures and 4 tables, avallable from JMC as RDB1B01)

The measured performance of a zeotropic ternary blend, $R-12 / R-22 / R-142 b(15 / 25 / 60)$ is compared to that of R-22 for two residential heat pumps. The units tested included an air-to-water heating-onily model and an air-to-air heatingand-cooling model. The charge and expansion device orifice (Accurator $(\mathrm{A})$ piston size) were optimized for capacity and efficlency. The heating capacity and coefficient of performance (COP) were approximately 52 and $15 \%$ lower respectively, with the refrigerant blend than with R-22 in the alr-to-water heat pump. The heating and cooling capacities were approximately 35 and $46 \%$ lower, respectively, in the air-to-air heat pump, but the efficiency increased t:y approximately $10 \%$ in the cooling mode and was nearly the same for heating. The test procedures and conditions are described in the report. The study concluded that the mixture is not a viable replacement in Carrier heat pump systems operating in the heating mode. Additional testing is recommended to determine if increases in efficiency can be achieved with the mixture in the cooling mode, based on further capillary tube and refrigerant charge optimization, despite the decreased cooling capacity.

L-Z. Han, M-S. Zhu, and Z-Z. Lin (Tsinghua University, China), Experimental Study on Blend HCFC. 22 /HFC-152a as a Refrigerant in Refrigerator, Proceedings of the International CFC and Halon Alternatives Conference (Baltimore, MD), Alliance for Responsible CFC Policy, Artington, VA, pages 494-501, December 1991 (8 pages with 4 figures and 1 table, RDB2311)

J. A. Jones and A. Lund, Low-Ozone Damaging Fluid Mix Substitutes for Refrigerant 12, Jet Propulsion Laboratory, California Institute of Technology, Pasadena, CA 1989 (RDB2338)

B. D. Joyner, Refrigerants 69-S and 69-L, "DropIn" Replacements for R-502, Proceedings of the International CFC and Halon Alternatives Conference (Baltimore, MD), Alliance for Responsible CFC Policy, Arlington, VA, December 1991 (RDB2303)
W. L. Kopko (York International Corporation), Extending the Search for New Refrigerants, International Journal of Refrigeration, Paris, France, volume 13, number 3, March 1990, pages 79 if (RDB2304)

H. Kruse and U. Hesse (Universität Hannover), Possible Substitutes for Fully Halogenated Chlorofluorocarbons Using Fluids Already Marketed, Status of CFCs - Refrigeration Systems and Refrigerant Properties (proceedings of the meetings of IIR Commissions B1, B2, E1, and E2, Purdue University, West Lafayette, IN), International Institute of Refrigeration, Paris, France, July 1988; republished in the International Journal of Refrigeration, Paris, France, volume 11, number 4, pages 276-283, 1988 (RDB2305)

L. J. M. Kuiljpers (Phillips Research Laboratories), J. A. De Witt, and M. J. P. Janssen, Possibilities for the Replacement of CFC 12 in Domestic Equipment, International Journal of Refrigeration, Paris, France, volume 11, number 4, pages 284-291, 1988 (RDB2258)

M. O. McLinden and D. A. Didion (National Institute of Standards and Technology, NIST), Quest for Alternatives, ASHRAE Journal, December 1987. republished in ASHRAE Special Publication, CFCs: Time of Transition, American Soclety of Heating, Refrigerating, and Alr-Conditioning Engineers, Atlanta, GA, pages 69-78, 1989 (6 pages with 9 figures and 1 table, RDB2259)

This article reviews the criteria required of refrigerants and the reasons chlorofluorocarbons (CFCs) were originally investigated. A systematic examination, based on molecular structure, reveals a range of compounds that should be environmentally acceptable and still retain de. sired attributes. 860 compounds were screened, resulting in 51 fluids warranting further examination. The article notes that the number of compounds from which to choose alternatives is limited; the chlorofluorocarbon family - including fluorocarbons and hydrocarbons - remains the clear choice by virtue of stability, thermodynamic properties, health and safety characteristics, and familiarity. Some compromise with traditional criteria (e.g., capacity, flammability, and efficlency) will be needed. Present refrigerants resulted from more than 30 years of research and development. Careful scientific and technological planning are required to effect a significant change, and to avoid a new solution that introduces more problems than it solves.

D. Naito (Daikin Industries, Limited), Alternatives to CFC Refrigerants, Proceedings of the $3 \mathrm{rd} / \mathrm{ln}$ ternational Energy Agency Heat Pump Conference (Tokyo, Japan, 12-15 March 1990), edited by $T$. 
Saito and $Y$. Igarashl, Pergamon Press, Elmsford, NY, pages $713-720,1990$ (8 pages, RDB0407)

G. J. O'Nell and R. S. Holdsworth W. R. Grace and Company), Bis (Difluoromethyl) Ether Refrigerant, patent 4,961,321, 9 October 1990 (4 pages, RDB1133)

This patent describes the use of E-134 as a refrigerant, either as a single component or in a blend. The refrigerant is described as environmentally safe, nontoxic, and nonflammable and as having the desired physical, chemical, and thermodynamic properties necessary for a refrigerant.

S. F. Pearson, (Star Refrigeration Limited), The Development of a Drop-In Replacement for R502, paper 92.4, Proceedings of the Institute of Refrig. eration, London, UK, January 1992 (9 pages with 15 figures and 1 table, RDB2306)

This paper describes the development, performance testing, flammability considerations, charging, and separation of two ternary zeotropes developed as replacements for R-502. Both are blends of R-22, R-218 (octafluoropropane), and R-290 (propane). One containing $39 \%$ R-218 results in marginally lower discharge temperatures; the other containing 20\% R-218 offers discharge temperatures between those of R-502 and R-22. These R-290/22/218 mixtures are nonflammable and of low toxicity. They exhibit ozone depletion potentials (ODPs) of 0.037 and 0.028 and nearty the same refrigerating effect as R-502. Measured coefficients of performance (COPs) with these blends were higher than for R-502 under comparable conditions. The paper describes the choice of components, including initlal consideration of blends containing R-125 and R-1270. The test rig, results, and effects of diffusion and replacement of lost refrigerants also are discussed. Extensive international field testing is mentioned, but not described.

S. F. Pearson, (Star Refrigeration Limited), Development of a Substitute for R502, paper 162 ., proceedings of the XVIIIth International Congress of Refrigeration (Montreal, Québec, Canada, August 1991), International Institute of Refrigeration, Paris, France, August 1991 (RDB2425)

S. F. Pearson, (Star Refrigeration Limited), Refrigeration after CFCs, proceedings of the Low Temperature Engineering and Cryogenics Conference, Southampton, 1990 (RDB2426)

X. He, U. C. Spindler, D. S. Jung, and R. Radermacher (University of Maryland), Investigation of R22/R-142b Mixture as a Substitute for $R-12$ in Single-Evaporator Domestic Refrigerators, paper
3557 (Winter Meeting, Anaheim, CA, January 1992) ASHRAE Transactions, American Society of Heating, Refrigerating and Air-Conditioning Engineers, Atlanta, GA, volume 98, part 1, in publication (RDB. 2340)

R. Radermacher and D. S. Jung (University of Maryland), Replacement Refrigerants for R-22, draft final report, U.S. Environmental Protection Agency, Washington, DC, Novernber 1990 (80 pages with 24 tables, RDB1134)

This peer-review draft examines alternative refrigerants for R-22. The report summarizes the simulation programs used, $\mathrm{HAC}$ and $\mathrm{HACT}$, to examine candidate refrigerants. Coefficients of performance (COPs) and seasonal performance factors (SPFs) were calculated for a number of mixtures. The report also reviews the design modifications considered and discusses requirements for future research. No single-component refrigerant was found as a substitute, but binary and ternary blends appear promising. The R-32/152a blend was identified as the most promising option, with an estimated COP increase of $11 \%$. A further increase by $4 \%$ was estimated with use of a suction gas heat exchanger. Addition of a third, nonflammable component is suggested to reduce flammability.

R. Radermacher (University of Maryland) and $J$. Lavelle (Elf Atochem North Arnerica, Incorporated). Comparison of R-12 with the Blend of R-22/R142b. Proceedings of the ASME Winter Annual Meeting, American Society of Mechanical Engineers, New York, NY, pages 22-30, 1988 (RDB. 2339)

J. R. Sand, S. K. Fischer (Oak Ridge National Laboratory, ORNL), Modeled Performance of Nonchlorinated Substitutes for CFC-11 and CFC-12 in Centrifugal Chillers, International Journal of Refrigeration, Paris, France, publication pending (6 pages, RDB2411)

J. R. Sand, S. K. Fischer (Oak Ridge National Laboratory, ORNL), and $P$. A. Joyner (Electric Power Research Institute. EPRI), Modeled Performance of Nonchlorinated Substitutes for CFC-11 and CFC-12 in Centrifugall Chillers, Proceedings of the International CFC and Halon Alternatives Conference (Baltimore, MD), Alliance for Responsible CFC Policy, Arlington, VA, pages 406-415, December 1991 (10 pages with 2 tables, RDB2260)

J. R. Sand and E. A. Vineyard, Report of Foreign Travel: 2-5 May 1989 [Zeotropic Blends in Refr'gerators], ORNL/FTR-3251, Oak Ridge National Láboratory, Oak Ridge, TN, 18 May 1989 (14 pages, RDB1135) 
This informal report summarizes meetings on refrigerator/freezer testing with zeotropic blends of refrigerants (nonazeotropic mixtures of refrigerants or NARMs) at the Universität Hannover (Hannover, FRG). The research investigated a freezer, modified with a polystyrene block to form separate freezer and fresh-food compartments, operating with an R-22/142b refrigerant blend. The simulation program, testing protocol, instrumentation, and plans for testing other blends were revlewed. Also addressed is a visit to AEG GmbH (Kassel, FRG), a major manufacturer of domestic appliances, to discuss research on alternative refrigerants. Compressor components were reviewed after 1000 hours accelerated life testing in R-134a and in R22/R-142b. Parts from the R-134a compressor looked very good, whereas parts from the R$22 / R-142 b$ test unit showed much more thermal breakdown. Some AEG engineers favor R$152 a$, or blends of R-152a with R-22 or R-134a, as an alternative to R-12.

I. R. Shankland (Allied-Signal Incorporated), CFC Alternatives for Thermal Insulation Foams, CFCs: Today's Options - Tomorrow's Solutions (proceedings of ASHRAE's CFC Technology Conference, National Institute of Standards and Technology, Gaithersburg, MD, September 1989), American Society of Heating, Refrigerating, and AirConditioning Engineers, Atlanta, GA, pages 87-95, 1990 (9 pages, RDB0518)

M. B. Shiflet and P. R. Reed, Alternative LowTemperature Refrigerants, paper 163 , proceedings of the XVIllth International Congress of Refrigeration (Montreal, Québec, Canada, August 1991), International Institute of Refrigeration, Paris, France, August 1991 (RDB2307)

T. G. Statt, An Overview of Ozone-Safe Refrigerants for Centrifugal Chillers, CFC Alternatives, technical data bulletin 6(1). American Society of Heating, Refrigerating, and Air-Conditioning Engineers, Atlanta, GA, pages 35-39, June 1990; republished in ASHRAE Transactions, American Society of Heating, Refrigerating and Air-Conditioning Engineers, Atlanta, GA, volume 96, part 1, 1990 (5 pages with 2 figures and 5 tables, RDB2335)

S. G. Sundaresan (Copeland Corporation), Alternate Refrigerants and Lubricants for Refrigeration Compressors, paper 151, proceedings of the XVIllth International Congress of Refrigeration (Montreal, Québec, Canada, August 1991), International Institute of Refrigeration, Paris, France, August 1991 (RDB2308)

D. W. Treadwell (Lennox Industries Incorporated), Application of Propane (R-290) to a Single Packaged Unitary Air-Conditioning Product, Pro- ceedings of the International CFC and Halon Alternatives Conference (Baltimore, MD), Alllance for Responsible CFC Pollicy, Artington, VA, pages 348351, December 1991 (4 pages with 1 table, RDB2261)

This paper discusses the safety considerations and two tests of propane (R-290) as a refrigerant in a single-package, unitary air conditioner. Advantages cited include lower discharge temperature and pressure compared to R-22, both favorable to compressor life, as well as higher efficiency (by $1.2 \%$ ) and materials compatibility. The low cost, availability, and favorable environmental attributes (no ozone-depletion potential and near zero global warming potential) are contrasted to its flammability. The paper estimates the charge quantity required to be less than half that of R-22, and concludes that the probability of reaching the lower flammability limit in a house - under identified leak assumptions - is remotg. The paper indicates that the potential risks should be evaluated in light of the environmental and other advantages.

E. A. Vineyard, J. R. Sand (Oak Ridge National Laboratory, ORNL), and T. G. Statt (U.S. Department of Energy, DOE), Selection of Ozone-Safe, Nonazeotropic Refrigerant Mixtures for Capacity Modulation in Residential Heat Pumps, paper 3199, ASHRAE Transactions, American Society of Heating, Refrigerating and Air-Conditioning Engineers, Atlanta, GA, volume 95, part 1, 1989 (12 pages with 4 figures and 4 tables, RDB1 136)

M-S. Zhu, L-Z. Han, and Z-Z. Lin (Tsinghua University, China), Researches of CFC Alternatives in Tsinghua University, Proceedings of the Interna. tional CFC and Halon Alternatives Conference (Baltimore, MD), Alliance for Responsible CFC Policy, Arlington, VA, pages 484-493, December 1991 (10 pages with 6 tables, RDB2312)

As Easy as 123, E. I. du Pont de Nemours and Company, Incorporated, Wilmington, $D E$; The Trane Company, La Crosse WI; and York International Corporation, York, PA; October 1990 (12. minute videotape, RDB1137)

This video explains how R-123 was developed to replace R-11 by balancing ozone-depletion, global-warming, and energy-efficiency considerations.

CFCs: Time of Transition, American Society of Heating, Refrigerating, and Air-Conditioning Engineers, Atlanta, GA, 1989 (274 pages with 32 pa. pers, RDB1138)

CFCs: Today's Options - Tomorrow's Solutions. proceedings of 1989 ASHRAE CFC Technology 
Conference (Gaithorsburg, MD, September 1989), American Society of Heating, Refrigerating, and AirCondlitioning Engineers, Atlanta, GA, 1990 (128 pages with 13 papers, RDB1139)

Proceedings of the 1990 USNC/IIR-Purdue Refrigeration Conference and ASHRAE-Purdue CFC Conference, edited by D. R. Tree, Ray W. Herrick Laboratories, Purdue University, West Lafayette, IN, July 1990 (526 pages with 56 papers, RDB1140)

Progress in Japan with Substitutes for CFC Refrigerants: Report on Trip to Japan (17 November - 2 December 1989), Air-Conditloning and Refrigeration Institute (ARI), Artington, VA, 1989 (17 pages including 2 tables, RDBOCO4)

This report summarizes observations made during a trip to Japan to investigate progress with substitutes for chlorofluorocarbon refrigerants, with emphasis on materials compatibility and lubricant research issues. The report summarizes status of refrigerants, research, and testing techniques; an itinerary and list of contacts are included. The substitutes being addressed match those being pursued in the United States, but the effort and depth of analysis are greater.

Research Needs for Energy Efficient Alternatives to Chlorofluorocarbons, request for proposals DE-RP01-89ER30155, U.S. Department of Energy (DOE), Washington, DC, August 1989 (170 pages, RDB1141)

Status of CFCs - Refrigeration Systems and Refrigerant Properties, proceedings of the meetings of IIR Commissions 81, B2, E1, and E2 (Purdue University, West Lafayette, IN), International Institute of Refrigeration, Paris, France, July 1988 (438 pages with 51 papers, RDB1142)

\section{ABSORPTION AND ADSORPTION}

M. R. Ally, Computer Simulation of Absorption Heat Pump Using Aqueous Lithium Bromide and Ternary Nitrate Mixtures, report ORNL/TM-10392, Oak Ridge National Laboratory, Oak Ridge, TN, June 1988 (52 pages, available from NTIS, RDB1143)

This report presents the results of a computer simulation study aimed at comparing the potential performance of lithium bromide ( $\mathrm{LIBr}$ ) and ternary nitrate aqueous mixtures in a heat pump. The falling-film heat transfer coefficient for the ternary nitrate mixture is estimated to be lower than that for $\mathrm{LIBr}$ by about one-third. Due to a lack of measured thermophysical properties, the estimates relied on extrapolations. The results show that the ternary nitrate mixture may be operated up to $260^{\circ} \mathrm{C}\left(500^{\circ} \mathrm{F}\right)$ boost temperature, which is approximately $80^{\circ} \mathrm{C}\left(176^{\circ} \mathrm{F}\right)$ higher than what has been demonstrated with LiBr. In higher temperature regimes, the nitrates show the potentlal for $10 \%$ higher COPs and a marginally greater absorber capacity than $L I B r$. Experimental measurements of the falling film heat transfer coefficlent, subcooling, and thermophysical properties are required to make a more definitive investigation.

R. L. Cox, Improvements and Enhancements of the ABSORB Computer Program for Modeling Chemical Absorption Heat Pump Systems, report ORNL/TM-9957, Oak Ridge Natlonal Laboratory, Oak Ridge, TN, July 1986 (56 pages, avallable from NTIS, RDB1144)

This report provides documentation for updates to ABSORB, a simulation program for modeling chemical absorption heat pump systems of varying configuration. A number of improvements and enhancements have been incorporated to improve the robustness, flexibility, and applicability of this code; these modifications include: 1) a revised strategy of solving the system equations, 2) increased modularization of the program, and 3) the first efforts to employ the code to determine an optimum economic design of a heat pump system. A listing of the FORTRAN source code for ABSORB is included as an appendix. The listing excludes the optimizing package NPSOL, which is proprietary and must be separately obtained. User documentation to run $A B S O R B$ is published separately in report ORNL/Sub/43337/2.

R. C. DeVault, Advanced Absorption Cycles: System Development and Supporting Research, Oak Ridge National Laboratory (ORNL), Oak Ridge, TN, March 1990 (48 pages, RDB1145)

G. Grossman and E. Michelson, Absorption Heat Pump Simulation and Studies, Part I: A Modular Computer Simulation of Absorption Systems. report ORNL/Sub/43337/2, Oak Ridge National Laboratory, Oak Ridge, TN (avallable from NTIS, RDB0926)

R. A. Macriss and T. S. Zawacki, Absorption Fluids Data Survey 1989 Update, report ORNL/ Sub/84-47989/4, Oak Ridge National Laboratory, Oak Ridge, TN, 1989 (52 pages with 21 tables, available from NTIS, RDB1146)

This document updates the series of reports on absorption fluids and data, ORNL/Sub/84. 
$47989 / 1,2,3$, with data developed and published primarily between 1985-1988, and by citation of 44 additional references. Seventy-four worldwide publlcations containing data relating to properties of binary, ternary, and multicomponent absorption fluids are identifled. The fluids discussed include combinations of 9 different refrigerant compounds, as well as 30 single, 7 binary, and 1 ternary absorbent compounds.

M. R. Patterson, R. N. Crosswhite, and H. PerezBlanco, A Menu..Driven Program for Determining Properties of Aqueous Lithium Bromide Solutions, report ORNL/TM-11331, Oak Ridge National Laboratory, Oak Ridge, TN, January 1990 (38 pages with program diskette, avallable from NTIS, RDB1147)

This report contains a description of and user's guide for the computer program LIMENU for calculating the thermodynamic and transport properties of aqueous solutions of lithium bromide (LIBr).

Working Fluids and Transport Phenomena in Advanced Absorption Heat Pumps, report HPTC$30-2$, edited by $T$. Salto, Heat Pump Technology Center of Japan, Tokyo, Japan, volume II, March 1990 (362 pages, RDB1148)

This report summarizes the findings of the International Energy Agency (IEA) research project on Working Fluids and Transport Phenomena in Advanced Absorption Heat Pumps (Annex XIV).

\section{RESEARCH PROGRAMS}

\begin{abstract}
J. M. Calm, Research of Alternative Refrigerants, presentation charts, ARI Spring Meeting, Alr-Conditioning and Refrigeration Institute, Arlington, VA, 2-4 April 1990 (6 pages, RDB0310)
\end{abstract}

M. O. McLinden, W. M. Haynes (National Institute of Standards and Technology, NIST, USA), J. T. R. Watson (National Engineering Laboratory, UK), and K. Watanabe (Kelo University, Japan), A Survey of Current Worldwide Research on the Thermodynamic Properties of Alternative Refrigerants, report NISTIR 3969, National Institute of Standards and Technology, Boulder, CO, June 1991 (84 pages, available from NTIS, RDB2262)

A survey of research on thermophysical propertles of alternative refrigerants is presented in tabular form. Research activities throughout the world, concerned with either measurements or correlations of properties, are summarized. The fluids include R-22, R-23, R-32, R-123, R-123a,
$R-124, R-125, R-134, R-134 a, F-141 b, R-142 b, R$ 143a, R-152a, E-134 (bis-diffuoromethylether), fluoroethers, and hydrofluoroethers along with mixtures containing at least one of these. The properties addressed are thermodynamlc, transport, phase equilibria, dielectric constant, and refractive index. The report provides sum. mary information about each research activity, Including the ranges of data, estimated accuracy, and references. The organizations and investigators involved as well as apparatus and techniques employed are tabulated by country. Nelther actual property data nor correlating equations are presented. The objectives were to assist in coordination of research programs, to expedite acquisition of required property data, and to serve as a guide for planning future research. The collaborative effort to compile this Information was undertaken under Annex 18. Thermophysical Properties of the Environmentally Acceptable Refrigerants, of the Advanced Heat Pump Programme of the Internatlonal Energy Agency.

K. Watanabe (Kelo University, Japan), Current Status of Thermophysical Properties Research on CFC Alternatives, Proceedings of the $3 \mathrm{rd} / \mathrm{n}$ ternational Energy Agency Heat Pump Conference (Tokyo, Japan, 12-15 March 1990) edited by T. Saito and $Y$. Igarashl, Pergamon Press, Elmsford, NY, pages 263-282, 1990 (22 pages, RDBO408)

\section{AFEAS}

Alternative Fluorocarbons Environmental ACceptability Study, program description, AFEAS, Washington, DC, April 1990 (4 pages, RDB1 149)

AFEAS was initiated in December. 1988, as a consortium of 12 chemical producers, to assess the potential impacts of chlorofluorocarbon refrigerant alternatives on the environment. Results were presented at the United Nations Environment Programme (UNEP) meeting in Nairobi In August 1989, and were incorporated as an appendix to the Sclentific Assessment under the Montreal Protocol on Substances that Deplete the Ozone Layer. The study is being expanded to conduct further related research. This brochure introduces AFEAS.

Alternative Fluorocarbons Environmental ACceptability Study (AFEAS) Summary Leaflets. Alternative Fluorocarbons Environmental Acceptability Study, Washington, DC, 31 May 1990 (10 pages, RDB1150)

This series of five leaflets summarize key AFEAS findings. They address Atmospheric Fluorocar. 
bons and Stratospheric Ozone, Breakdown Products of Alternatives, UV-B Radlation Measurements, Alternative Fluorocarbons and Global Warming, and a Glossary of Terms.

\section{ARI}

ARI Research Plan, Alr-Condlitioning and Refrigeration Institute, Arlington, VA, 25 September 1991 (56 pages, RDBOC01)

This plan documents research needs for airconditioning and refrigeration, with primary fo. cus on refrigerants, energy conservation, and building environment. It provides industry guid. ance for public-sector research organizations and sponsors. It also may be useful to individual companies in planning proprietary research and development or cooperative programs. A specific plan for materlals compatibility and lubricant research, the basls for the Alr-Conditloning and Refrigeration Technology Institute (ARTI) Materials Compatlbility and Lubricant Research (MCLR) Program, is included as an appendix. A second appendix provides a series of charts, to show the status of alternative refrigerants and projections for their commercialization. The charts also list announced production plants. Charts are included for R-32, R123, R-124, R-125, R-134a, R-142b, R-143a, R152a, and E-134. A third appendix provides elaborations for selected research recommendations including objectives, rationale, suggested approaches, and estimated or recommended budgets and time requirements. This version updates and replaces those published on 6 November 1989, 30 April 1990, and $19 \mathrm{De}$ cember 1990 .

\section{ARTI}

S. R. Szymurski, Materials Compatibility and Lubricants Research on CFC-Refrigerant Substitutes, report DOE/CE/23810-1, Air-Conditloning and Refrigeration Technology Institute (ARTI), Arlington, VA, January 1992 (6 pages, available from JMC as RDB2414)

This interim report summarizes the progress of the Materials Compatibility and Lubricant Research (MCLR) Program. It is Jointly funded under a grant form the Department of Energy and cost sharing from the air-conditioning and refrigeration industry. The program address refrigerant and lubricant properties, materials compatibility, and lubricants for alternative refrigerants. The program comprises projects to measure thermophysical properties, test the chemical and thermal stability of refrigerant-Iubricant mixtures with metals, and measure the misclbility of lubricants with refrigerants. Three projects will provide information on the compatlbillty of refrigerants and lubricants with motor materials, elastomers, and engineering plastics. A seventh project will collect and facilitate dissemination of data through development and administration of a refrigerant database. The scope of the program, objectives of the seven Initlal projects, and highlights of the first quarter are presented. The primary effort focused on solicitation, evaluation, and negotiation of proposals for the cited projects. A grant proposal for the second phase was completed and submitted to the DOE.

\section{ASHRAE}

1992-1993 ASHRAE Research Plan, American Soclety of Heating, Refrigerating, and Alr-Conditloning Engineers, Atlanta, GA, 1 January 1992 (25 pages, RDB2426)

This list of prospective research subjects identifles 182 high-priority projects, grouped into eight project classifications based on approved funding guidelines. Projects relating to refrigerants fall in several of these categories, including the highest priority topic, Environmentally-Safe Materials (CFC, etc.). The research areas were proposed by ASHRAE Technical Committees, Task Groups, and other committees; they were prioritized by ASHRAE's Research and Technical Committee. The highest priority group (three stars) Includes research of thermophysical properties of R-123, R-125, R-134a, and R$141 \mathrm{~b}$, as well as measurement of two-phase re frigerant liquid-vapor mass flow rates. The next classification includes real-time determination of the lubricant concentration dissolved in alternative refrigerants, evaluation of leak detection methods for non-CFC refrigerants, and flow regime mapping of $R-134 a /$ lubricant mixtures in smooth and internally enhanced tubes. It also includes experimental determination of heat transfer with R-134a and P-22 refrigerants in water-cooled condensers and direct-expansion water coolers using brazed plate heat exchangers. The one-star priority group includes research of alternatives to replace R-22 and R502 , development of a uniform equation of state for alternative refrigerants, and determination of properties and heat transfer effects for mixtures of alternative refrigerants and lubricants. Research of ammonia (R-717) dispersion in the atmosphere also is included. This plan summa. rizes anticipated funding and procedures for 
implementing the research identifled; it replaces the versions publlshed for preceding years (see RDB1152).

1991-1992 ASHRAE Research Plan, American Society of Heating, Refrigerating, and Air-Condltioning Engineers, Atlanta, GA, 1 December 1990 (32 pages, RDB1152)

\section{DOE}

Refrigeration Systems Program Summary, report DOE/CH10093-120, U.S. Department of Energy, Washington, DC, December 1991 (24 pages, available from NTIS as GPO \#573-122/40020 at price code A03, RDB2263)

This document summarizes results, current activities, and objectives of the U.S. Department of Energy (DOE) for research of refrigerators, air conditioners, heat pumps, chillers, and supermarket systems. Key activities include investigation of alternative refrigerants and refrigeration cycles, developing advanced technologles for future air-conditioning and refrigeration equipment designs, and developing advanced insulation for appliances. The program structure and opportinitles for collaboration with industry are outline $\mathrm{J}$.

\section{PAFT}

Program for Alternative Fluorocarbon Toxicity Testing, program description, PAFT, Bristol, United Kingdom, May 1990 (4 pages, RDB1151)

\section{MISCELLANEOUS DOCUMENTS}

V. D. Baxter, Report of Foreign Travel: 9-11 May 1990 [Application of Zeotropic Mixture Refrigerants in Refrigerators and Use of the Lee-Kesler-Plöcker Equation of State], ORNL/FTR-3611, Oak Ridge National Laboratory, Oak Ridge, TN, 14 May 1990 (20 pages, RDB1153)

This informal report summarizes the final working meeting of the International Energy Agency (IEA) research project on State and Transport Properties of High-Temperature Working Fluids and Nonazeotropic Mixtures (Annex XIII). It also addresses research at the Universität Hannover, funded by the U.S. Environmental Pro- tection Agency, on application of refrigerant blends in refrigerators and separate work to use the Lee-Kesler-Plöcker equation of state to predict refrigerant properties.

J. M. Calm (Engineering Consultant), Refrigerant Database, report DOE/CE/23810-2G, Air-Conditioning and Refrigeration Technology Institute (ARTI), Arlington, VA, 30 April 1992 (56 pages, avallable from JMC as RDB2434)

This document provides bibliographic citations for 336 publications that may be useful in re. search and design of air-coriditioning and rePrigeration equlpment. Abstracts, emphasizing the content, materials addressed, and key conclusions, are provided for approximately half of these documents. The database identifles sources of specific information on R-32, R-123, R-124, R-125, R-134a, R-141b, R-142b, R-143a, R-152a, R-290 (propane), R-717 (ammonia), ethers, and others as well as azeotropic and $z e$ otropic blends of these fluids. It addresses polyalkylene glycol (PAG), ester, and other lubricants. It also references documents ad. dressing compatibility of refrigerants and lubricants with metals, plastics, elastomers, motor insulation, and other materials used in refrigerant circuits. The database is avallable in a computerized version, to facilitate searches for specific information, and as a listing in report form. Ordering instructions for both the com. puterized and manual version of the database, as well as for documents and software cited in it, are included.

J. M. Calm (Engineering Consultant), Refrigerant Database, report DOE/CE/23810-1G, Air-Conditioning and Refrigeration Technology Institute (ARTI), Artington, VA, 28 February 1992 (42 pages, available from JMC as RDB2415, superseded by RDB2434)

This document provides bibliographic citations for 244 publications that may be useful in research and design of air-conditioning and refrigeration equipment. Abstracts, emphasizing the content, materials addressed, and key conclusions, are provided for approximately a third of these documents. (Please see RDB2434 for a more complete abstract.)

E. Johnson and J. Noble, A Survey of Alternatives to Ozone-Destroying Technologies, Greenpeace International, Washington, DC, June 1990 (35 pages, RDB1154)

This report is a survey of innovations old and new that could provide the goods and services currently dependent on ozone-destroying chemicals. It is represented as an attempt to show the range of technologies that could be used as replacemerits without adverse impact 
on the ozone layer. The survey notes that the HCFC and HFC alternatives have not been proven to be harmless to the ozone layer, but are greenhouse gases and have serious toxicity problems.

JICOP Guide, Japan Industrlal Conference for Ozone Layer Protection, Tokyo, Japan, January 1991 (8 pages, avallable from JMC as RDB1204)

JICOP was formed in 1988 as the Promotion Conference for Rational Use of Specified CFCs and renamed in June 1990. It is an organization of Industrial producers and consumers addressing ozone-layer protection in Japan. Its main activities include publicity, information sharing, surveys of actions by other countries, preparation of guides, and training. This leaflet introduces the organization and lists the 55 current members. Included are the Japan Association of Refrigeration, Japan Association of Refrigeration and Air-Conditioning Contractors, Japan Flon Gas Assoclation, and Japan Pefrigeration and Alr-Conditioning Industry Association.

K. Ushimaru (Energy Internatlonal, Incorporated), Impact of CFC Curtailment on Refrigeration and Mitigation Research in Japan, CFCs: Today's Options-Tomorrow's Solutions (proceedings of ASHRAE's 1989 CFC Technology Conference, Gaithersburg, MD, 27-28 September 1989), American Society of Heating, Refrigerating, and Air-Conditioning Engineers, Atlanta, GA, pages 107-117, 1990; republished in International Journal of Refrigeration, Paris, France, volume 13 , number 3 , pages 131-141, March 1990 (10 pages with $10 \mathrm{fig}$ ures and 2 tables, RDB1205)

This paper focuses on efforts in Japan to develop technical optlons for reducing CFC emissions. Alternative refrigerants for R-12 (used in automobile air-conditioners and residentlal refrigerators) and R-113 (used extensively as a solvent and cleaning agent) are presented. CFC mitigation options are discussed for control technologies, work practices and economics, chemical substitutes, and product substitutes. Japan's usage profile and historical background on its environmental responsiveness are addressed. The article notes that $R$ 113 recovery and recycling equipment are already marketed in Japan and that the demand for this equipment is projected to grow to $\$ 15$ billion by 1998 . Additionally, leading Japanese chemical producers are moving forward with plans for the production of R-134a as a substitute for R-12. 
The Refrigerant Database is supported in part by U.S. Department of Energy grant number DE-FG02-91CE23810, Materials Compatibility and Lubricant Research (MCLR) on CFC-Refrigerant Substitutes. Federal funding for Phase I of the MCLR program constitutes $93.94 \%$ of allowable costs.

Funding from the air-conditioning and refrigeration industry for Phase I of the MCLR Program consists of direct cost sharing of $6.06 \%$ of allowable costs and in-kind contributions,

Funding for the Refrigerant Database constitutes less than $2 \%$ of the total and is supplemented by in-kind cost sharing by James M. Calm. Support of the MCLR Program by the U.S. Department of Energy and the air-conditioning and refrigeration industry does not constitute an endorsement of the views expressed herein. 

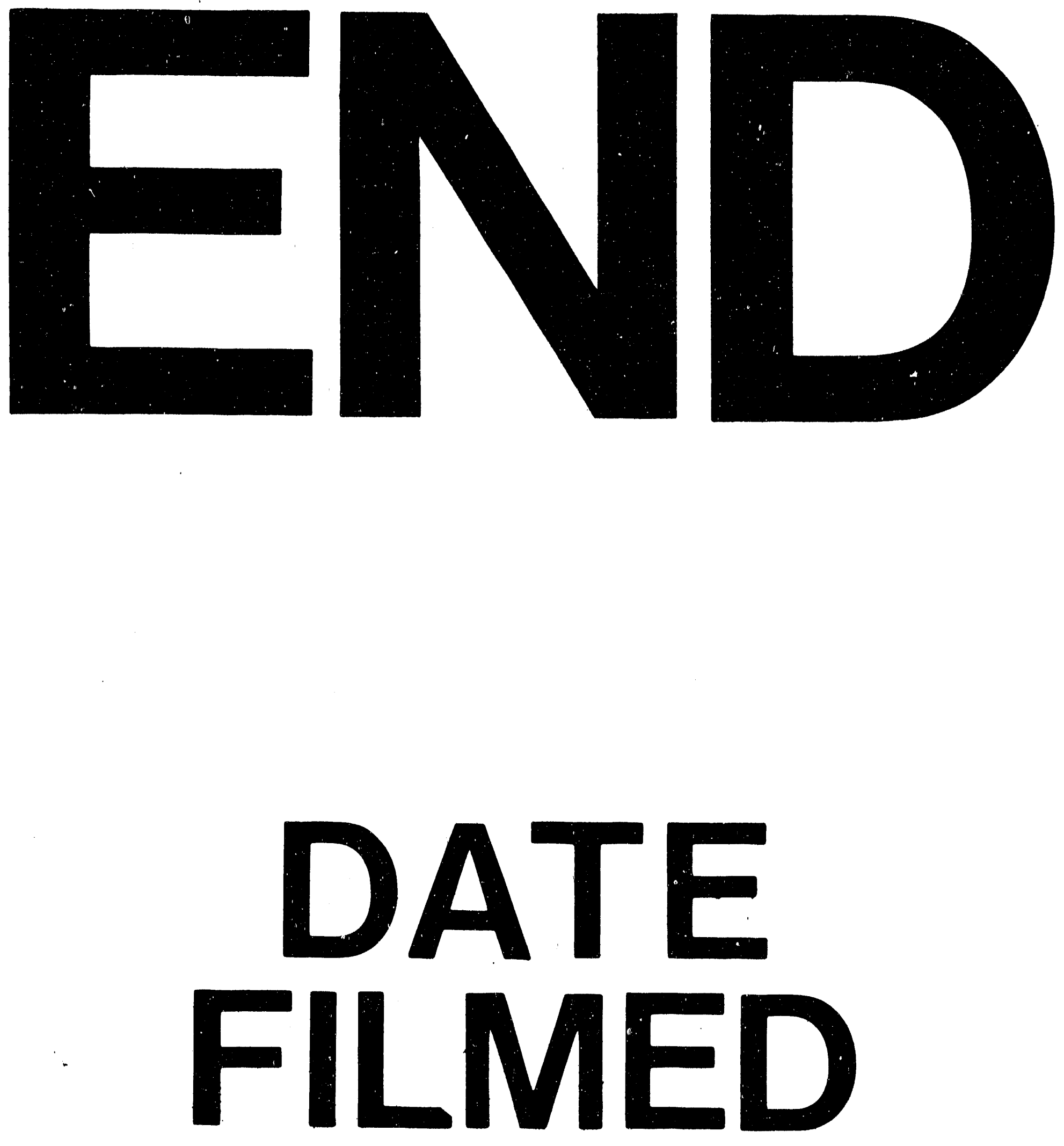

$\rightarrow$

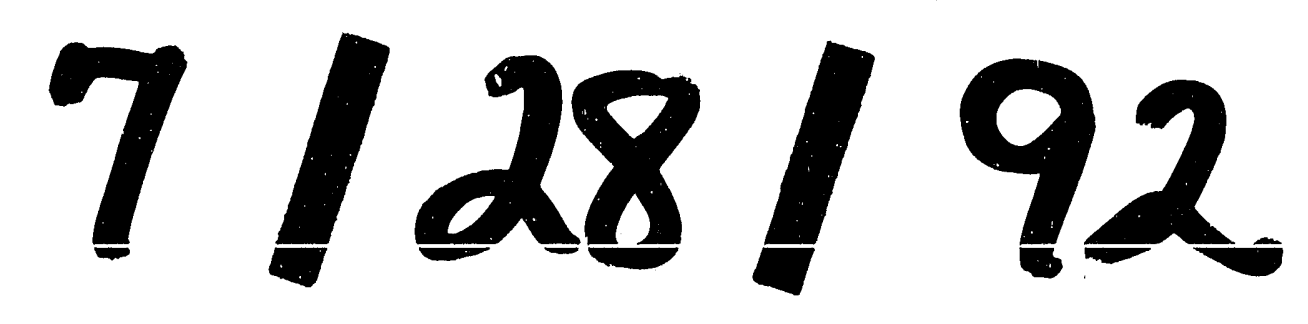


